NASA/TM-2020-220485

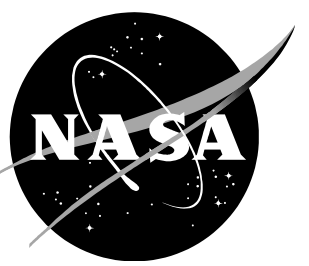

\title{
Mars Science Helicopter Conceptual Design
}

Wayne Johnson, Shannah Withrow-Maser, Larry Young, Carlos Malpica, Witold J.F. Koning, Winnie Kuang, Mireille Fehler, Allysa Tuano, Athena Chan

Ames Research Center, Moffett Field, California

Anubhav Datta, Cheng Chi, Ravi Lumba, Daniel Escobar

University of Maryland

J. Balaram, Theodore Tzanetos, Håvard Fjar Grip

Jet Propulsion Laboratory, California Institute of Technology

March 2020 


\section{NASA STI Program ... in Profile}

Since its founding, NASA has been dedicated to the advancement of aeronautics and space science. The NASA scientific and technical information (STI) program plays a key part in helping NASA maintain this important role.

The NASA STI program operates under the auspices of the Agency Chief Information Officer. It collects, organizes, provides for archiving, and disseminates NASA's STI. The NASA STI program provides access to the NTRS Registered and its public interface, the NASA Technical Reports Server, thus providing one of the largest collections of aeronautical and space science STI in the world. Results are published in both nonNASA channels and by NASA in the NASA STI Report Series, which includes the following report types:

- TECHNICAL PUBLICATION. Reports of completed research or a major significant phase of research that present the results of NASA Programs and include extensive data or theoretical analysis. Includes compilations of significant scientific and technical data and information deemed to be of continuing reference value. NASA counter-part of peer-reviewed formal professional papers but has less stringent limitations on manuscript length and extent of graphic presentations.

\section{- TECHNICAL MEMORANDUM.}

Scientific and technical findings that are preliminary or of specialized interest, e.g., quick release reports, working papers, and bibliographies that contain minimal annotation. Does not contain extensive analysis.

- CONTRACTOR REPORT. Scientific and technical findings by NASA-sponsored contractors and grantees.
- CONFERENCE PUBLICATION. Collected papers from scientific and technical conferences, symposia, seminars, or other meetings sponsored or co-sponsored by NASA.

- SPECIAL PUBLICATION. Scientific, technical, or historical information from NASA programs, projects, and missions, often concerned with subjects having substantial public interest.

- TECHNICAL TRANSLATION. Englishlanguage translations of foreign scientific and technical material pertinent to NASA's mission.

Specialized services also include organizing and publishing research results, distributing specialized research announcements and feeds, providing information desk and personal search support, and enabling data exchange services.

For more information about the NASA STI program, see the following:

- Access the NASA STI program home page at http://www.sti.nasa.gov

- E-mail your question to help@sti.nasa.gov

- Phone the NASA STI Information Desk at 757-864-9658

- Write to:

NASA STI Information Desk

Mail Stop 148

NASA Langley Research Center

Hampton, VA 23681-2199 
NASA/TM-2020-220485

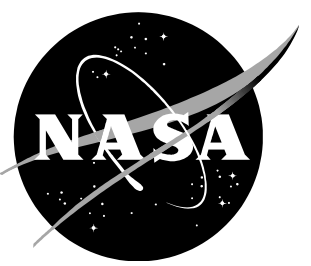

\section{Mars Science Helicopter Conceptual Design}

Wayne Johnson, Shannah Withrow-Maser, Larry Young, Carlos Malpica, Witold J.F. Koning, Winnie Kuang, Mireille Fehler, Allysa Tuano, Athena Chan

Ames Research Center, Moffett Field, California

Anubhav Datta, Cheng Chi, Ravi Lumba, Daniel Escobar

University of Maryland

J. Balaram, Theodore Tzanetos, Håvard Fjar Grip

Jet Propulsion Laboratory, California Institute of Technology

National Aeronautics and

Space Administration

Ames Research Center

Moffett Field, CA 94035-1000

March 2020 
This report is available in electronic form at http://ntrs.nasa.gov 


\begin{abstract}
Robotic planetary aerial vehicles increase the range of terrain that can be examined, compared to traditional landers and rovers, and have more near-surface capability than orbiters. Aerial mobility is a promising possibility for planetary exploration as it reduces the challenges that difficult obstacles pose to ground vehicles. The first use of a rotorcraft for a planetary mission will be in 2021, when the Mars Helicopter technology demonstrator will be deployed from the Mars 2020 rover. The Jet Propulsion Laboratory and NASA Ames Research Center are exploring possibilities for a Mars Science Helicopter, a second-generation Mars rotorcraft with the capability of conducting science investigations independently of a lander or rover (although this type of vehicle could also be used assist rovers or landers in future missions). This report describes the conceptual design of Mars Science Helicopters. The design process began with coaxial-helicopter and hexacopter configurations, with a payload in the range of two to three $\mathrm{kg}$ and an overall vehicle mass of approximately twenty $\mathrm{kg}$. Initial estimates of weight and performance were based on the capabilities of the Mars Helicopter. Rotorcraft designs for Mars are constrained by the dimensions of the aeroshell and lander for the trip to the planet, requiring attention to the aircraft packaging in order to maximize the rotor dimensions and hence overall performance potential. Aerodynamic performance optimization was conducted, particularly through airfoils designed specifically for the low Reynolds number and high Mach number inherent to operation on Mars. Rotor structural designs were developed that met blade frequency and weight targets, subject to material stress limits. The final designs show a substantial capability for science operations on Mars: a $31 \mathrm{~kg}$ hexacopter that fits within a $2.5 \mathrm{~m}$ diameter aeroshell could carry a $5 \mathrm{~kg}$ payload for $10 \mathrm{~min}$ of hover time or over a range of $5 \mathrm{~km}$.
\end{abstract}

\title{
Introduction
}

The Mars Helicopter, launching as a part of the Mars 2020 mission, will begin a new era of planetary exploration. Mars research has historically been conducted through landers, rovers, and satellites. As both government and private industries prepare for human exploration of the Martian surface within two decades, more in-depth knowledge of what awaits on the surface is critical. Planetary aerial vehicles increase the range of terrain that can be examined, compared to traditional landers and rovers, and have more nearsurface capability than orbiters. The Jet Propulsion Laboratory (JPL) and NASA Ames Research Center are exploring possibilities for a Mars Science Helicopter (Ref. 1), a second-generation Mars rotorcraft with the capability of conducting science investigations independently of a lander or rover (although this type of vehicle could also be used assist rovers or landers in future missions). JPL is leading this exploration, with NASA Ames responsible for the aircraft sizing and packaging, rotor design, and mission performance analysis. The University of Maryland contributed the rotor structural design and analysis. The results will also provide baseline designs for future helicopters on Mars.

The first use of a rotorcraft for a planetary mission will be in 2021, when the Mars Helicopter (MH) technology demonstrator will be carried by and deployed from the Mars 2020 rover (Ref. 2). The goal of the $\mathrm{MH}$ (Figure 1) is to demonstrate the viability and potential of heavier-than-air flying vehicles in the Martian atmosphere. $\mathrm{MH}$ is a coaxial helicopter with a mass of $1.8 \mathrm{~kg}$ and rotor diameter of $1.21 \mathrm{~m}$. The helicopter relies on solar cells and a battery system for power, allowing up to 90 second flight endurance that is conducted fully autonomously due to the communication delay between Earth and Mars. The MH will perform five ninety-second flights as a technology demonstration of the first powered flight on another planet.

The Mars Science Helicopter (MSH) investigation has the goal of establishing the feasibility of flying a larger, more capable rotorcraft on Mars. The MH does not have a dedicated science payload apart from the instruments required for flight, and $\mathrm{MH}$ flights will take place over relatively flat, rock-free terrain using a visual-inertial navigation system. The larger MSH will be capable of more payload, longer sorties, all terrain overflight, and communication through an orbiter to enable operation at unrestricted distances from 
other landed assets. Initial design requirements for the MSH mission include a two to three kilogram payload (such as could be used for onboard science instruments intended for mapping, stratigraphy, remote sensing, etc.), an extended range (2-4 km) and increased hover time (2-4 minutes) sufficient to enable significant science investigations both inflight as well as when on the surface. The aircraft design target mass to accomplish such science missions is around $20 \mathrm{~kg}$. The MSH vehicle will require improved handling qualities for control, more efficient rotor blade performance, and optimized lightweight structural design in order to be successful. This report describes the conceptual design of Mars Science Helicopters. The goal of the vehicle design work is to establish the general capability of helicopters for science operations on Mars.

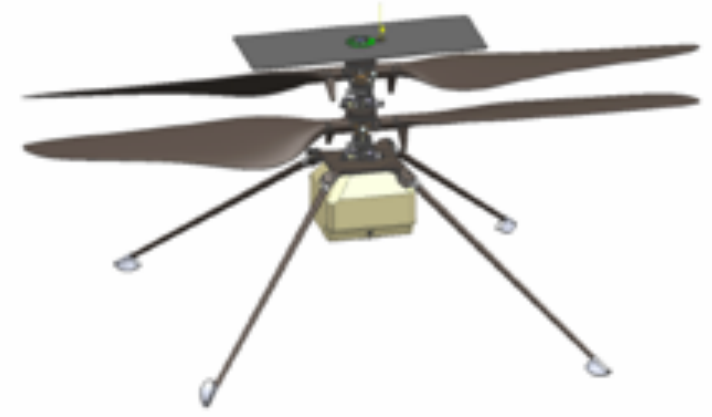

Figure 1. Mars Helicopter technology demonstrator, part of the Mars 2020 mission.

\section{Background}

Early work on aerial exploration of planetary bodies was performed by Young and Aiken, et al. (Refs. 3-6). In response to a 2002 American Helicopter Society student design competition (sponsored by NASA and Sikorsky Aircraft), Martian rotorcraft designs were developed by University of Maryland (Ref. 7) and Georgia Institute of Technology (Ref. 8). The University of Maryland aircraft, MARV, was designed for a weight of $50 \mathrm{~kg}$ with a rotor diameter of $4.26 \mathrm{~m}$, range of $25 \mathrm{~km}$, and endurance of $39 \mathrm{~min}$. GTMARS, the Georgia Institute of Technology design, weighed $10 \mathrm{~kg}$ with a rotor diameter of $1.84 \mathrm{~m}$ and endurance of $30 \mathrm{~min}$. More recent designs for Martian rotorcraft were developed by Georgia Institute of Technology (MEUAV, Ref. 9), Delft University of Technology (VITAS, Ref. 10), and Tohoku University (JMH, Ref. 11). Figure 2 illustrates these designs.

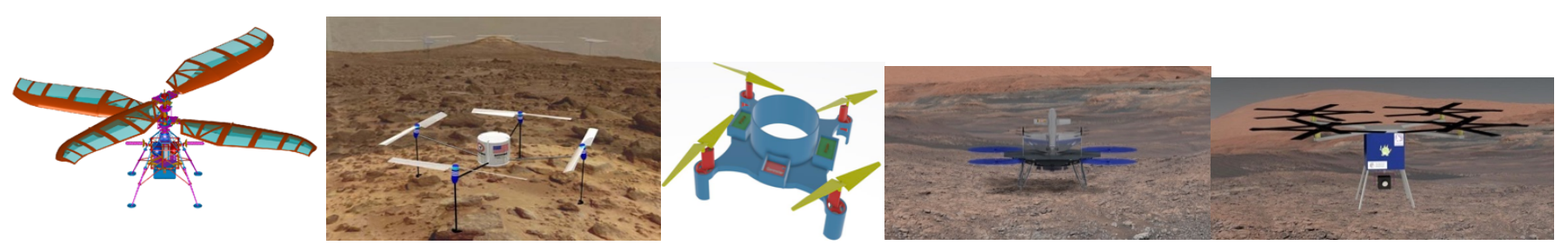

Figure 2. Martian rotorcraft designs (left to right): MARV, GTMARS, MEUAV, VITAS, JMH.

The development of the Mars Helicopter technology demonstrator was led by the Jet Propulsion Laboratory. Balaram, et al. (Ref. 1) described the MH project; Grip, et al. (Refs. 12-14) described the MH flight dynamics, control, and guidance; Pipenberg, et al. (Refs 15-16) described the rotor and aircraft design and fabrication. Koning, et al. (Ref. 17) presented performance calculations for the MH. The Mars Helicopter is the only aircraft constructed and tested for flight on Mars (though actual flights on Mars will not occur until 2021), so the MH weights and performance were the foundation of conceptual design of Mars Science Helicopters. 
Balaram (Ref. 1) described potential Mars Science Helicopter missions. The MSH will be able to explore extreme terrains that a rover or lander could not access. For example, it can overcome and hover next to steep slopes, fly over rocky ground, and otherwise observe hazardous terrains that would be inaccessible to a rover. Visible imaging from a helicopter would bridge the resolution gap between orbital images and landed investigations. One mission concept involves landing on the flat, smooth floor of a crater with recurring slope lineae and/or gullies on its interior walls. A remote sensing platform on the lander could perform long-duration, multi-instrument remote observations of the surrounding walls from the crater floor. This would be augmented by contact interrogations performed by the helicopter. Another concept involves one or more stand-alone helicopters communicating directly with orbiters to relay data to Earth. This larger helicopter could scout out complex terrains with many different geologic features of astrobiologic importance. Possible scientific areas of study that would be enabled by these technical capabilities include the following.

Mapping/Stratigraphy: A helicopter would be able to access regional geology in three dimensions, making it very capable for a mapping and stratigraphy investigation. Layered deposits, for example, could be imaged and sampled through their depths across tens to hundreds of kilometers.

Polar Science: An aerial vehicle could conduct detailed mapping of ice-rich layers exposed at the poles (e.g., polar troughs). These layers are thought to reflect changes in climate over the past few million years. Steep, cliff-like terrain along the periphery of the polar layered deposits is another candidate site that would benefit from exploration of a Mars helicopter.

Recurring Slope Lineae: RSL are special regions that are difficult to explore without danger of contamination. However, a helicopter could fly or hover over RSL without touching them. Spectral properties, daily changes and the timing of appearance and fading behaviors, and nearby moisture and wind content could all reveal the true nature of these enigmatic features.

Low-Latitude Volatiles (icy scarps): An aerial platform could conduct along-scarp mapping of ice-rich layers comprising an ancient ice sheet, now exposed at the surface. In addition to characterizing icy layers, the vehicle could also study ice sheet overburden and the erosional products at the base of the scarp.

Atmospheric Science: Vertical profiles could be acquired for atmospheric species of interest (e.g., $\mathrm{H}_{2} \mathrm{O}, \mathrm{CO}_{2}, \mathrm{CH}_{4}$ ) in the lowest region of the boundary layer, which are difficult to obtain from orbit. Vertical changes in wind speed could also be measured. These measurements are crucial for understanding interaction between the surface and the atmosphere.

Subsurface Geophysics: Geophysical studies of Mars are especially timely given the new information the InSight mission is revealing about the interior of Mars. The subsurface could be explored in detail over a wide area using the capabilities of a helicopter.

By providing a new platform for regional high-resolution sensing and extreme terrain access, Mars helicopters will enable new mission concepts responsive to the strategic themes of life (access to RSL), geology (access to diverse sites and extreme terrains), climate (direct observation of low-altitude wind fields), and preparing for human exploration (demonstrating helicopter scouting concepts).

\section{Rotor Aerodynamics and Performance}

The fundamentals of rotor and rotorcraft performance are presented in Reference 18. Evaluating aerodynamic performance of a rotary wing starts with the lift and drag behavior of the airfoil sections. From lift and drag of the sections, the thrust and power of the rotor can be calculated. The lift and drag coefficients 
are the scaled characteristics of the section: $c_{l}=L /\left(\frac{1}{2} \rho V^{2} c\right)$ and $c_{d}=D /\left(\frac{1}{2} \rho V^{2} c\right)$; where $L$ is the section lift, $D$ the section drag, $\rho$ the gas density, $V$ the speed, and $c$ the section chord. The coefficients vary with the airfoil section angle-of-attack $\alpha$ (Figure 3 ). The effects of viscosity are characterized by the Reynolds number, $R e=\rho V c / \mu$ (where $\mu$ is the gas viscosity). The effects of compressibility are characterized by the Mach number, $M=V / a$ (where $a$ is the speed of sound in the gas). Figure 3 shows the lift and drag coefficients as a function of angle-of-attack for several Mach numbers, for an NACA 23012 airfoil at Reynolds numbers typical of a helicopter on Earth. For low angle-of-attack, the lift is linear with $\alpha$ and the drag is small. At some angle of attack (here about $12 \mathrm{deg}$ for $M=0.4$ ) the flow separates from the airfoil upper surface (the airfoil stalls), which causes the lift to decrease and the drag to increase. As Mach number increases, the lift-curve-slope increases below stall, but the maximum lift decreases. At high Mach numbers, shocks occur on the airfoil, and the drag rises substantially. At the very small Reynolds numbers characteristic of flight on Mars, the maximum lift is smaller than shown in Figure 3, and the drag is greatly increased, by a factor of 4 or 5 , even at low angle-of-attack. The best (highest lift-to-drag ratio) airfoils at low Reynolds number are thin, and compressibility effects are delayed for thin sections.
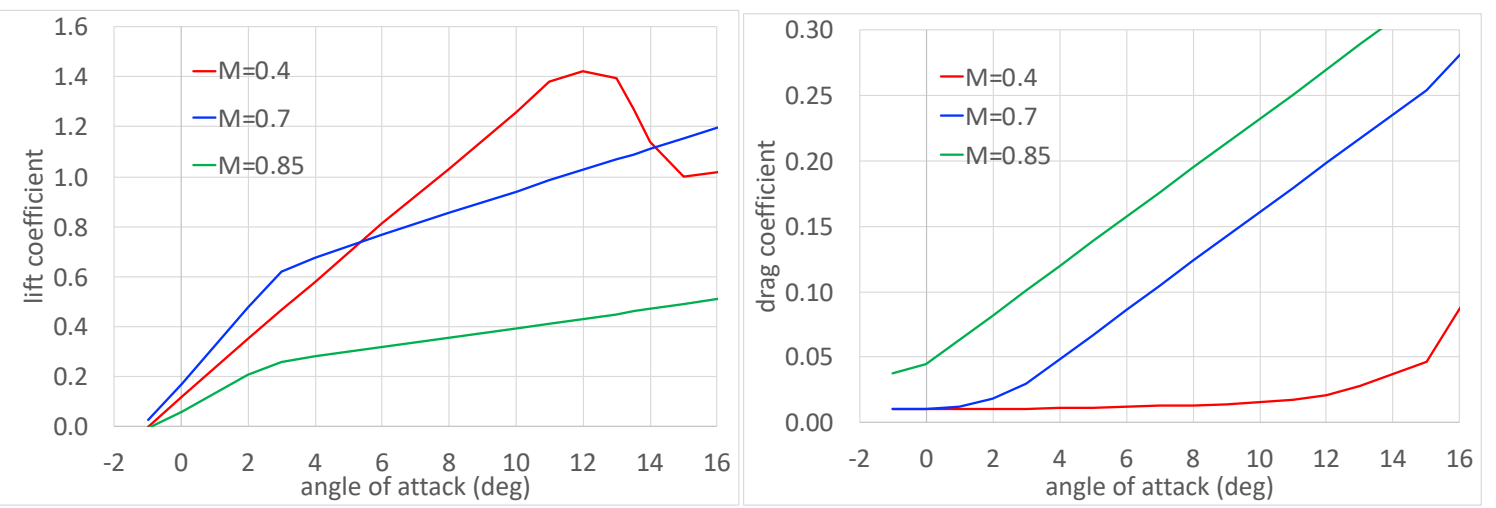

Figure 3. Airfoil lift and drag characteristics (NACA 23012).

Rotor hover power consists of induced power (energy lost in the wake, because the rotor generates thrust) and profile power (energy lost to section drag forces):

$$
P=\kappa T \sqrt{\frac{T}{2 \rho A}}+\rho A_{b} V_{\text {tip }}^{3} \frac{1}{8} c_{d \text { mean }}
$$

where $P$ is the rotor power, $T$ the rotor thrust, $A$ the disk area, $A_{b}$ the total blade area, $V_{\text {tip }}$ the blade tip speed, and $\sigma=A_{b} / A$ the rotor solidity. The induced power factor $\kappa$ is the ratio of the actual induced power to the ideal (momentum theory) power, typically about $\kappa=1.2$ in hover and $\kappa=2.0$ or more in edgewise forward flight of a rotor. The mean drag coefficient, $c_{d \text { mean }}$, characterizes the profile power, and so the value reflects the extent of stall on the rotor blade. The mean lift coefficient of the rotor blade is proportional to the blade loading:

$$
\frac{c_{l \text { mean }}}{6} \cong \frac{C_{T}}{\sigma}=\frac{T}{\rho A_{b} V_{\text {tip }}^{2}}
$$

The blade loading $C_{T} / \sigma$ of a rotor is thus limited by stall, and the maximum or design value then determines the blade area and tip speed required. The ratio of power and thrust can be written:

$$
\frac{P}{T}=\kappa \sqrt{\frac{T}{2 \rho A}}+V_{\text {tip }} \frac{c_{d \text { mean }}}{8 C_{T} / \sigma}
$$


from which it follows that low disk loading $T / A$ (large diameter) and high airfoil $c_{l} / c_{d}$ reduces the power. The impact of low density is to increase the induced power, and to increase the profile power through the influence of Reynolds number on the drag coefficient. The tip speed must be high to minimize the blade area.

The induced power depends on the structure of the rotor wake. Figure 4 illustrates the geometry of the wake of a hovering rotor. The photographs show the rolled-up tip vortices (visualized by natural condensation) of a single main rotor helicopter and a coaxial rotor helicopter. The mutual interference between the upper and lower rotor wakes in the coaxial configuration reduces the hover power, but greatly complicates the aerodynamic analysis and design of the system. The sketch shows the basic structure of the hovering rotor wake (of a single-bladed rotor, for simplicity). A rolled-up tip vortex with strong swirl velocities forms just behind the blade, and convects downward and inward due to the mutual interference with tip vortices below it. When this tip vortex encounters the following blade, it is inboard of and very close below the tip. The airloads produced by this encounter are crucial to the performance of the rotor. After encountering this blade, the vortex is convected downward at a higher rate, proportional to the mean induced velocity at the rotor disk. There is also a sheet of vorticity emanating from the inboard portion of the blade, which is rapidly convected downward.
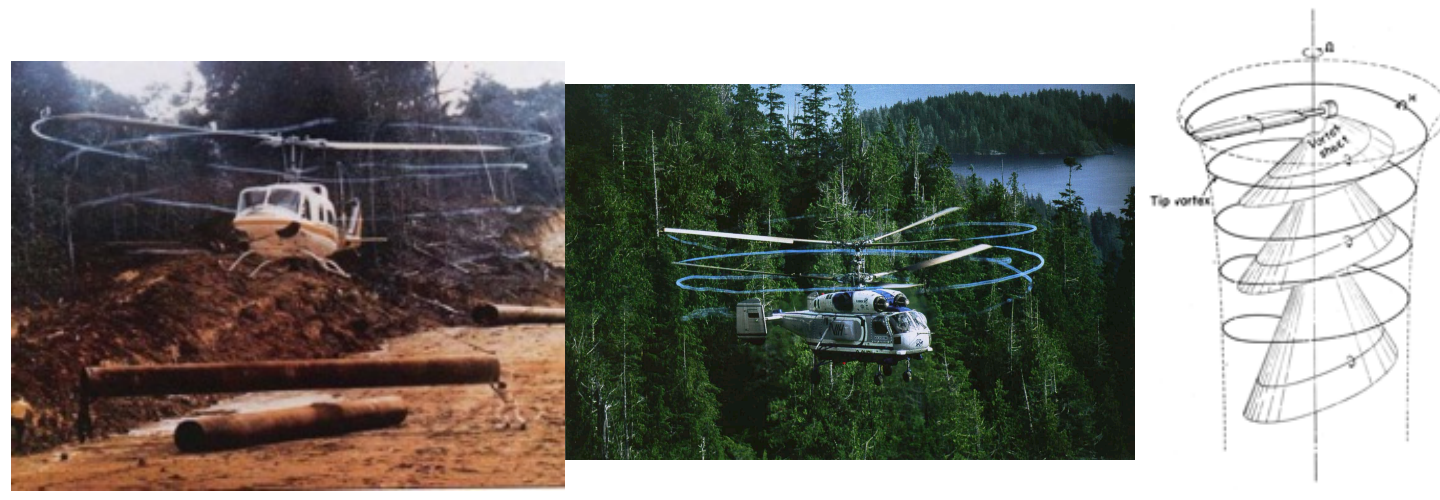

Figure 4. Rotor wake geometry structure in hover.

A measure of the efficiency of a hovering rotor is the figure of merit $(F M)$, which is the ratio of the ideal and actual hover power required:

$$
F M=\frac{P_{\text {ideal }}}{P}=\frac{T \sqrt{\frac{T}{2 \rho A}}}{\kappa T \sqrt{\frac{T}{2 \rho A}}+\rho A_{b} V_{\text {tip }}^{3} \frac{1}{8} c_{d \text { mean }}}
$$

The figure of merit roughly represents the ratio of profile power and induced power, so is best used in comparisons at fixed disk loading. Figure 5 illustrates the variation of figure of merit with rotor thrust coefficient, showing measurements and calculations for the Mars Helicopter. The figure of merit increases with thrust, as the induced power increases, until stall causes the profile power to increase and $F M$ drops. At low Reynolds number, the airfoil drag coefficient increases, perhaps to 4 or 5 times that shown in Figure 3, thereby increasing the profile power. Consequenty, a small helicopter on Earth has a low figure of merit. For a rotor operating on Mars, the low density means that the induced power is also high: the rotor hovering efficiency is good (good figure of merit, Figure 5), but the power required is large.

The maximum Mach number of the blade occurs on the advancing tip: $M_{a t}=\left(V+V_{t i p}\right) / a$. The advancing tip Mach number $M_{a t}$ is constrained by the airfoil drag divergence, hence it is a key parameter determining forward flight efficiency of the rotor. 


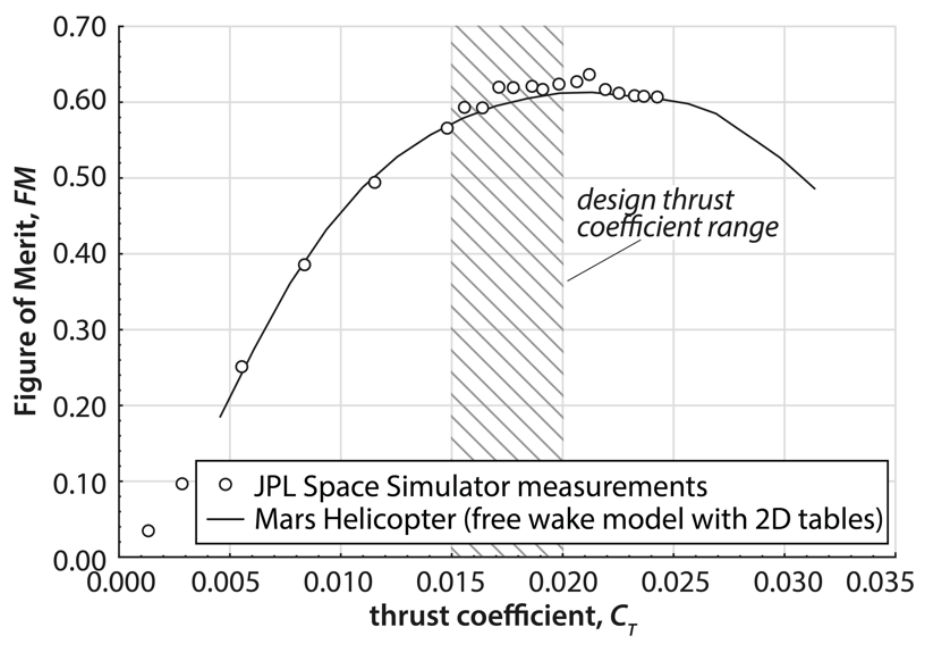

Figure 5. Hover figure of merit of the Mars Helicopter.

\section{Mars Atmosphere}

The possibilities for flight on Mars are dominated by the very low density of the Martian atmosphere. Table 1 compares the characteristics of the atmospheres on Earth and Mars. The density on Mars is approximately $1 \%$ of that on Earth with a variation between 0.010 and $0.020 \mathrm{~kg} / \mathrm{m}^{3}$ depending on ground elevation, as well as yearly and daily variations. Because of the low density, the Reynolds numbers of airfoils on rotors designed for Martian operations are in the range 10000 to 25000, which has a significant impact on airfoil behavior. The Martian atmosphere consists primarily of carbon dioxide, the gas properties of which lead to lower speed of sound than in the nitrogen-oxygen atmosphere of Earth, which is exacerbated by the low temperatures.

The low density of the atmosphere on Mars reduces the lift per blade-area that can be produced by a rotor. The low Reynolds number reduces the maximum lift coefficient and increases the drag coefficient of airfoils, and the optimum airfoil shape is much different than that for high Reynolds numbers. For a given design Mach number, the lower speed of sound on Mars reduces the maximum possible tip speed of the rotor.

Table 1. Comparison of atmospheres on Earth and on Mars.

\begin{tabular}{llcc}
\hline \hline & & Earth $\left(\mathrm{N}_{2}+\mathrm{O}_{2}\right)$ & Mars $\left(\mathrm{CO}_{2}\right)$ \\
\hline Density, $\rho$ & $\mathrm{kg} / \mathrm{m}^{3}$ & 1.225 & 0.017 \\
Temperature, $T$ & $\mathrm{C}$ & 15 & -50 \\
Viscosity, $\mu$ & $\mathrm{Ns} / \mathrm{m}^{2}$ & 0.0000175 & 0.0000113 \\
Sound speed, $a$ & $\mathrm{~m} / \mathrm{s}$ & 340.3 & 233.1 \\
Tip speed, $V_{t i p}$ & $\mathrm{~m} / \mathrm{s}$ & 238 & 163 \\
(Mach number $=0.7)$ & & & \\
$\begin{array}{l}\text { Reynolds number, } R e \\
\text { (Mach number }=0.5, \text { chord }\end{array}$ & $0.1 \mathrm{~m})$ & $1,297,000$ & 19,100 \\
\hline \hline
\end{tabular}




\section{Computational Methods}

A spreadsheet was developed to size a helicopter for Mars missions. Calibrated to the MH, the spreadsheet provided a simple and quick first estimate of the aircraft size. The principal software tools used in this investigation were NDARC and CAMRAD II. The rotorcraft design and analysis code NDARC uses detailed performance models of the rotor, battery, motor, and other components to perform more complete analysis of missions. The rotorcraft comprehensive analysis CAMRAD II was used to calculate the performance of the rotor and aircraft.

NDARC (NASA Design and Analysis of Rotorcraft) is a conceptual/preliminary design and analysis computer program for rapidly sizing and conducting performance analysis of new vehicle concepts with particular emphasis on vertical lift configurations (Ref. 19). The design task sizes the vehicle to satisfy a set of design conditions and missions. The analysis tasks include off-design mission analysis and flight performance calculation for point operating conditions. The aircraft size is characterized by parameters such as aircraft total weight, weight empty, component dimensions, battery capacity, and motor power. To achieve flexibility in configuration modeling, NDARC constructs a vehicle from a set of components, including fuselage, wings, tails, rotors, transmissions, and engines. For efficient program execution, each component uses a surrogate model for performance and weight estimation. Higher fidelity component design and analysis programs as well as databases of existing components provide the information needed to calibrate these surrogate models, including the influence of size and technology level. The reliability of the synthesis and evaluation results depends on the accuracy of the calibrated component models. The NDARC rotor performance model represents the rotor power as the sum of induced, profile, and parasite terms: $P=P_{i}+P_{o}+P_{p}$. The parasite power (including climb/descent power for the aircraft) is obtained from the rotor wind-axis drag force and rotor velocity. Induced power is the energy lost in the wake, calculated from the ideal momentum theory power times an induced power factor $\kappa$. The profile power is the energy required to turn the rotor in the viscous air, expressed in terms of a mean drag coefficient $c_{d \text { mean }}$. Performance calculations from the comprehensive analysis are correlated with test data; then rotor performance is calculated for the full range of expected flight and operating conditions; finally, the parameters of the NDARC rotor performance model are developed based on the calculated $\kappa$ and $c_{d \text { mean }}$.

Performance analyses were conducted with the comprehensive rotorcraft analysis CAMRAD II (Refs. 20-22). CAMRAD II is an aeromechanics analysis of rotorcraft that incorporates multibody dynamics, nonlinear finite elements, and rotorcraft aerodynamics. The trim task finds the equilibrium solution for a steady state operating condition and produces the solution for performance, loads, and vibration. The CAMRAD II aerodynamic model for the rotor blade is based on lifting-line theory, using steady twodimensional airfoil characteristics and a vortex wake model. The wake analysis calculates rotor nonuniform induced velocities, using free wake geometry. Airfoil characteristics were obtained from tables for the appropriate airfoils. Performance calculations for calibration of the NDARC rotor models considered first an isolated rotor, in particular to define profile power including the influence of stall and compressibility. Then calculations for the multiple rotors (coaxial or hexacopter) were used to calibrate the rotor-rotor interference effects on induced power.

Aircraft structural design and analysis were conducted using SolidWorks, a 3D CAD (computer aided design) system from Dassault Systèmes. SolidWorks was also used for the packaging investigations.

The rotor blade structural design and analysis were conducted using the three-dimensional multi-body structural dynamics code X3D (Ref. 23), from US Army Aviation Development Directorate and the University of Maryland. The multi-body analysis formulation of X3D models elastic components using 3D nonlinear solid finite elements. Kinematic couplings are simulated by the multi-body analysis and 3D stresses and strains are recovered from the finite element analysis. The FEA solver supports second order 27-node hexahedron elements. The geometry for the X3D models was constructed using CATIA, a 3D $\mathrm{CAD}$ and project life cyclic management system from Dassault Systèmes. Structural analysis meshes were defined using CUBIT, from Sandia National Laboratories. 
Airfoil design, analysis, and optimization were conducted using the Reynolds-averaged Navier-Stokes computational fluid dynamics code OVERFLOW from NASA (Ref. 24). The analysis used twodimensional structured grids, with the implicit, compressible solver of OVERFLOW, to evaluate airfoil section lift and drag.

In future tasks for the Mars Science Helicopter design, flight dynamics modeling and assessment will be performed for the rotorcraft using FlightCODE (Ref. 25).

\section{Helicopter Design Process}

The helicopter design process begins with the definition of the mission, particularly payload, range, and hover time. The fundamental requirement for a reliable conceptual design of an aircraft is a complete identification of all the components and subsystems that make up the vehicle. Then for each component, weight and performance models are needed. The weight models reflect scaling with size of the component. The performance models in particular are needed for rotor hover and forward flight operation. These weight and performance models are calibrated to existing aircraft, which in the case of flight on Mars is only the Mars Helicopter. The power system needs models for motor and battery performance. Power requirements of the payload must also be specified.

To start the sizing of the Mars Science Helicopter, a spreadsheet was developed, and it was calibrated to the weight and power of the Mars Helicopter. With a preliminary examination of packaging and folding options for a rotorcraft in an aeroshell, the spreadsheet sizing tool produced initial estimates of the designs. Next, NDARC models were developed, with detailed performance models for the rotor, battery, and motor, and detailed mission analysis. The weight models began in a form similar to the spreadsheet. CAMRAD II was used to determine blade planform and twist to optimize the rotor performance, and then used to generate rotor performance models for NDARC. The battery model was calibrated to the specification data for a Liion cell. A simple motor efficiency model was used. The conceptual design process iterates between the sizing task and the rotor performance and structural analysis.

\section{Mars Science Helicopter Mission}

A mission was defined by JPL for the Mars Science Helicopter. For mapping, stratigraphy, and remote sensing operations (Ref. 1), a payload of $2.02 \mathrm{~kg}$ was identified. The mission consisted of the following segments (Figure 6):

a) $30 \mathrm{sec}$ takeoff at hover power

b) climb to altitude of $200 \mathrm{~m}$

c) $1 \mathrm{~km}$ cruise flight to science site

d) 2 min hover at science site

e) land

f) sleep for 1 sol, and recharge

The energy source for flight is batteries, with electric motors supplying the rotor power. The aircraft does not return to a lander (indeed, there may not be a separate lander for the mission), so the batteries are recharged from onboard solar cells. The aircraft must have enough energy to complete the mission (with reserves) and survive one night on the surface before recharging starts. At $30 \mathrm{~m} / \mathrm{sec}$ flight speed, the mission duration is about 3 minutes; at $4 \mathrm{~m} / \mathrm{sec}$, it is about 7 minutes. Since with electric propulsion the aircraft weight does not change during the mission, the order of the cruise flight $(1 \mathrm{~km})$ and hover $(2 \mathrm{~min})$ operations can be changed without affecting the design.

The operation site chosen for design and analysis of the MSH was the Jezero Crater in the spring, for which the typical atmospheric conditions are a density of $0.015 \mathrm{~kg} / \mathrm{m}^{3}$ and temperature of $-50 \mathrm{deg}$ C. 


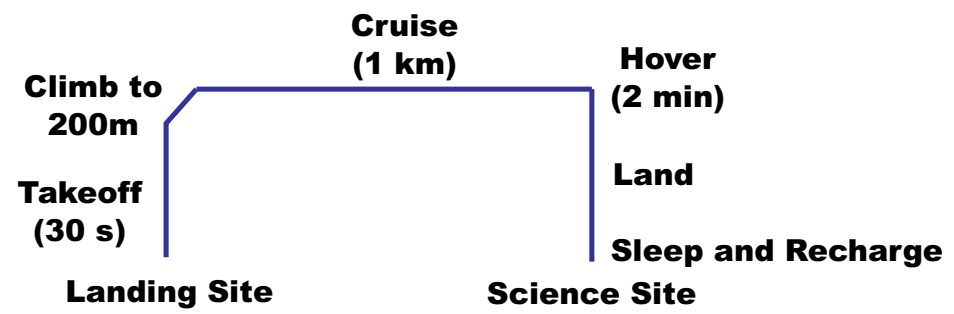

Figure 6. Mars Science Helicopter design mission.

This mission was intended to be representative of a useful scientific endeavor on Mars, without being so challenging that it was beyond projected technology. After designing a helicopter for this mission, the possibilities for expanded capabilities were explored.

\section{Initial Sizing}

Two aircraft configurations were considered for the Mars Science Helicopter, illustrated in Figure 7. The coaxial helicopter has the advantage of directly inheriting experience from the Mars Helicopter development, testing, and operation, but has potential problems with flight dynamics (discussed below). The hexacopter has better performance (due to lower disk loading) and flight dynamics characteristics, and it could operate with power out to one or two rotors, but it is expected to have larger airframe weight.
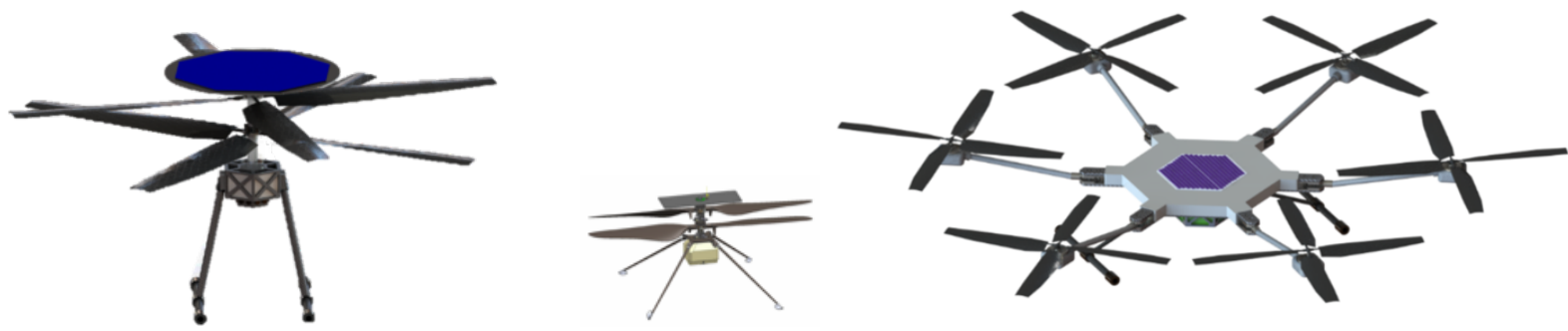

Figure 7. Mars Science Helicopter configurations, with Mars Helicopter (center) for scale.

To start the sizing of the Mars Science Helicopter, a spreadsheet was developed, and calibrated to the weight and power of the Mars Helicopter. The spreadsheet implemented simple models for rotor performance, motor and battery efficiency, and component weights. The spreadsheet sizing gave an aircraft gross weight of about $20 \mathrm{~kg}$, and a rotor diameter of 2.5-2.7 m for the coaxial helicopter or $1.0-1.4 \mathrm{~m}$ for the hexacopter (compared to $1.8 \mathrm{~kg}$ and $1.21 \mathrm{~m}$ for the Mars Helicopter).

Planetary aircraft size will always be constrained by packaging for the trip to the destination. For this initial sizing effort, the legacy Pathfinder aeroshell was considered, notably imposing a maximum diameter of $2.5 \mathrm{~m}$ for the aircraft when folded/packaged in the aeroshell prior to deployment on the Martian surface. It was assumed that the problems of landing and extraction are solvable and most of the volume within the aeroshell is potentially usable. More detailed studies (described below) considered the volumetric implications of not only fitting MSH vehicles inside the aeroshell but also fitting within the original Pathfinder airbag tetrahedral petal lander.

Numerous folding methods for both the coaxial and hexacopter designs were examined to determine which yielded the most efficient use of the aeroshell volume. Figure 8 shows the best options for the coaxial helicopter. The in-plane fold option permitted the largest blade radius $(1.34 \mathrm{~m})$, but had lower aspect-ratio blades, since this option requires 3 blades. The droop fold option had an adequate blade radius $(1.25 \mathrm{~m})$, and with 4 blades per rotor could better accommodate increased solidity. Figure 9 shows the best options for the hexacopter. The hinged fold option had a blade radius of only $0.5 \mathrm{~m}$, resulting in substantially more weight and power for the aircraft, while the rotating arm fold option had a blade radius of $0.64 \mathrm{~m}$. 

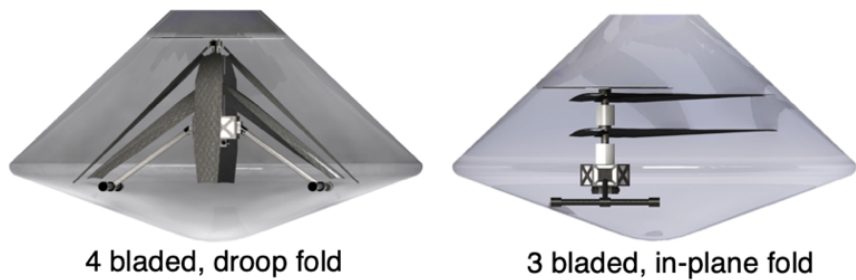

Figure 8. Folding options for coaxial helicopter in aeroshell.
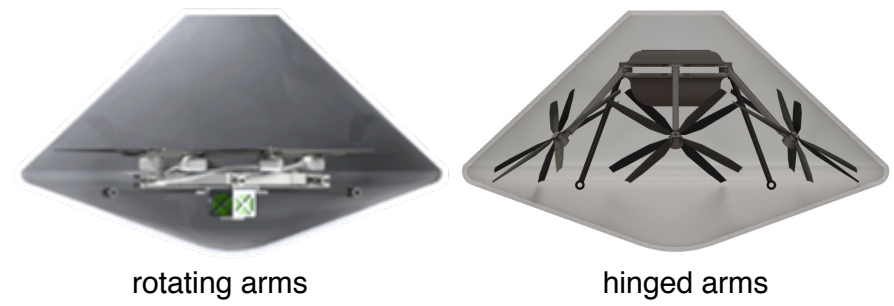

Figure 9. Folding options for hexacopter in aeroshell.

The conclusion of the initial sizing and packaging effort was that there are feasible rotorcraft that can perform the MSH design mission, although with relatively high disk loading and solidity because of the aeroshell constraint on folded size. The aircraft considered for more detailed and accurate analysis were the coaxial helicopter with droop fold and rotor radius of $1.25 \mathrm{~m}$, and the hexacopter with rotating fold and rotor radius of $0.64 \mathrm{~m}$. The initial estimates of weight and power for these two aircraft were similar, but the hexacopter had 57\% more disk area than the coaxial helicopter, which was expected to result in a more efficient aircraft.

In general, using a larger aeroshell would enable a larger and more capable rotorcraft. In particular, when the complete EDL (entry, descent, and landing) solution is considered, especially the lander, either a less capable aircraft or a larger aeroshell may well be required.

\section{Rotor Performance}

The rotor performance was calculated using the lifting-line analysis of CAMRAD II, which obtains the blade airloading and induced velocity (hence rotor power) from a distorted free wake geometry (including interaction between the rotors, especially for the coaxial configuration) and two-dimensional airfoil tables, which account for the effects of viscosity (drag and stall), compressibility, and Reynolds number. The Martian operating environment is characterized by low Reynolds number, about $R e=11000$ for $\mathrm{MH}$ and $R e=15000-25000$ for MSH, and high Mach number, $M=0.7$ to 0.9. There is no experimental data for airfoils at such low Reynolds number and high Mach number, so the airfoil characteristics were calculated using OVERFLOW. These characteristics are the lift, drag, and moment coefficients as a function of angle-of-attack and Mach numbers, for a particular atmosphere (density, speed of sound, viscosity), chord length (so Reynolds number is proportional to Mach number), and airfoil shape.

\section{Mars Helicopter Blade Design and Performance Correlation}

The Mars Helicopter rotor blade was designed by AeroVironment, as described in Refs. 15-16. The airfoil section for the outboard half of the blade is the CLF5605 (Figure 10), which was based on a series of AeroVironment airfoils designed for high altitude propellers with the camber line and thickness modified to operate at higher lift coefficients and to increase the spar depth. Designed for Reynolds numbers around 100000, the CLF5605 section is a compromise between the thickness needed for low drag and that needed for structural requirements, with a camber intended to delay the onset of laminar separation (Ref. 16). Inboard sections of the $\mathrm{MH}$ blade have increasing thickness ratios for structural rigidity, and blend into a 
circular section at the hub. The initial blade planform and twist distribution were generated using XROTOR's minimum-induced-loss method for propellers, through the CROTOR program that automates the process of calculating the interference velocities between the upper and lower rotors (Ref. 16). The geometry was refined using the AeroVironment analysis PROP, which is based on bladeelement/momentum theory, and has been validated for low Reynolds number propellers and hovering rotors. The impact of the twist and the vortex wake of the coaxial rotor were further assessed using CAMRAD II. Figure 10 shows the final planform of the MH. The MH rotor was tested at Martian atmospheric conditions in the JPL 25-ft Space Simulator (Ref. 2). Given the assumptions and limitations of the design tools for the $\mathrm{MH}$, it was expected that improved performance would be possible. However, the Space Simulator tests demonstrated that the hover performance and thrust capability of the Mars Helicopter rotor would be sufficient to perform the demonstration mission.

The data from the test of the Mars Helicopter rotor was used to demonstrate the capability to predict the hover performance. The characteristics of the CLF5605 airfoil (as well as the inboard sections of the $\mathrm{MH}$ rotor) were calculated using computational fluid dynamics (Ref. 17). Figure 11 shows the lift and drag coefficients for the CLF5605 airfoil at density of $0.017 \mathrm{~kg} / \mathrm{m}^{3}$ and temperature of $-50 \mathrm{deg}$ C. The MH rotor performance was calculated with CAMRAD II, using free wake for the coaxial rotors and these airfoil tables. Good agreement was obtained with the measured performance, as shown in Figure 12 for the figure of merit.
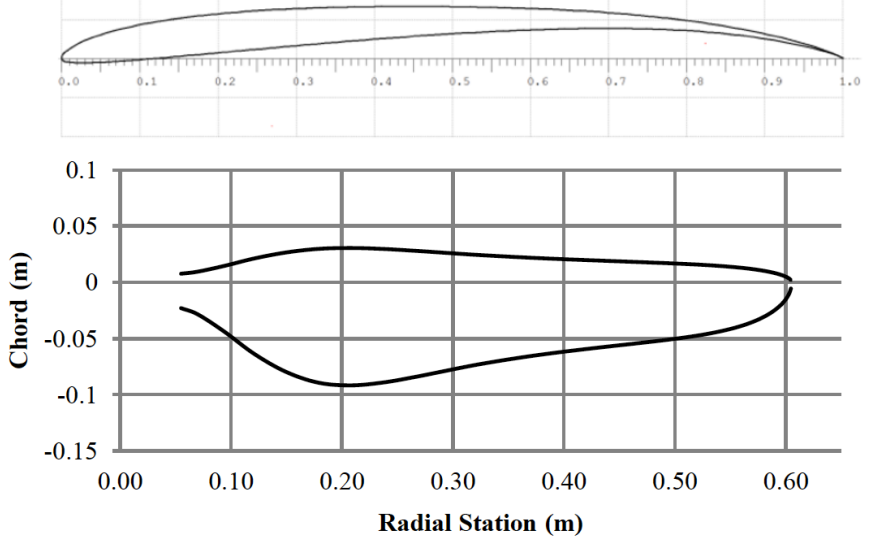

Figure 10. Mars Helicopter airfoil (CLF5605) and planform.
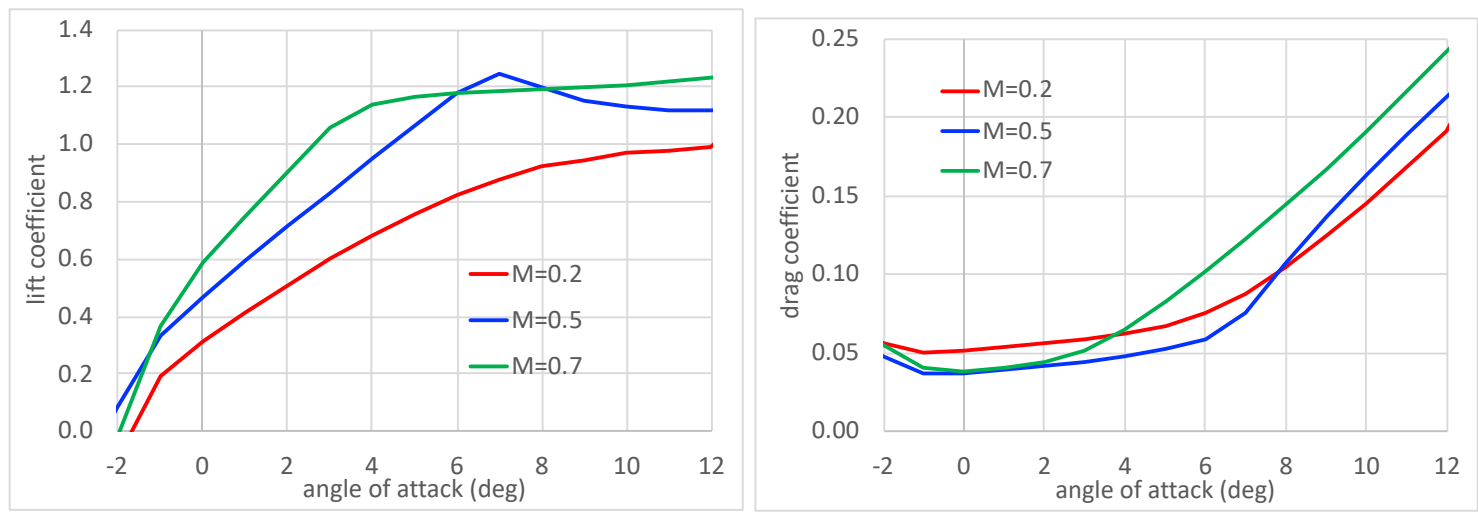

Figure 11. CLF5605 airfoil lift and drag characteristics (Re/M=24000). 


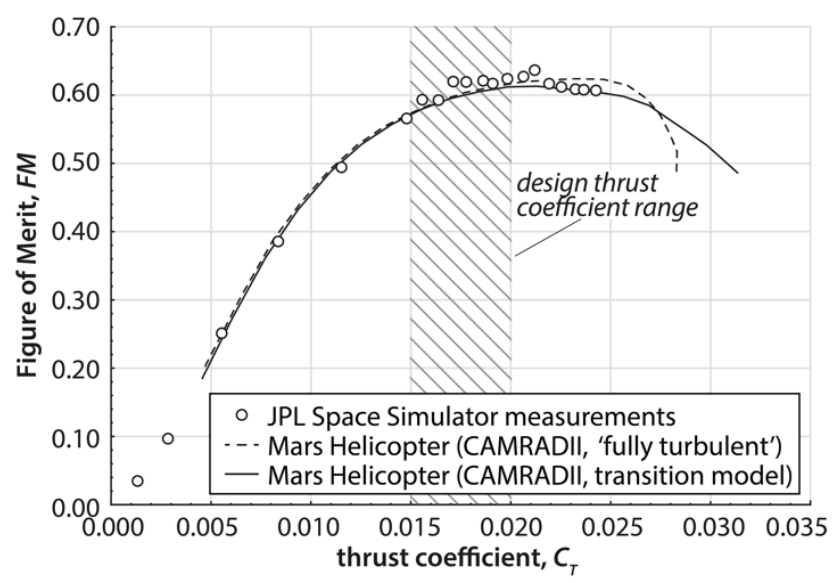

Figure 12. Comparison of measured and calculated performance of the Mars Helicopter.

\section{Airfoils for Low Reynolds Number}

Koning (Refs. 26, 27, 17) summarized the information available to support selection of airfoils for a future Mars helicopter. The low chord-based Reynolds number of the $\mathrm{MH}$ rotor results in relatively poor lift-to-drag ratios. Below approximately $\mathrm{Re}=100000$, the boundary-layer state can be subcritical. The flow is called subcritical if the boundary-layer of a streamlined shape is laminar for the range of angles-of-attack. The corresponding Reynolds number at which the boundary layer just begins to exhibit turbulent features is the critical Reynolds number, which is a function of the section shape, lift coefficient, free stream turbulence, external disturbances, and surface roughness. McMasters and Henderson (Ref. 28) provide an overview of experimental airfoil performance over a wide range of Reynolds number. Figure 13 shows the maximum section lift-to-drag ratio versus Reynolds number. The performance drop is observed around Re $=100000$. Rough airfoils exhibit higher performance down to slightly lower Reynolds numbers, because of the roughness contribution to boundary-layer transition. The performance drop at low Reynolds numbers is primarily attributed to the rise in drag coefficient in the critical Reynolds number range (Figure 13). In the low-Reynolds-number regime, the boundary layer can still be laminar after the point of pressure recovery. The laminar boundary layer at lower Reynolds numbers does not encounter sufficient amplification of disturbances in time to experience on-body transition or turbulent flow reattachment after laminar separation. The laminar boundary layer carries much less momentum near the surface due to the absence of the momentum exchanges found in a typical turbulent boundary layer, and therefore cannot withstand a strong adverse pressure gradient without separating. Separation of the laminar boundary layer then gives rise to a large pressure drag component. Furthermore, the relatively thick boundary layer at low Reynolds numbers reduces the effective camber of the airfoil, reducing the attainable lift coefficient, especially if a separated shear layer fails to reattach. The turbulent boundary layer exhibits higher resultant losses and friction drag compared with laminar boundary layer. However, the turbulent layer has higher near-wall velocity and momentum that allows for larger positive pressures (due to an adverse pressure gradient) before separation, resulting in higher airfoil performance of airfoils in supercritical states. 

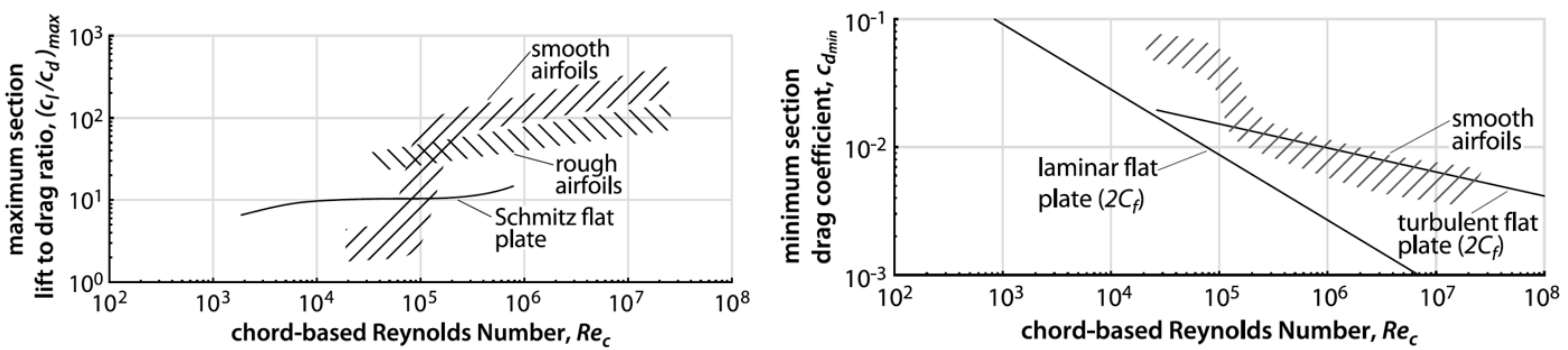

Figure 13. Variation of airfoil section maximum lift-to-drag ratio and minimum drag coefficient with chord Reynolds number (Ref. 28).
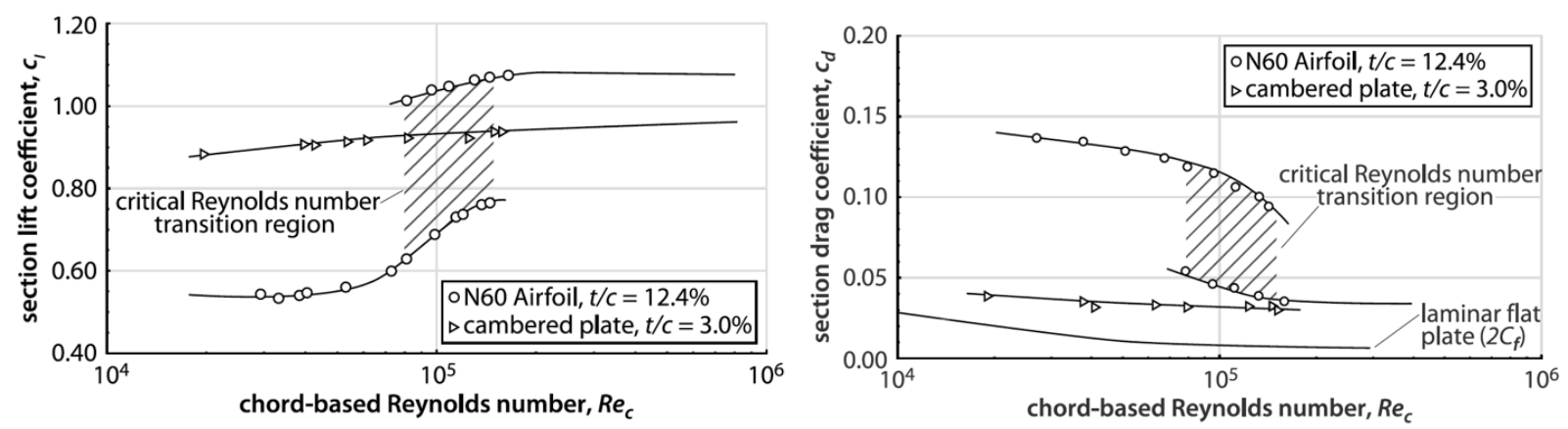

Figure 14. Variation of airfoil section lift and drag coefficients at constant angle-of-attack with chord Reynolds number (Ref. 29).

Flat plates, especially with sharp leading edges, behave differently at low Reynolds numbers than conventional airfoils (Refs. 26, 27, 17). Below the critical Reynolds number, flat and cambered plates can outperform smooth airfoils with rounded leading edges. Hoerner (Ref. 29) compares the performance of a flat plate and an airfoil crossing the critical Reynolds number transition region (Figure 13). The flat plates in the comparison have a thickness ratio of 3.0\%. A low thickness ratio has a beneficial effect on the drag coefficient. The sharper the leading edge, the earlier transition starts. For all positive angles of attack, the stagnation point moves downstream on the lower surface, creating a turbulent edge, essentially forcing supercritical behavior up to low Reynolds numbers. A sharp-leading-edge flat plate will therefore not exhibit a critical Reynolds number because the point of breakaway is fixed.

At lower Reynolds numbers the sharp leading edge creates an immediate separation location resulting in a separated shear layer that is susceptible to inviscid instabilities (such as the Kelvin-Helmholtz instability) and ultimately causes breakdown to vortex shedding over the upper surface of the airfoil. At low enough Reynolds numbers, in absence of laminar-turbulent transition in the separated shear layer (or further downstream), these instabilities and resulting vortex shedding can provide the required mixing to avoid laminar flow separation or complete stall. Neither the trailing edge shape nor free-stream turbulence levels seem to impact cambered flat plate performance to any significant extent. No hysteresis occurs for thin flat plates, compared to that observed for thicker airfoils, because the nose turbulence and/or laminar instabilities increase faster than the pressure increase. Camber usually has a positive effect on plate performance because of the low incidence angle between the free-stream and the camber line at the leading edge. The instabilities generated by the sharp leading edge and the concave underside both aid in lift generation, while sufficiently small upper surface camber allows largely attached flow.

Table 2 summarizes the factors influencing the choice of airfoils for a helicopter operating at the Reynolds numbers encountered near the Martian surface. 
Table 2. Overview of airfoil behavior at low Reynolds number (Ref. 26).

\begin{tabular}{|c|c|c|c|c|}
\hline Airfoil geometry & $\begin{array}{l}\text { Sensitivity to Re } \\
\text { and FST }\end{array}$ & $\begin{array}{l}\text { Hysteresis with } \\
\text { condition }\end{array}$ & $\begin{array}{l}\text { Demonstrated } \\
\text { concept }\end{array}$ & Comments \\
\hline $\begin{array}{l}\text { Conventional } \\
\text { airfoil }\end{array}$ & $\begin{array}{l}\text { Large sensitivity } \\
\text { possible }\end{array}$ & $\begin{array}{l}\text { Hysteresis } \\
\text { possible (LSB } \\
\text { induced) }\end{array}$ & $\begin{array}{l}\text { If outside } \\
\text { critical Re } \\
\text { region; used for } \\
\text { small unmanned } \\
\text { aerial vehicles } \\
\text { (UAVs) }\end{array}$ & $\begin{array}{l}\text { Can work reliably if } \\
\text { Reynolds number is too } \\
\text { low for boundary layer } \\
\text { transition throughout } \\
\text { operational regime (as for } \\
\text { MH) }\end{array}$ \\
\hline $\begin{array}{l}\text { Tripped airfoil, } \\
\text { rough airfoil }\end{array}$ & $\begin{array}{l}\text { If transition is } \\
\text { fixed, sensitivity } \\
\text { is minimized }\end{array}$ & $\begin{array}{l}\text { Hysteresis } \\
\text { possible if } \\
\text { bubble occurs } \\
\text { before trip }\end{array}$ & $\begin{array}{l}\text { Difficult to } \\
\text { ensure trip } \\
\text { works below } \\
\mathrm{Re}=30,000 ; \\
\text { uncertain at } \\
\text { higher } \mathrm{Re}\end{array}$ & $\begin{array}{l}\text { Transition needs to be } \\
\text { guaranteed for all } \\
\text { conditions, otherwise } \\
\text { unpredictable flight } \\
\text { dynamics can ensue }\end{array}$ \\
\hline $\begin{array}{l}\text { Cambered plate, } \\
\text { curved plate }\end{array}$ & $\begin{array}{l}\text { Leading-edge } \\
\text { separation of } \\
\text { large angle-of- } \\
\text { attack range } \\
\text { reduces } \\
\text { sensitivity }\end{array}$ & $\begin{array}{l}\text { Hysteresis less } \\
\text { likely because } \\
\text { most operating } \\
\text { conditions have } \\
\text { leading-edge } \\
\text { separation }\end{array}$ & $\begin{array}{l}\text { Used for many } \\
\text { small UAVs or } \\
\text { micro aerial } \\
\text { vehicles } \\
\text { (MAVs) }\end{array}$ & $\begin{array}{l}\text { Possible stiffness issues } \\
\text { due to low thickness-to- } \\
\text { chord ratio }\end{array}$ \\
\hline $\begin{array}{l}\text { Corrugated } \\
\text { airfoil }\end{array}$ & $\begin{array}{l}\text { Separation at } \\
\text { corrugation } \\
\text { features likely to } \\
\text { reduce sensitivity }\end{array}$ & $\begin{array}{l}\text { Hysteresis less } \\
\text { likely because of } \\
\text { separation at } \\
\text { corrugation } \\
\text { features }\end{array}$ & $\begin{array}{l}\text { No known } \\
\text { rotary-wing } \\
\text { experiments } \\
\text { using corrugated } \\
\text { airfoils }\end{array}$ & $\begin{array}{l}\text { Performance only } \\
\text { competitive at lower } \\
\operatorname{Re}<10,000\end{array}$ \\
\hline Polygonal airfoil & $\begin{array}{l}\text { Separation at } \\
\text { corrugation } \\
\text { features likely to } \\
\text { reduce sensitivity }\end{array}$ & $\begin{array}{l}\text { Hysteresis less } \\
\text { likely because of } \\
\text { separation }\end{array}$ & $\begin{array}{l}\text { No known } \\
\text { rotary-wing } \\
\text { experiments } \\
\text { using polygonal } \\
\text { airfoils }\end{array}$ & $\begin{array}{l}\text { Possible mediation of } \\
\text { stiffness issues due to } \\
\text { increased thickness-to- } \\
\text { chord ratio }\end{array}$ \\
\hline
\end{tabular}

$\mathrm{Re}=$ Reynolds number, FST $=$ freestream turbulence, $\mathrm{LSB}=$ laminar separation bubble

\section{Cambered Plate Airfoil for Mars}

Based on this assessment of the aerodynamics of airfoils at low Reynolds number, a cambered plate with sharp leading-edge should be a good airfoil for a helicopter on Mars (Ref. 27). OVERFLOW was used to calculate the section lift and drag of a plate with 5\% camber, $1 \%$ thickness, and a sharp leading edge (Figure 15), for the Mars conditions of $0.017 \mathrm{~kg} / \mathrm{m}^{3}$ density and $-50 \mathrm{deg} \mathrm{C}$ temperature. This airfoil had a good lift-to-drag ratio, and the loads was not sensitive to Reynolds number or free stream turbulence. No hysteresis was observed in the calculations. With $1 \%$ thickness-to-chord ratio, the possibility of issues with rigidity of the blade must be examined by structural analysis. 


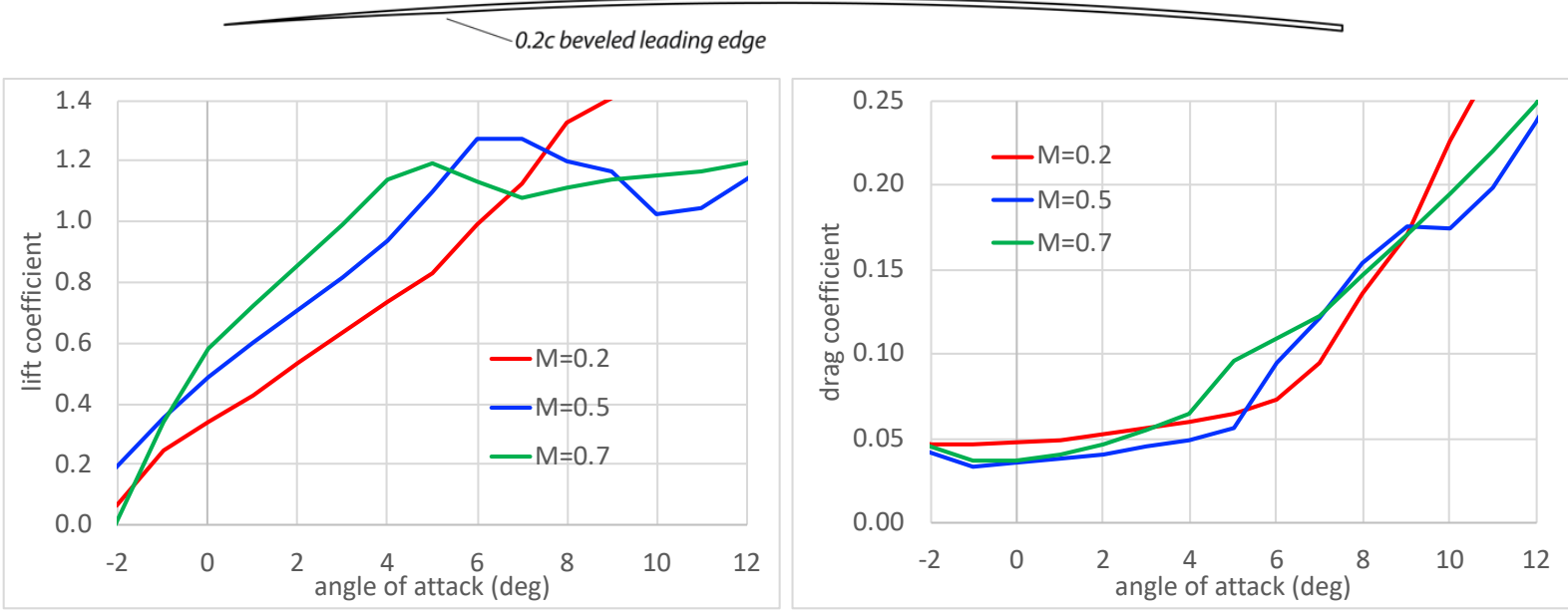

Figure 15. Cambered plate airfoil lift and drag characteristics (Re/M=26000).

The MH rotor performance was calculated with CAMRAD II, using the airfoil characteristics of the cambered plate or circular arc. The calculated hover figure of merit is shown in figure 16, compared with the performance of the rotor with the CLF5605 airfoil. The rotor with the circular arc airfoil had improved performance. The better airfoil lift-to-drag ratio of the circular arc produced a higher peak figure of merit, and hence lower power. The better stall characteristics led to a higher maximum lift, which will allow a larger design blade loading $C_{T} / \sigma$, hence more lift capability for the same blade area and weight.

For initial designs using NDARC, the rotor performance model was calibrated to CAMRAD II calculations for a rotor using the circular arc airfoil section. The airfoil characteristics for the conditions at $92 \% \mathrm{R}$ of the $\mathrm{MH}$ blade were used, with a Reynolds correction (reduction for higher Re) of drag.

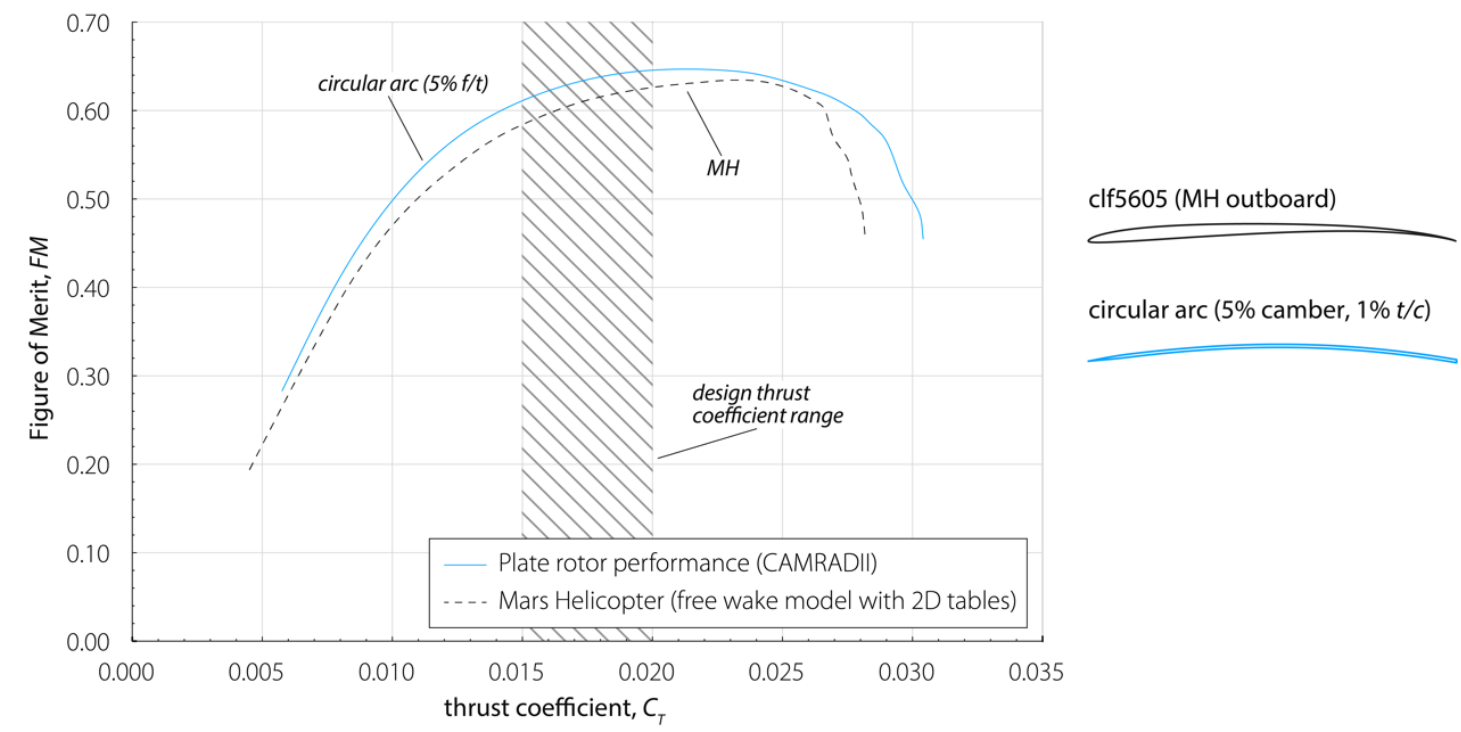

Figure 16. Performance of the Mars Helicopter rotor, comparing hover figure of merit with CLF5605 and circular arc airfoil sections. 


\section{Blade Geometry Optimization}

The rotor performance in hover and forward flight were calculated using CAMRAD II, using the airfoil table for the circular arc section (5\% camber, $1 \%$ thickness). Planform taper and blade twist were varied to minimize the rotor power required at the design conditions, keeping the blade thrust-weight solidity constant. A square tip is needed so the tip vortex forms at the blade tip (not inboard), which gives the best hover performance. The root cutout was $9 \%$ R. For a low Reynolds number, high-solidity rotor the performance was not very sensitive to blade taper. Overall taper ratios from 0.5 to 1.0 were considered. Reduced chord was considered for the root (negative taper, to $0.25 \mathrm{R}$ ) to reduce weight, since inboard chord is not very important for performance. Additional taper was considered at the tip (outboard of $0.75 \mathrm{R}$ ). The optimum linear taper was $c_{\text {tip }} / c_{\text {root }}=0.85$, with more taper at the tip $(0.43)$ and reduced chord at the root. Figure 17 shows the planforms for the coaxial helicopter blade and the hexacopter blade. As solidity changed during the design process, the chord was scaled keeping the taper ratios constant.

Large negative twist is good for hover and low speed rotor performance. Twist values from -12 to -24 deg (linear, root to tip) were considered, including different inboard and outboard twists. The optimum was found to be -18 deg linear twist.

The rotor performance was calculated for this optimum blade (airfoil, twist, and planform) with CAMRAD II, and the results were used to calibrate the NDARC rotor performance model. Figure 18 shows the NDARC results for the rotor power required of the Mars Science Helicopter. The larger total rotor disk area of the hexacopter led to lower power required compared to the coaxial helicopter. The minimum power speed was about $30 \mathrm{~m} / \mathrm{sec}$ (best endurance speed). Best range speed was $50-60 \mathrm{~m} / \mathrm{sec}$. The corresponding aircraft hover figure of merit was $F M=0.675$ for the coaxial helicopter, and $F M=0.615$ for the hexacopter.

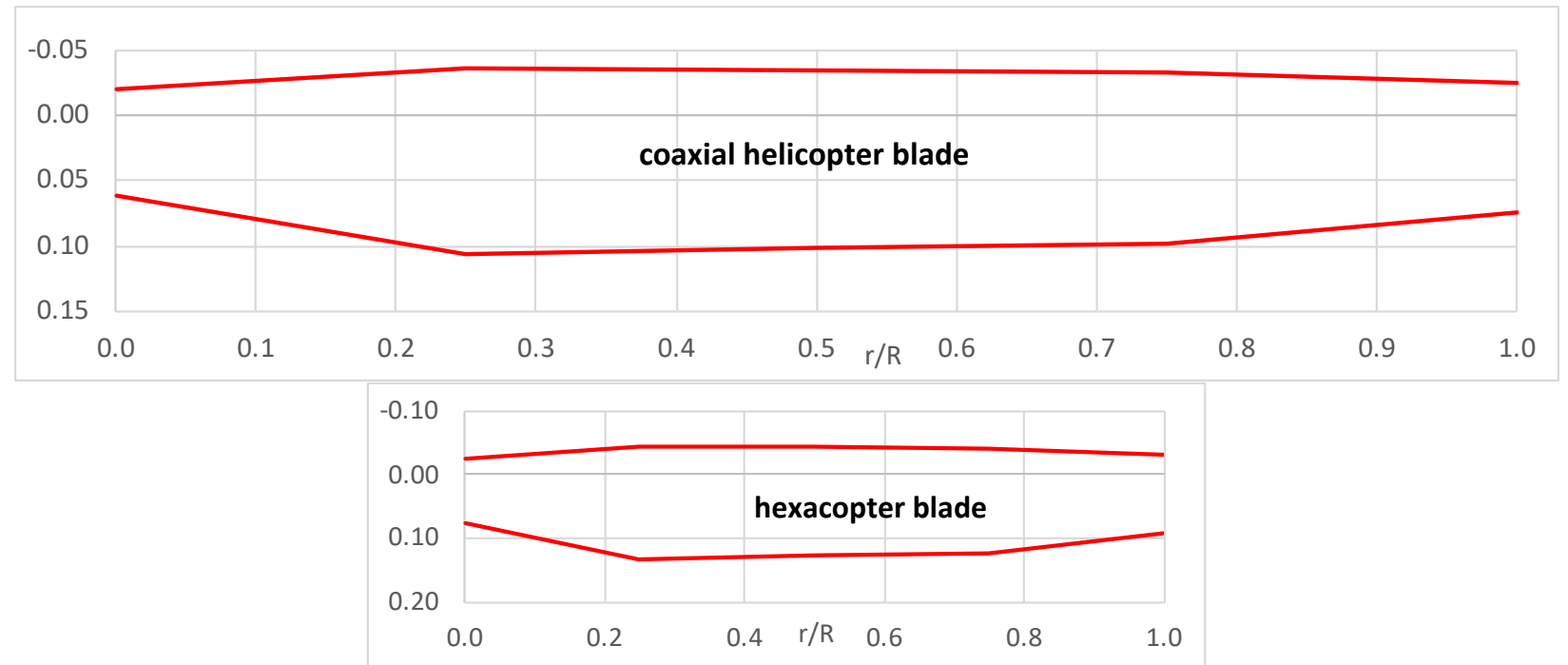

Figure 17. Mars Science Helicopter blade planform for four-bladed coaxial helicopter (radius $=1.25 \mathrm{~m}$, solidity $=0.155$ ) and four-bladed hexacopter (radius $=0.64 \mathrm{~m}$, solidity $=0.193$ ). The root cutout (not shown) is typically $9 \% \mathrm{R}$. 

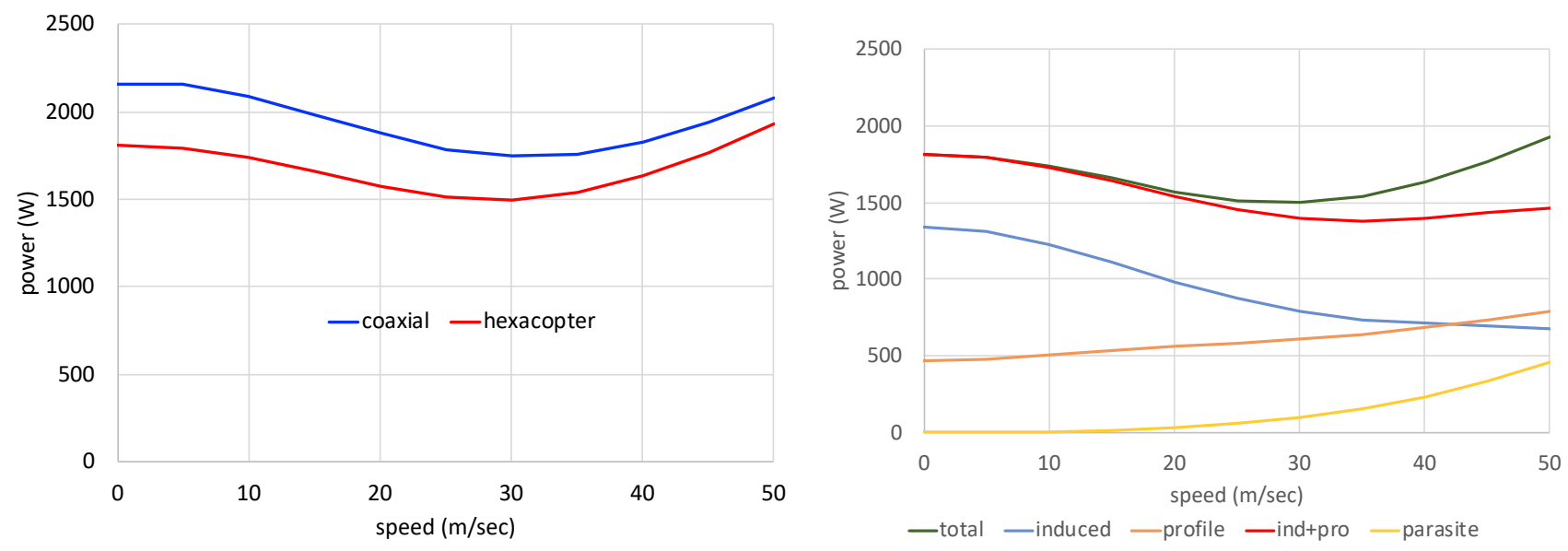

Figure 18. Mars Science Helicopter forward flight performance.

\section{NDARC Models for Mars Helicopters}

The helicopters for the Mars science mission were sized using the rotorcraft design and analysis code NDARC. NDARC has detailed performance models of the rotor, battery, motor, and other components, with a detailed description of the mission. The rotor performance model was calibrated from CAMRAD II calculations of hover and forward flight performance for the optimized rotors (described above). Weight models were calibrated to the actual weights of the Mars Helicopter (Refs. 2, 15, 16), informed by the calculated weight of the MARV design (Ref. 7). Energy and power margins were based on the Mars Helicopter.

\section{Mission}

The payload of the Mars Science Helicopter was $2.02 \mathrm{~kg}$, with a corresponding equipment power of 35 W. In addition, there was $1.2 \mathrm{~kg}$ of avionics weight, including $0.1 \mathrm{~kg}$ for telecom and $0.1 \mathrm{~kg}$ for other equipment. The design included a contingency weight equal to $20 \%$ of the aircraft empty weight.

The MSH design mission is shown in Figure 6: (a) $30 \mathrm{sec}$ takeoff at hover power, (b) climb to altitude of $200 \mathrm{~m}$, (c) $1 \mathrm{~km}$ flight to science site, (d) 2 min hover at science site, (e) land, (f) sleep for $1 \mathrm{sol}$, and recharge. The battery capacity was sized to the energy required for this mission, plus a reserve of $20 \%$ of the mission energy.

The sleep energy was assumed to scale with aircraft length, hence with the $1 / 3$ power of the gross weight: $E_{\text {sleep }}=15 \mathrm{~W}^{1 / 3} \mathrm{Wh} / \mathrm{sol}$ (calibrated to $\mathrm{MH}$ ), hence the sleep power was $P_{\text {sleep }}=0.518 \mathrm{~W}^{1 / 3} \mathrm{~W}$ (for $1 \mathrm{sol}=1477 \mathrm{~min}$, including battery efficiency of $85 \%$ ). This power was modelled as equipment power, taking energy directly from the battery.

\section{Design Variables}

The design blade loading was $C_{T} / \sigma=0.11$, which given the tip speed, air density, and rotor thrust determined the blade area. The design blade loading of the $\mathrm{MH}$ was $C_{T} / \sigma=0.10$, allowing a $40 \%$ increase in thrust (beyond hover level flight) for control of the helicopter. Based on the measured and calculated thrust capability of the MH rotor (Figure 12) and the increased capability expected with the circular arc airfoil (Figure 16), the design blade loading was increased by $10 \%$. 
The hover tip Mach number was 0.7 , based on the MH experience and the calculated airfoil behavior at high Mach number. The speed of sound on Mars is $233.1 \mathrm{~m} / \mathrm{sec}$ at $-50 \mathrm{deg} \mathrm{C}$, hence the tip speed at this Mach number was $163.2 \mathrm{~m} / \mathrm{sec}$.

The cruise flight speed was $30 \mathrm{~m} / \mathrm{sec}$, which was the minimum power speed (Figure 18). The flight speed of the $\mathrm{MH}$ was much smaller, due to limitations of the visual navigation system. It was assumed that the navigation system of the MSH supports flight speeds up to $50 \mathrm{~m} / \mathrm{sec}$. At $30 \mathrm{~m} / \mathrm{sec}$ flight speed and tip Mach number of 0.7 , the advance ratio was $V / V_{\text {tip }}=0.18$, and the advancing tip Mach number was $M_{a t}=$ 0.83. That was a modest advance ratio, and the calculated airfoil characteristics show that the compressibility limits were above that Mach number. If higher $M_{a t}$ were possible (as below), the design tip speed could be increased, and the blade area decreased, resulting in benefits for weight and performance. Not much energy was used in cruise, so while flying faster (best range speed was above $50 \mathrm{~m} / \mathrm{sec}$ ) would reduce the cruise power, the impact on the aircraft size would be small.

\section{Motor}

For control authority and margin, the motors were sized to $150 \%$ hover power. The motors were connected directly to the rotors, so the design motor speeds were about $1200 \mathrm{rpm}$ (coaxial) and $3000 \mathrm{rpm}$ (hexacopter). The coaxial helicopter propulsion system would probably be lighter using a transmission. The motor weight scaled with torque: $W_{\text {motor }}=0.076 Q^{0.86} \mathrm{~kg}$ (current technology scaling, calibrated to $\mathrm{MH}$ ). The efficiency was constant at $68 \%$, due to motor and electronic control system efficiency of $80 \%$ and rotor control servo power equal to $15 \%$ of rotor power.

\section{Solar Cell}

The solar cell power density was $540 \mathrm{Wh} / \mathrm{m}^{2} / \mathrm{sol}$, or $21.9 \mathrm{~W} / \mathrm{m}^{2}$ (based on $\mathrm{MH}$ ). Charging $1.2 \mathrm{MJ}$ in one sol required a power of $13.54 \mathrm{~W}$, hence a solar cell area of $0.62 \mathrm{~m}^{2}$ is required. The solar cell weight density was $2.0 \mathrm{~kg} / \mathrm{m}^{2}$, hence the solar cell weight was $1.23 \mathrm{~kg}$.

\section{Battery}

The battery model was based on a JPL technology forecast. The weight was $278 \mathrm{Wh} / \mathrm{kg}$ cell, $230 \mathrm{Wh} / \mathrm{kg}$ pack (including battery management system), $218.5 \mathrm{Wh} / \mathrm{kg}$ at end of life. The volume density was 420 $\mathrm{Wh} / \mathrm{L}$. The usable energy was $70 \%$ of the nominal capacity ( $10 \%$ to $80 \%$ depth-of-discharge). The MSH required 1.2-1.4 MJ, hence had a battery weight of $1.5-1.7 \mathrm{~kg}$. The efficiency of the battery was obtained from the curve of voltage vs. state-of-discharge during various rates of discharge. This curve was obtained from documented performance of current Li-ion batteries (specifically the $\mathrm{MH}$ battery). The resulting discharge efficiencies were $88-92 \%$. A mission time of 6 minutes implied an average discharge C-rate (1/hr) of 10. That is a high discharge rate, within the capability of current batteries, but expected to reduce battery life.

\section{Drag}

The rotor propulsive power depends on the aircraft drag, which was calculated as the sum of contributions from the fuselage, landing gear, rotor hub and pylon, and rotor support arms:

Fuselage: scale with wetted area, $D / q=C_{D} S_{\text {wet }} \mathrm{m}^{2}, C_{D}=1.2, S_{\text {wet }}=27.5(W / 1000)^{2 / 3} \mathrm{~m}^{2}$ (weight $W$ in $\mathrm{kg}$ )

Landing gear: fixed, $D / q=0.05 \mathrm{~m}^{2}$

Rotors: scale with rotor disk area, $D / q=\left(C_{D h u b}+C_{D p y l o n}\right) A \mathrm{~m}^{2}, C_{D h u b}=0.003(0.0015$ for faired hub), $C_{\text {Dpylon }}=0.015$ (low drag pylon),

Rotor support arms (hexacopter): $D / q=C_{\text {Darm }} A \mathrm{~m}^{2}, \quad C_{D a r m}=C_{D} L c / A=C_{D}(L / R)^{2}(c / L) / \pi=$ $0.1\left(1.2^{2}\right) / 15 / \pi=0.003(L=$ arm length, $c=$ chord $)$. 


\section{Weights}

The aircraft gross weight is the sum of the weight empty and the payload. The component weights were estimated as follows:

Weight Empty:

Structure

\section{Rotor Group}

Blade: scale with blade area, $W_{\text {blade }}=1.1 A_{\text {blade }} \mathrm{kg}(110 \% \mathrm{MH})$

Hub: scale with rotor thrust, $W_{\text {hub }}=0.05\left(W / N_{\text {rotor }}\right) \mathrm{kg}$ each rotor $(120 \% \mathrm{MH})$

Shaft: scale with blade radius, $W_{\text {shaft }}=0.15 L_{\text {shaft }} \mathrm{kg}, L_{\text {shaft }}=0.15 R \mathrm{~kg}$ each rotor $(\mathrm{MH})$

Rotor support arms (hexacopter): scale with blade radius, $W_{\text {support }}=0.2 R \mathrm{~kg}$ each rotor (finite element model, $\mathrm{MH}$ rotor shaft)

Fuselage Group: scale with gross weight, $W_{\text {fuselage }}=28(W / 1000)^{2 / 3}(\mathrm{MH}, W$ in $\mathrm{kg})$

Alighting Gear: scale with gross weight, $W_{\text {gear }}=0.067 \mathrm{~W}(\mathrm{MH})$

Propulsion

Motor: scale with torque, $W_{\text {motor }}=0.076 Q^{0.86}(\mathrm{MH})$

Solar Cell: scale with area, $2.0 \mathrm{~kg} / \mathrm{m}^{2}(\mathrm{MH})$

Battery: JPL technology forecast, $218.5 \mathrm{Wh} / \mathrm{kg}$ (pack, including battery management system, endof-life)

Systems and Equipment

Flight Controls: scale with blade weight, $W_{\text {control }}=0.84 W_{\text {blade }}(80 \% \mathrm{MH})$

Avionics: $1.2 \mathrm{~kg}$ (including $0.1 \mathrm{~kg}$ telecom, $0.1 \mathrm{~kg}$ other)

Contingency: 20\% Weight Empty

Payload: $2.02 \mathrm{~kg}$

\section{Mars Science Helicopter Designs}

A coaxial helicopter and a hexacopter (Figure 19) were sized using NDARC to perform the Mars Science Helicopter mission. Table 3 summarizes the aircraft characteristics, with the Mars Helicopter for comparison. The rotor radius was maximized for the folded configuration. The hexacopter has more total disk area than the coaxial helicopter, hence less energy required and less weight. The disk loading is high (for the low density), which is reflected in the high solidity values. Table 4 shows the design mission performance for the hexacopter. Most of the energy was expended in the hover segments. The high discharge current (about 10C) probably reduces battery life.
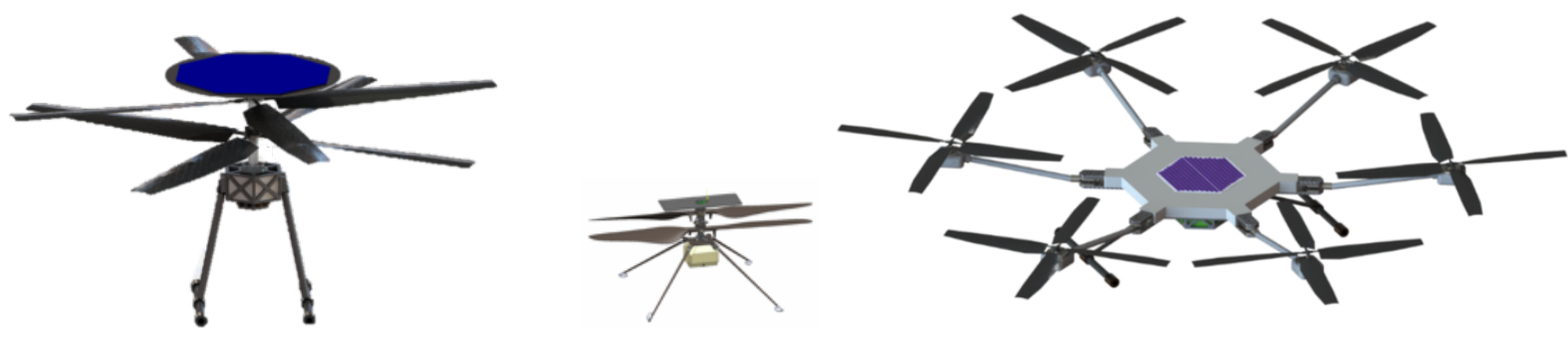

Figure 19. Mars Science Helicopter configurations, with Mars Helicopter (center) for scale. 
Table 3. Mars Science Helicopter designs.

\begin{tabular}{|c|c|c|c|c|c|c|c|}
\hline & & \multicolumn{2}{|c|}{$\overline{\mathrm{MSH}}$} & \multirow[t]{2}{*}{$\overline{\mathrm{MH}}$} & \multicolumn{3}{|c|}{ "Weights (kg) } \\
\hline & & coaxial & hex & & & coaxial & hex \\
\hline radius & $\mathrm{m}$ & 1.25 & 0.64 & 0.605 & GROSS WEIGHT & 18.032 & 17.662 \\
\hline gross weight & $\mathrm{kg}$ & 18.03 & 17.66 & 1.80 & WEIGHT EMPTY & 16.012 & 15.646 \\
\hline number rotors & & 2 & 6 & 2 & STRUCTURE & 5.858 & 6.405 \\
\hline number blades & & 4 & 4 & 2 & rotor group & 2.724 & 3.322 \\
\hline disk area & $\mathrm{m}^{2}$ & 4.91 & 7.72 & 2.30 & blade & 1.755 & 1.719 \\
\hline disk loading & $\mathrm{kg} / \mathrm{m}^{2}$ & 3.67 & 2.29 & 0.78 & hub & 0.902 & 0.883 \\
\hline $\operatorname{Re}(75 \% \mathrm{R})$ & & 24752 & 15784 & 11412 & shaft & 0.068 & 0.086 \\
\hline solidity & & 0.310 & 0.193 & 0.148 & rotor support & & 0.634 \\
\hline tip speed & $\mathrm{m} / \mathrm{sec}$ & 163.17 & 163.17 & 163.17 & fuselage group & 1.925 & 1.899 \\
\hline rotor speed & $\mathrm{rpm}$ & 1247 & 2435 & 2575 & alighting gear & 1.208 & 1.183 \\
\hline motor power & $\mathrm{kW}$ & 3.17 & 3.32 & 0.36 & PROPULSION & 4.269 & 3.460 \\
\hline solar cell & $\mathrm{m}^{2}$ & 0.62 & 0.62 & 0.04 & motor & 1.345 & 0.741 \\
\hline \multirow[t]{3}{*}{ battery } & $\mathrm{Ah}$ & 128 & 113 & 12 & solar cell & 1.197 & 1.197 \\
\hline & & & & & battery & 1.727 & 1.522 \\
\hline & & & & & SYS \& EQUIP & 2.674 & 2.644 \\
\hline \multirow[t]{4}{*}{ drag } & $\mathrm{m}^{2}$ & 0.481 & 0.492 & & flight controls & 1.474 & 1.444 \\
\hline & & & & & avionics & 1.200 & 1.200 \\
\hline & & & & & CONTINGENCY & 3.200 & 3.127 \\
\hline & & & & & PAYLOAD & 2.020 & 2.020 \\
\hline
\end{tabular}

Table 4. Design mission performance (hexacopter).

\begin{tabular}{lllllll}
\hline Design Mission & time & distance & speed & energy & energy (\%) & current \\
\hline & min & $\mathrm{m}$ & $\mathrm{m} / \mathrm{sec}$ & MJ & & $1 / \mathrm{hr}$ \\
\hline \hline takeoff & 0.5 & 0 & 0 & 0.0863 & $12 \%$ & 9.4 \\
climb to 200m & 0.33 & 0 & 0 & 0.0693 & $10 \%$ & 11.8 \\
fly to site & 0.56 & 1000 & 30 & 0.0784 & $11 \%$ & 7.9 \\
hover at site & 2 & 0 & 0 & 0.3486 & $50 \%$ & 9.9 \\
sleep 1 sol & 1477 & 0 & 0 & 0.1161 & $17 \%$ & 0.005 \\
\hline \hline
\end{tabular}




\section{Blade Structural Analysis}

The blade structure was analyzed using the three-dimensional finite element analysis code X3D. X3D can calculate the stress and strain of the rotating structure under loading, and it can obtain the natural frequencies of vibration. The blades of the coaxial helicopter and the hexacopter were analyzed at the design rotational speed and for a rotor speed sweep. The blades had the cambered plate airfoil (5\% camber, $1 \%$ thickness ratio), and the optimized twist and taper (Figure 17). The root cutout was 9\%R. The material was carbon fiber 60 gsm HR40 spread tow Bi-D carbon fiber with a reduction of material stiffness consistent with the MH design.

The target blade flap frequency was $1.5 / \mathrm{rev}$ at the design rotational speed. This requirement was based on the stability margin for control, as discussed below. The root thickness was increased as required to achieve this stiffness. The following blade designs were analyzed:

a) Coaxial helicopter: thickness ratio $\mathrm{t} / \mathrm{c}=12 \%$ at $20 \% \mathrm{R}$ (root cutout) to $1 \%$ at $45 \% \mathrm{R}$ to tip.

b) Hexacopter: thickness ratio $\mathrm{t} / \mathrm{c}=6 \%$ at $22 \% \mathrm{R}$ (root cutout) to $1 \%$ at $50 \% \mathrm{R}$ to tip.

c) Hexacopter: thickness ratio $t / c=1 \%$ over entire blade (blade flap frequency fallout).

For comparison, the $\mathrm{MH}$ blade is similar to a conventional propeller design: thickness ratio $\mathrm{t} / \mathrm{c}=96 \%$ at $9 \% \mathrm{R}, \mathrm{t} / \mathrm{c}=22 \%$ at $20 \% \mathrm{R}, \mathrm{t} / \mathrm{c}=5 \%$ at $48 \% \mathrm{R}$ to tip (CLF5605 airfoil).

Figure 20 shows the calculated strain in blade during flap motion and the blade frequencies as a function of rotor speed. The lowest blade frequency is for the flap mode. The light lines are constant per-rev values, and the flap frequency was $1.5 / \mathrm{rev}$ at the design rotational speed (1247 rpm for coaxial, $2435 \mathrm{rpm}$ for hexacopter). The strain plots show that this flap frequency was achieved by making the inboard part of the blade stiff, so there was an effective flap hinge at about $45 \% \mathrm{R}$. The structural analysis gave an estimate of the blade weight: $492 \mathrm{~g}$ for the coaxial blade, and $70 \mathrm{~g}$ for the hexacopter blade. These estimates were not used to update the NDARC designs, but eventually the results of the rotor structural design and analysis must be used to revise the NDARC blade weight models.

\section{Flight Dynamics and Control}

\section{Helicopter Control}

Helicopter rotors are controlled by collective (mean) and cyclic (once-per-revolution) changes in the blade pitch (Ref. 18). Collective pitch changes the rotor thrust, and cyclic pitch (cosine and sine harmonics) produces hub moments and tilt of the thrust vector (about two axes). Usually the pitch motion is rotation about a bearing at the blade root. A swashplate mechanism transforms three controls (collective, lateral cyclic, and longitudinal cyclic) from the pilot or actuators into rotating frame mean and $1 /$ rev pitch bearing motion.

Controlling the rotorcraft requires the ability to produce roll, pitch, and yaw moments on the aircraft, and a vertical force. A coaxial helicopter has collective and cyclic controls on both rotors. Changing the collective of both rotors produces the vertical force, and differential collective change produces a yaw moment. Cyclic control to both rotors produces pitch and roll moments. It is possible to control the helicopter using cyclic on only one of the coaxial rotors, but that results in half the control power and undesirable coupling between the control modes.

A hexacopter has collective control on each rotor, without rotor cyclic. Changing the collective of all rotors produces the vertical force, and differential collective (based on rotor rotation direction) produces a yaw moment. With four rotors, there is a unique combination of thrust changes on the rotors that produces pitch or roll moment with no net vertical force or yaw moment. With six rotors, there is an optimum way to produce the moments on the aircraft (which would change if one or two of the rotors became inoperative). 


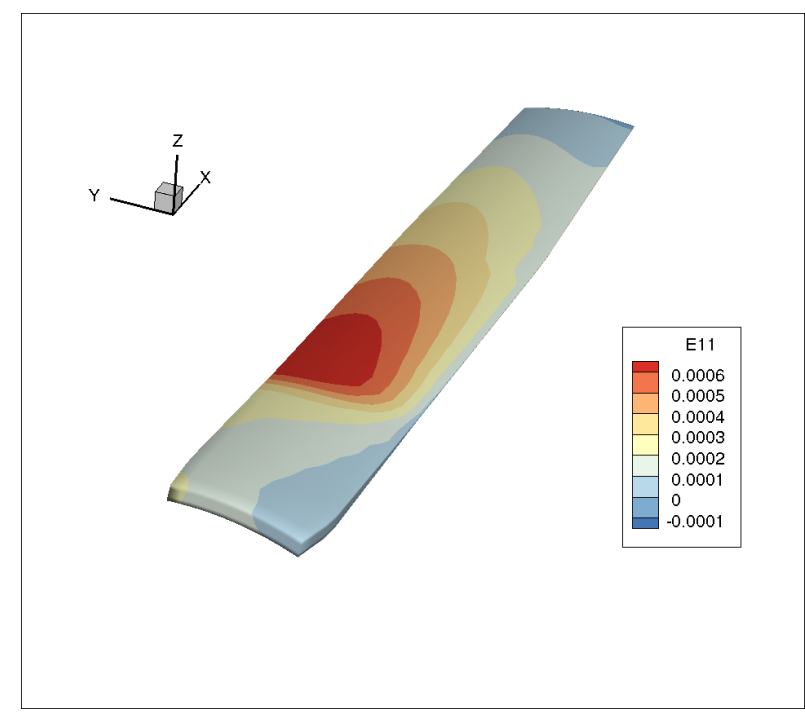

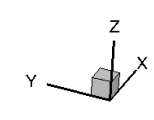
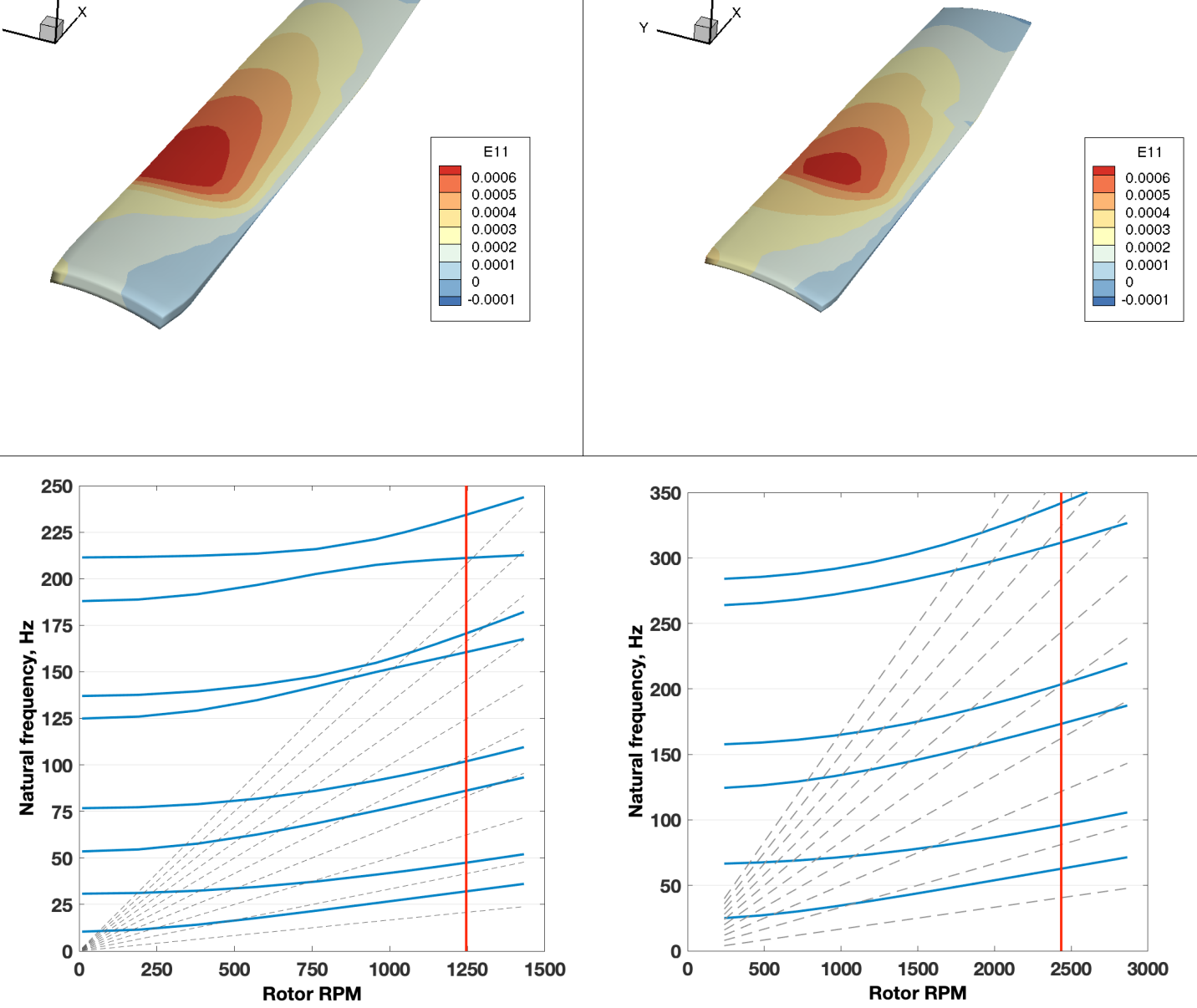

Figure 20. Calculated strain in blade during flap motion (top) and blade frequencies as a function of rotor speed (bottom), for coaxial helicopter blade and hexacopter blade.

A multicopter can be controlled using either collective or rpm change to produce a thrust change on each rotor. It is possible that rpm control would be lighter, because of the absence of the swashplate and its actuator. It is also possible that the control bandwidth required by the mission would not be achievable with rpm control, particularly for a large helicopter in the Mars environment. The operating tip Mach number range of the rotor would change with rpm control. Further investigation is needed to support the design choice. However, in terms of the impact of the control on flight dynamics, both collective and rpm control operate by changing the rotor thrust, hence will be subject to the same limitation associated with the blade flap dynamics.

The rotor blade flapping motion responds to pitch control (Ref. 18). A collective pitch change produces a dynamic coning response of the rotor blades, with a resonant frequency equal to the rotating natural flap frequency $v_{\text {flap }}$. Dynamic cyclic pitch change produces a tip-path plane wobble, with a resonant frequency equal to $v_{\text {flap }}-1 / \mathrm{rev}$, which is significantly lower than the coning mode frequency. 


\section{Blade Flap Dynamics on Mars}

Grip et al. (Refs. 12-13) identified the impact of the rotor flap response on the flight dynamics of a helicopter on Mars. The damping of the blade flap mode comes from the aerodynamics: as the blade flaps up and down, the section angle-of-attack changes, which produces a lift change opposing the flap motion. For a helicopter blade on Earth this aerodynamic damping is large, on the order of $50 \%$ critical, so blade flap motion in response to control and disturbances reaches steady state in less than one rotor revolution. The lift change produced by flap motion is proportional to the fluid density, so on Mars the aerodynamic damping is small. The Mars Helicopter blade has a flap frequency of about 2/rev, and a Lock number (which characterizes the flap damping) of $\gamma=0.3$, and hence only about 3\% critical flap damping. Figure 21 illustrates the blade flap response to pitch input (in the rotating frame) for a rotor on Earth (high damping) and on Mars (low damping). A dynamic system with low damping exhibits a large amplification of the response and a fast phase change near the resonant frequency. For collective and cyclic pitch input to the rotor, the flapping of individual blades responds together in coning and tip-path-plane tilt modes. These nonrotating modes of flap motion inherit the low damping of the rotating frame flap motion (same real part of the eigenvalues, hence same time to half amplitude). Coning response to collective occurs at the frequency of the rotating flap mode, $v_{\text {flap }}$. Tip-path-plane response to cyclic occurs in regressive and progressive flap modes (tip-path-plane wobble) at frequencies $v_{\text {flap }}-1 / \mathrm{rev}$ and $v_{\text {flap }}+1 / \mathrm{rev}$, respectively. The resulting aircraft response to cyclic control exhibits strong resonant peaks at the regressive and progressive flap mode frequencies (Figure 22).

Grip discussed the consequences of these low-damped flap modes for the Mars Helicopter (Refs. 1213). Poorly damped modes like the ones shown in Figure 22 are problematic for control, due to the potential for destabilization through interaction with the flight control system. In general, there are three main strategies available to deal with modes of this kind:

1) Phase-stabilizing the modes, by ensuring that the phase of the control loop prevents unwanted encirclements of the critical point.

2) Employing notch filters to reduce the gain of the control loop at the particular frequencies in question.

3) Gain-stabilizing the modes by ensuring that the control loop gain rolls off well in advance of the modes.

Of these, the first two require good knowledge of the dynamics around the relevant frequencies, and confidence that the dynamics will never change. Such assumptions are not well justified for the Mars Helicopter, in part because of the difficulty of accurately identifying dynamics at these frequencies in the right environment; and in part because the actual dynamics, once other sources of flexibility (e.g., bending of the mast) are coupled in with the flap dynamics, will look far more complicated than indicated in Figure 22. The third option is more robust, but it may place restrictions on achievable closed-loop bandwidth. For the Mars Helicopter, there were minimum bandwidth requirements due to the need to stabilize the helicopter dynamics, which were open-loop unstable, and performance requirements in gusty conditions. In order to achieve the necessary bandwidth, the resonant modes must be moved to sufficiently high frequencies through the mechanical design. To the achieve this, the blades and hub for the Mars Helicopter were designed to be unusually stiff. Together with other stiffness requirements for the mast and landing gear, all resonant modes in the flight dynamics were then at sufficiently high frequencies.

The rotor frequencies scale with rotational speed: blade modal frequencies specified as per-revolution imply frequencies that are proportional to rotor $\mathrm{rpm}$. The rotor rotational speed decreases as size increases: for a given tip speed, $\Omega=V_{t i p} / R$. So dimensional frequencies decrease with rotor size. The control bandwidth required is dimensional $(\mathrm{rad} / \mathrm{sec})$, being determined by the mission tasks, not by the aircraft size. Consequently, the rotor design requirements are expected to change as the aircraft size increases, to compensate for decreases in rotor frequencies while the bandwidth requirement is fixed. 


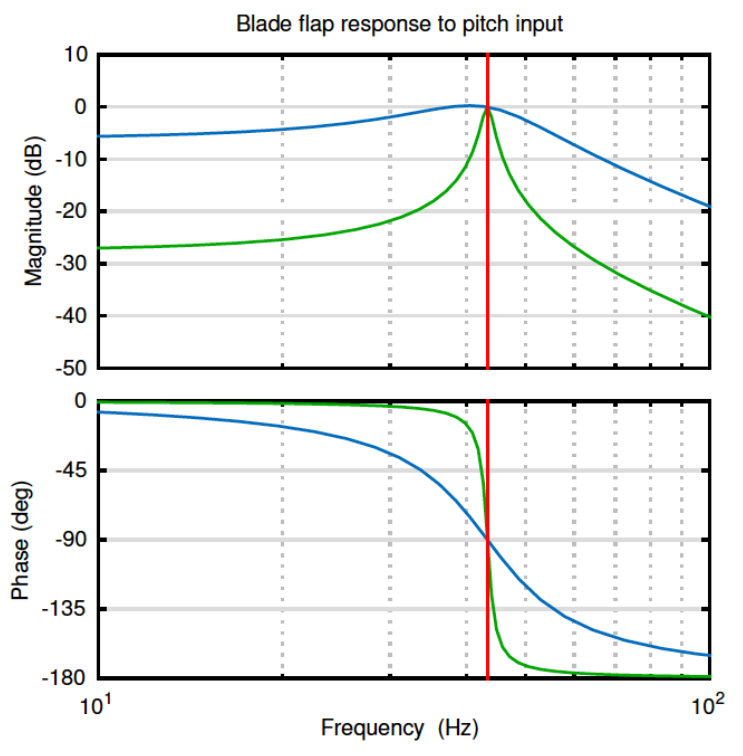

Figure 21. Frequency response of blade flap to pitch input, for blade with central hinge; on Earth with large aerodynamic damping (blue) and on Mars with small aerodynamic damping (green); from Ref. 12.
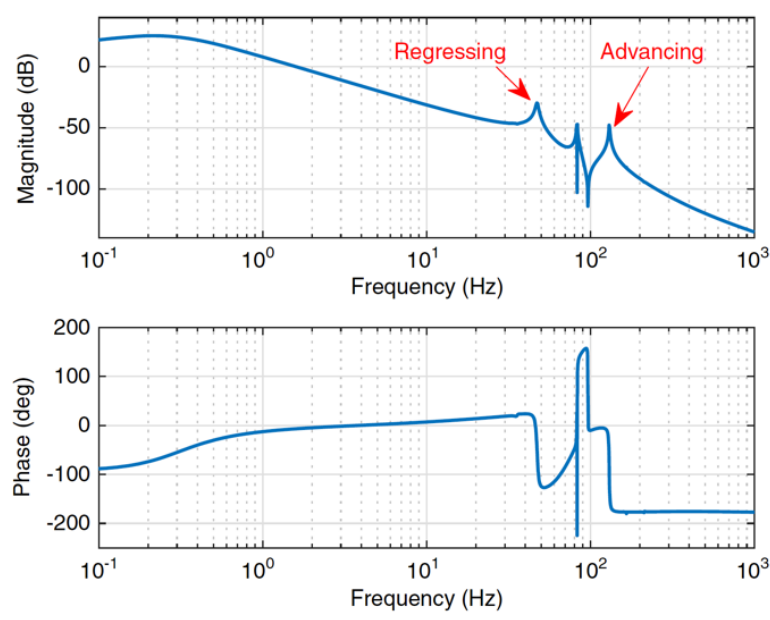

Figure 22. Frequency response of aircraft pitch attitude to cosine cyclic rotor input, for coaxial helicopter on Mars; from Ref. 12.

In the absence of an investigation of the control requirements and design for the MSH mission, the bandwidth criterion was based on the Mars Helicopter. The MH blade has a flap frequency of 2.02/rev at $2575 \mathrm{rpm}$, so the regressive flap mode frequency is $275 \mathrm{rad} / \mathrm{sec}$. The bandwidth requirement was thus 275 $\mathrm{rad} / \mathrm{sec}$. The regressive flap mode frequency must be greater than $275 \mathrm{rad} / \mathrm{sec}$ for the coaxial helicopter with cyclic control. The coning mode frequency must be greater than $275 \mathrm{rad} / \mathrm{sec}$ for the hexacopter with thrust control (collective pitch or rpm). The coaxial helicopter rotor was larger than the hexacopter rotor, and the regressive flap mode frequency was smaller than the coning mode frequency. Thus, a stiffer and heavier blade was required for the coaxial helicopter, in order to meet the same dimensional bandwidth requirement as the hexacopter. The regressive flap mode still exists for the hexacopter, but that mode is not directly involved in aircraft control. It is assumed that the control system can be designed such that the response of the regressive flap mode is not a factor in the hexacopter flight behavior.

\section{Impact of Control Bandwidth Requirement}

For the initial structural design of the MSH blade, the criterion specified was a flap frequency of $1.5 / \mathrm{rev}$. The blade weight must increase as flap frequency increases. As described above, blades were designed for the following cases:

a) Coaxial helicopter: thickness ratio $\mathrm{t} / \mathrm{c}=12 \%$ at $20 \% \mathrm{R}$ (root cutout) to $1 \%$ at $45 \% \mathrm{R}$ to tip.

b) Hexacopter: thickness ratio $\mathrm{t} / \mathrm{c}=6 \%$ at $22 \% \mathrm{R}$ (root cutout) to $1 \%$ at $50 \% \mathrm{R}$ to tip.

c) Hexacopter: thickness ratio $\mathrm{t} / \mathrm{c}=1 \%$ over entire blade (blade flap frequency fall-out).

Table 5 summarizes the results for bandwidth and weights. For the hexacopter blades, the coning mode was above the required bandwidth, even if the blade root was not thickened and so the fallout flap frequency was only $1.1 / \mathrm{rev}$. For the coaxial blade design for $1.5 / \mathrm{rev}$ flap frequency, the regressive flap mode frequency was well below the required bandwidth, and the blade weight was well above the target. Achieving 275 $\mathrm{rad} / \mathrm{sec}$ bandwidth for the coaxial blade would require a flap frequency of $3.1 / \mathrm{rev}$, resulting in an even heavier blade. 
Table 5. Control bandwidth of Mars Science Helicopter blade designs.

\begin{tabular}{|c|c|c|c|c|c|}
\hline & & \multicolumn{3}{|c|}{ Mars Science Helicopter } & \multirow{2}{*}{$\begin{array}{c}\text { Mars } \\
\text { Helicopter }\end{array}$} \\
\hline & & coaxial & hex & hex $(1 \%)$ & \\
\hline radius & $\overline{\mathrm{m}}$ & 1.25 & 0.64 & 0.64 & 0.605 \\
\hline gross weight & $\mathrm{kg}$ & 18.03 & 17.66 & 17.66 & 1.8 \\
\hline number of rotors & & 2 & 6 & 6 & 2 \\
\hline number of blades & & 4 & 4 & 4 & 2 \\
\hline area of one blade & $\mathrm{m}^{2}$ & 0.1905 & 0.0622 & 0.0622 & 0.0425 \\
\hline $\operatorname{design} \Omega\left(\mathrm{M}_{\mathrm{tip}}=0.7\right)$ & $\mathrm{rad} / \mathrm{sec}$ & 131 & 255 & 255 & 270 \\
\hline design $\operatorname{rpm}\left(\mathrm{M}_{\text {tip }}=0.7\right)$ & $\mathrm{rpm}$ & 1247 & 2435 & 2435 & 2575 \\
\hline flap frequency & $/ \mathrm{rev}$ & 1.537 & 1.546 & 1.105 & 2.02 \\
\hline flap frequency & $\mathrm{Hz}$ & 32.1 & 62.7 & 44.8 & 86.7 \\
\hline flap frequency & $\mathrm{rad} / \mathrm{sec}$ & 201 & 394 & 282 & 545 \\
\hline collective "bandwidth" (coning) & $\mathrm{rad} / \mathrm{sec}$ & 201 & 394 & 282 & 545 \\
\hline cyclic "bandwidth" (regr-flap) & $\mathrm{rad} / \mathrm{sec}$ & 71 & 139 & 27 & 275 \\
\hline blade weight & g & 492 & 70 & 39 & 43 \\
\hline target weight & $\mathrm{g}$ & 219 & 66 & 66 & \\
\hline
\end{tabular}

A feasible aircraft configuration for the Mars Science Helicopter was the hexacopter, with rotational fold (Figure 23). A high gain control should be possible with the hexacopter, using either collective or rpm control. In addition, the hexacopter design had lower energy and lower gross weight than the coaxial design (Table 3).

It is difficult to design a large coaxial helicopter for Mars (larger than the Mars Helicopter) that meets the control requirements. The coaxial helicopter configuration would be feasible if sufficient mechanical or structural damping could be introduced for the flap motion. Such damping would benefit the hexacopter configuration as well.

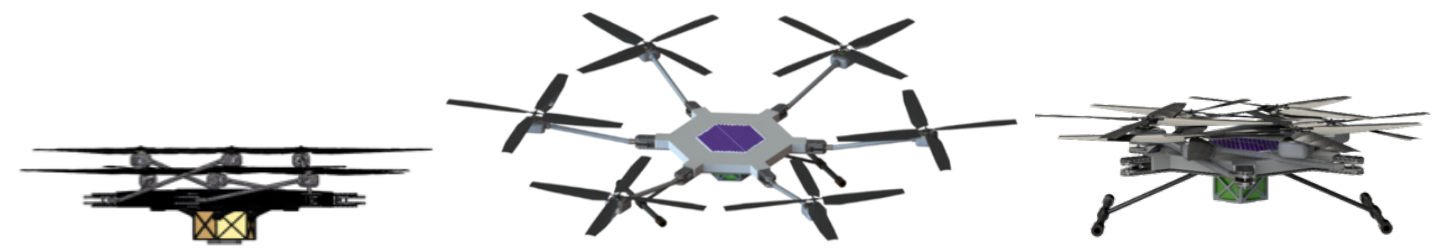

Figure 23. Mars Science Helicopter in hexacopter configuration, folded and unfolded. 


\section{Packaging for Mars}

An entry, descent, and landing (EDL) system is needed to get the helicopter from Earth orbit to the surface of Mars. The initial sizing of the Mars Science Helicopter was based on a $2.5 \mathrm{~m}$ diameter constraint of the folded aircraft (Figures 8-9). Perhaps a new aeroshell and lander could be developed for the MSH, but likely there would be project efficiencies if an existing design could be used. Figure 24 illustrates heritage EDL systems from the Viking, Pathfinder, and Mars Science Laboratory missions to Mars. Selection of the EDL system will define the geometric constraint, and hence the mission capability of the MSH. A larger aeroshell will always permit more capability, or more conservatism in the design.

Pathfinder

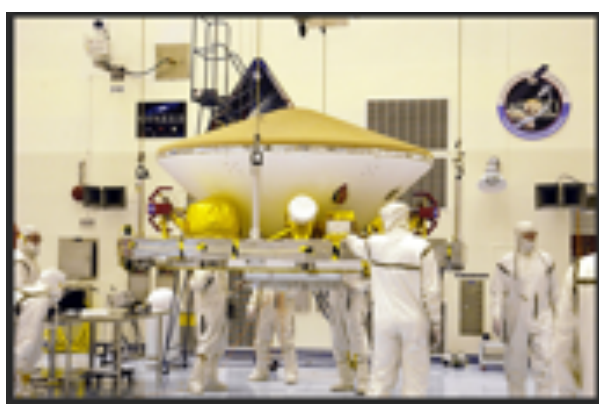

Viking

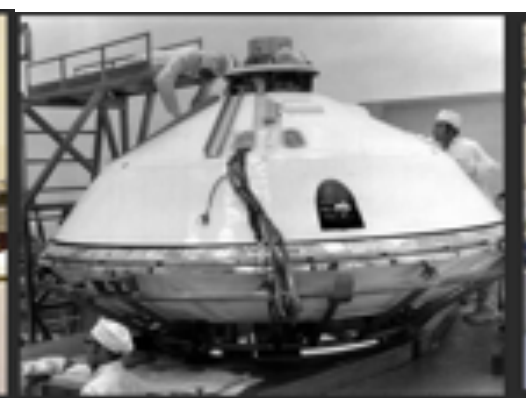

Mars Science Laboratory

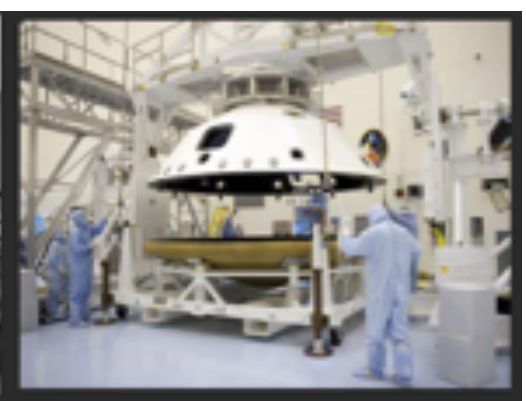

Figure 24. Heritage entry, descent, and landing (EDL) systems: Pathfinder aeroshell $(1997,2.65 \mathrm{~m}$ diameter), Viking aeroshell (1976, $3.505 \mathrm{~m})$, and Mars Science Laboratory aeroshell (2012, $4.5 \mathrm{~m})$.

The hexacopter design (Figure 23) fits in the Viking aeroshell (3.505 $\mathrm{m}$ diameter) with space for a landing system. Conceptual designs were developed for airbag-based (like Pathfinder) and propulsionbased (like Viking) landers in the Viking aeroshell (Figure 25). The helicopter would travel in the lander with supplemental support to alleviate loads generated by liftoff and landing phases of the delivery to Mars.
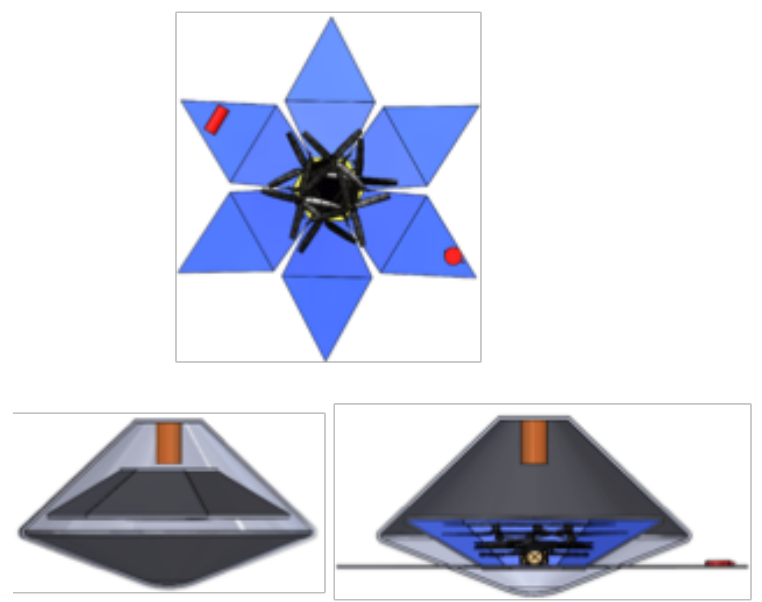
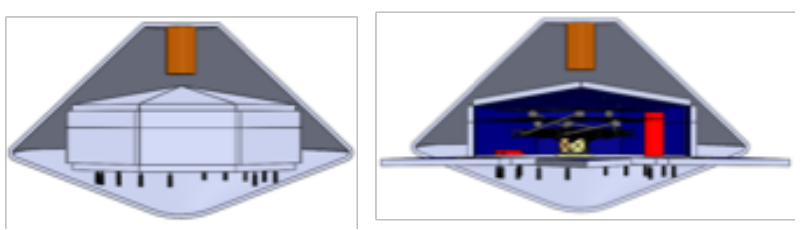

Figure 25. Airbag-based (left) and propulsion-based (right) lander configurations for the MSH hexacopter in the Viking aeroshell (the parachute canister is in orange).

The hexacopter with $0.64 \mathrm{~m}$ radius rotors does not fit in the legacy tetrahedral petal lander of the Pathfinder. The rotating folded configuration (Figure 23) interferes with the sides of the lander. Alternatively, folding the arms upward would result in interference with the parachute canister and sides of the lander. In order for the aircraft to fit in the Pathfinder lander, changes to the design were required: smaller radius, different landing gear, and different folding concepts, including folding (scissoring) of the rotor blades. The design solutions took advantage of the long diagonal sides of the petal lander, while 
maintaining the placement of the payload at the bottom of the aircraft for camera visibility. Figure 26 illustrates the layered A design: blade radius of $0.50 \mathrm{~m}$, different folding mechanism for adjacent arms. Figure 27 illustrates the layered B design: larger blade radius of $0.58 \mathrm{~m}$, but scissored fold of the rotor blades (folded so the blades are on top of each other). Table 6 compares the hexacopter designs (the rotating design is shown in Figure 23). Since the mission was the same for all of the designs, reducing the rotor radius led to larger weight, power, and energy. The layered B configuration had a larger radius, hence better performance, but scissoring the blades added considerable complexity. Both designs left volume unoccupied in the lander, available for other payload, either associated with the helicopter (perhaps swappable payloads) or separate science applications. Nonetheless, feasible design approaches for an MSH hexacopter that fit in the Pathfinder lander have been identified.
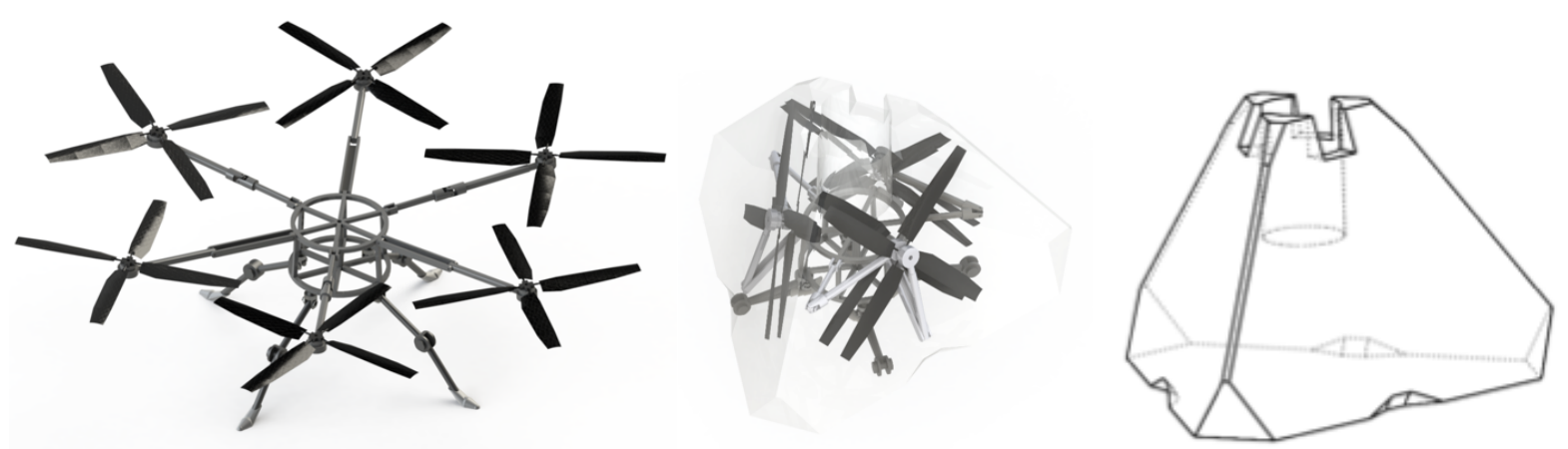

Figure 26. Hexacopter for the Pathfinder lander, folding arms (Layered A design).
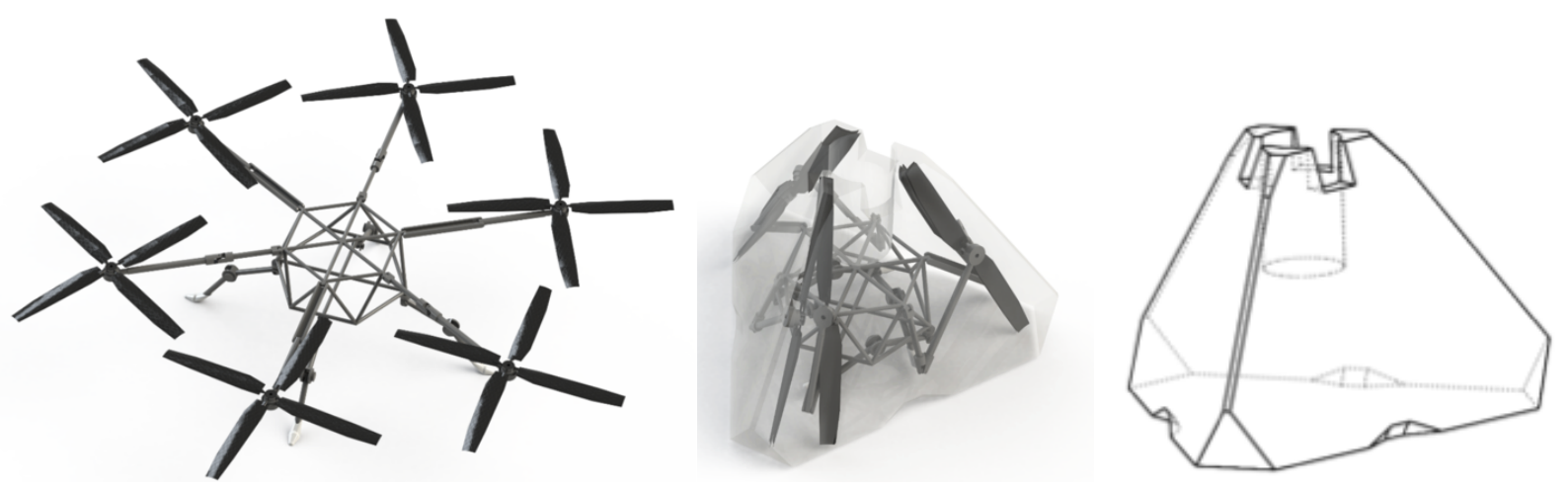

Figure 27. Hexacopter for the Pathfinder lander, folding arms and scissored blades (Layered B design).

Table 6. Comparison of MSH hexacopter designs for the Pathfinder lander.

\begin{tabular}{lccc}
\hline \hline Configuration & Layered A & Layered B & Rotating \\
\hline \hline Radius (m) & 0.50 & 0.58 & 0.64 \\
Solidity & 0.25 & 0.176 & 0.142 \\
Mean chord (m) & 0.1029 & 0.0837 & 0.0746 \\
Aspect Ratio & 4.9 & 6.9 & 8.6 \\
Weight (kg) & 19.06 & 17.99 & 15.66 \\
Power (kW) & 3.51 & 2.87 & 2.80 \\
Energy (MJ) & 2.37 & 1.98 & 1.82 \\
Remaining volume in lander $\left(\mathrm{m}^{3}\right)$ & 0.168 & 0.215 & \\
\hline \hline
\end{tabular}




\section{Rotor Blade Airfoil Optimization}

Optimized airfoil geometries were found, tailored to the unique demands of a second-generation Mars rotorcraft (Refs. 30-31). Airfoil flow and the section lift and drag coefficients were calculated using the three-dimensional, time-accurate RANS computational fluid dynamics code OVERFLOW 2.20, with the SA turbulence model. A genetic algorithm optimized the geometry to maximize lift-to-drag ratio for a specified lift coefficient at the Reynolds number and Mach number appropriate to the MSH hexacopter blade. Airfoils were designed for sections at $7 \% \mathrm{R}$ (root), $25 \% \mathrm{R}, 50 \% \mathrm{R}, 75 \% \mathrm{R}$, and $100 \% \mathrm{R}$ (tip). For the inboard two sections the minimum thickness ratio was constrained to $8 \%$, to reflect the structural requirements of the blade design. The structural design may well require even thicker sections inboard.

Unconventional airfoil shapes with sharp leading edges were explored and optimized. Figure 28 shows the shapes considered. A large thickness is shown for clarity, but without a constraint on thickness ratio all shapes optimized to thin sections. The distinct topologies were designated cambered plate (CP), doubleedged plate (DEP), arbitrary continuous airfoil (ACA), and polygonal airfoil (PA). The optimization algorithm searched the values of a small number of variables that parameterized the geometry. The common features of the shapes are thinness and a sharp leading edge. These features result in immediate leadingedge separation, which provides higher efficiency (lift-to-drag ratio) at low Reynolds number.
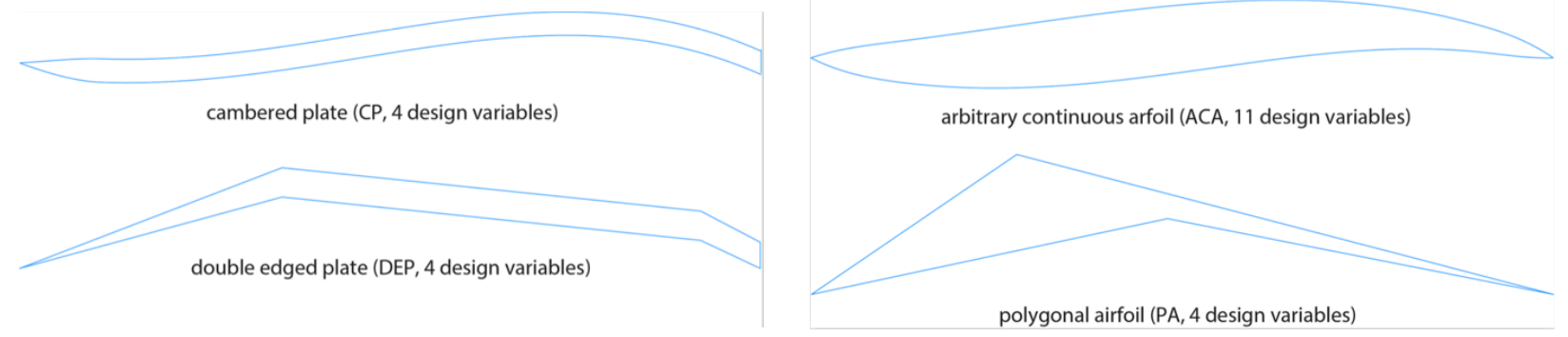

Figure 28. Topologies of airfoil shapes considered in the airfoil optimization.

Sharp leading edges initiate immediate flow separation, and the occurrence of large-scale vortex shedding was found to contribute to the relative performance increase of the optimized airfoils, compared to conventional airfoil shapes. The oscillations were shown to occur independent from laminar-turbulent transition and therefore resulted in sustainable performance at lower Reynolds numbers (Ref. 31). Figure 29 shows the flow field about the optimized double-edged plate, which was identified as the best shape for the outboard blade sections. Experimental work (Ref. 32) has identified a similar shape as giving good performance at low Reynolds number, although only considering low Mach number. There is also computational and experimental support (Ref. 33) for the performance of triangular airfoils, including the effects of compressibility at low Reynolds numbers.

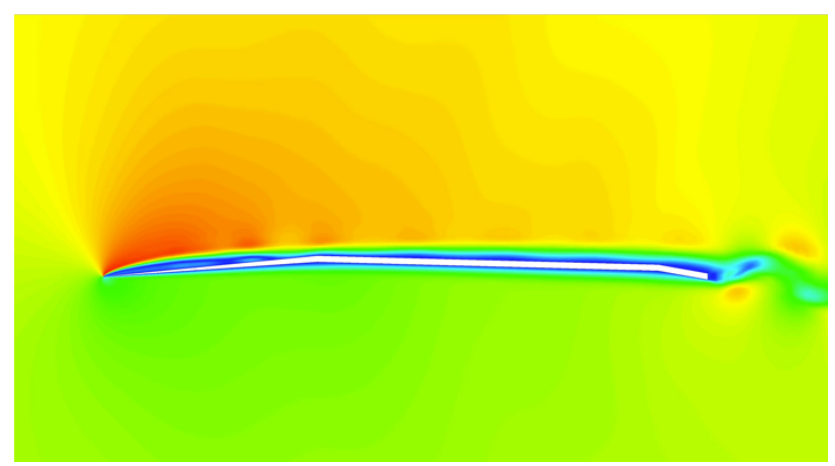

Figure 29. Velocity magnitude in flow field about optimized double-edged plate;

$$
\operatorname{Re}=16862, \mathrm{M}=0.52, c_{l}=0.65 \text {. }
$$


Table 7 shows the performance of the airfoils optimized for the outboard sections, compared to the CLF5605 airfoil of the Mars Helicopter and the circular arc. The design conditions are $\operatorname{Re}=11,354, \mathrm{M}=$ $0.35, c_{l}=0.65$ at $50 \% \mathrm{R}$, and $\mathrm{Re}=16,682, \mathrm{M}=0.52, c_{l}=0.65$ at $75 \% \mathrm{R}$. All geometries optimized to thin sections. Significant improvements in performance relative the $\mathrm{MH}$ airfoil and the circular arc were found. The double-edge plate was chosen for these outboard sections. With the constraint on thickness ratio, polygonal airfoils gave the best results for the inboard sections. Figure 30 shows the lift and drag coefficients for the blade tip airfoil.

Table 7. Performance of optimized airfoil sections.

\begin{tabular}{lcc}
\hline \hline Airfoil & $c_{l} / c_{d}$ & Improvement \\
\hline \hline CLF5605 (MH) & 18.34 & - \\
Circular arc & 20.51 & $12 \%$ \\
Cambered plate (CP) & 23.70 & $29 \%$ \\
Arbitrary continuous airfoil (ACA) & 21.51 & $17 \%$ \\
Double-edged plate (DEP) & 23.43 & $28 \%$ \\
Polygonal airfoil (PA) & 22.57 & $23 \%$ \\
\hline \hline
\end{tabular}

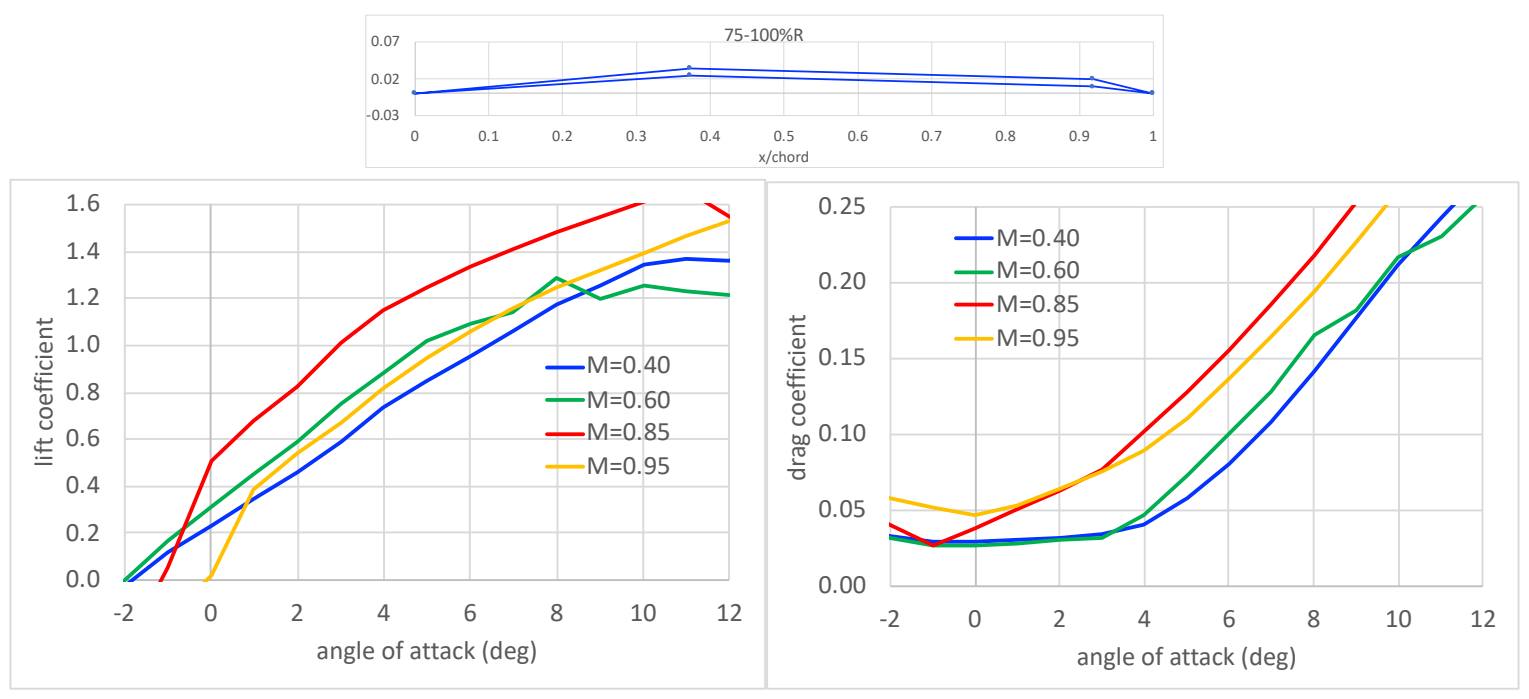

Figure 30. Double-edged plate airfoil lift and drag characteristics ( $\mathrm{Re} / \mathrm{M}=27500)$.

Figure 31 shows the optimized aerodynamic shape for the MSH hexacopter blade, with radius of 0.64 $\mathrm{m}$ and solidity $=0.193$. The inboard sections use diamond airfoils with $8 \%$ thickness-to-chord ratio. The outboard sections use thin double-edged plate airfoils, with optimized chordwise position of the kinks. It is anticipated (and shown below) that thicker inboard sections are required to meet the goals of the structural design, but that is expected to have little impact on the rotor performance.

Figures 32-34 show the performance of a single rotor of the hexacopter, in hover (figure of merit) and cruise (power as a function of speed), calculated using CAMRAD II. The three cases are for different outboard (50-100\%R) airfoils: MH airfoil CLF5605 (Figure 32), circular arc airfoil (Figure 33), and optimized double-edged plate airfoils (Figure 34). The same diamond airfoils (Figure 31) were used inboard $(7-50 \% \mathrm{R})$ for all three cases. The hover performance is shown for tip Mach numbers from 0.7 to 0.9 ; the 
cruise performance for $\mathrm{M}_{\text {tip }}$ to 0.85 . Figure 35 compares the performance at $\mathrm{M}_{\text {tip }}=0.75$ for the three outboard airfoils.

In hover, the optimized airfoils produced higher figure of merit (4-7\%), lower power, and better stall behavior. In forward flight there was lower power (6-10\%) at fixed flight speed with the double-edged plate airfoils; or increased flight speed (12-23\%) for fixed power. For each airfoil, power required increased in both hover and forward flight as the tip Mach number was increased, although the increase was minimized with the optimized airfoils. But while the airfoil lift and drag (Figure 30) showed an influence of compressibility, there was no evidence of drag divergence in the integrated rotor forward flight performance, up to an advancing tip Mach number of $\mathrm{M}_{\mathrm{at}}=0.95$. The hover figure of merit showed a gradual decrease with increasing $C_{T} / \sigma$ for the optimized airfoils, instead of an abrupt drop observed with the other airfoils due to encountering the maximum thrust capability of the rotor. Helicopters designed to use the optimum airfoils will have lower power required, increased flight speed or tip speed, and increased design $C_{T} / \sigma$.
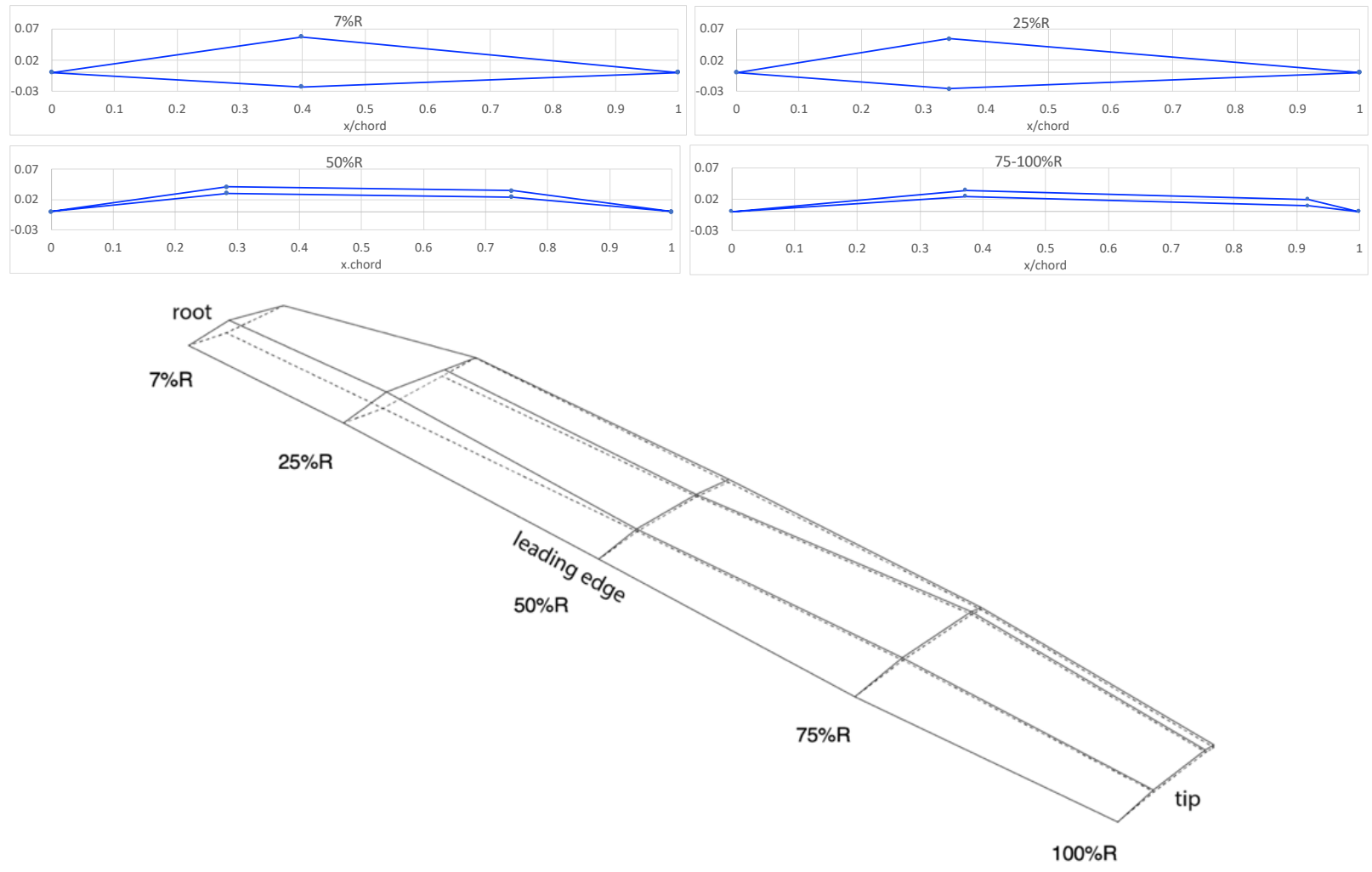

Figure 31. Optimized rotor blade for Mars Helicopter 

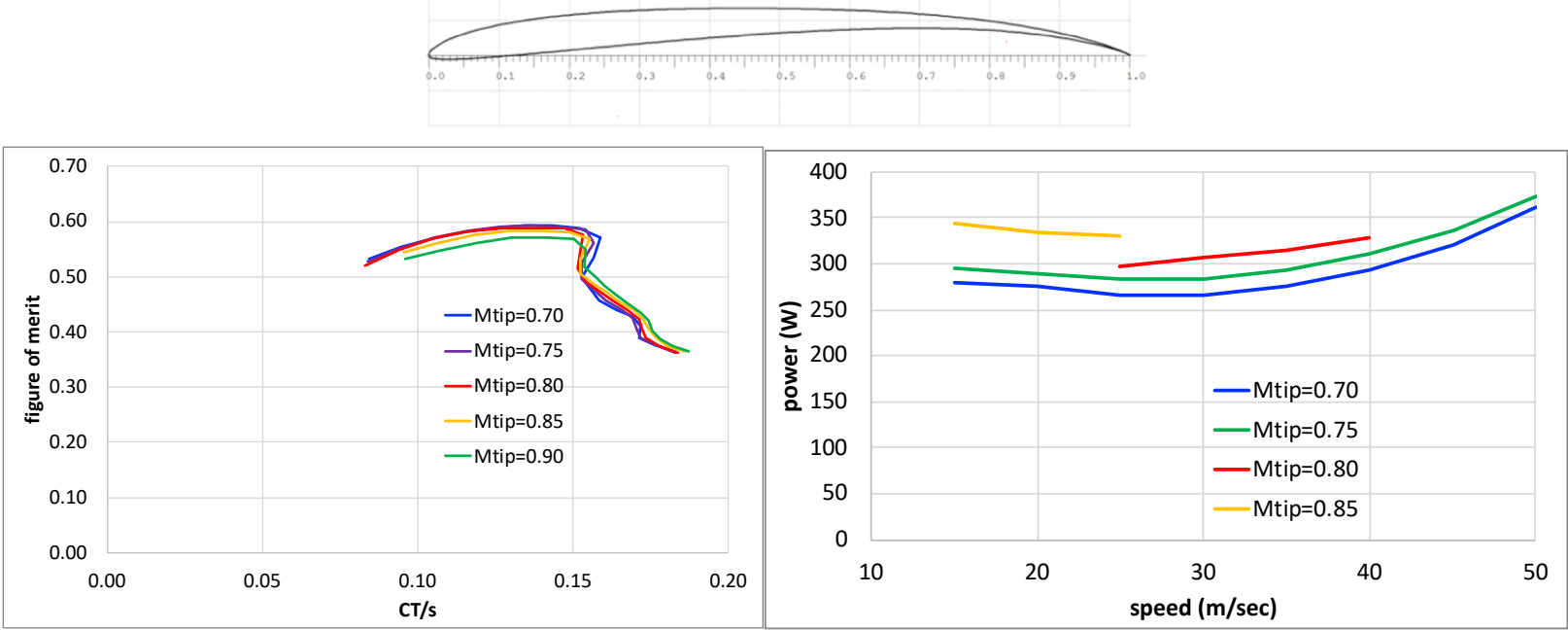

Figure 32. Hover and cruise performance of single hexacopter rotor, with CLF5605 outboard airfoils.

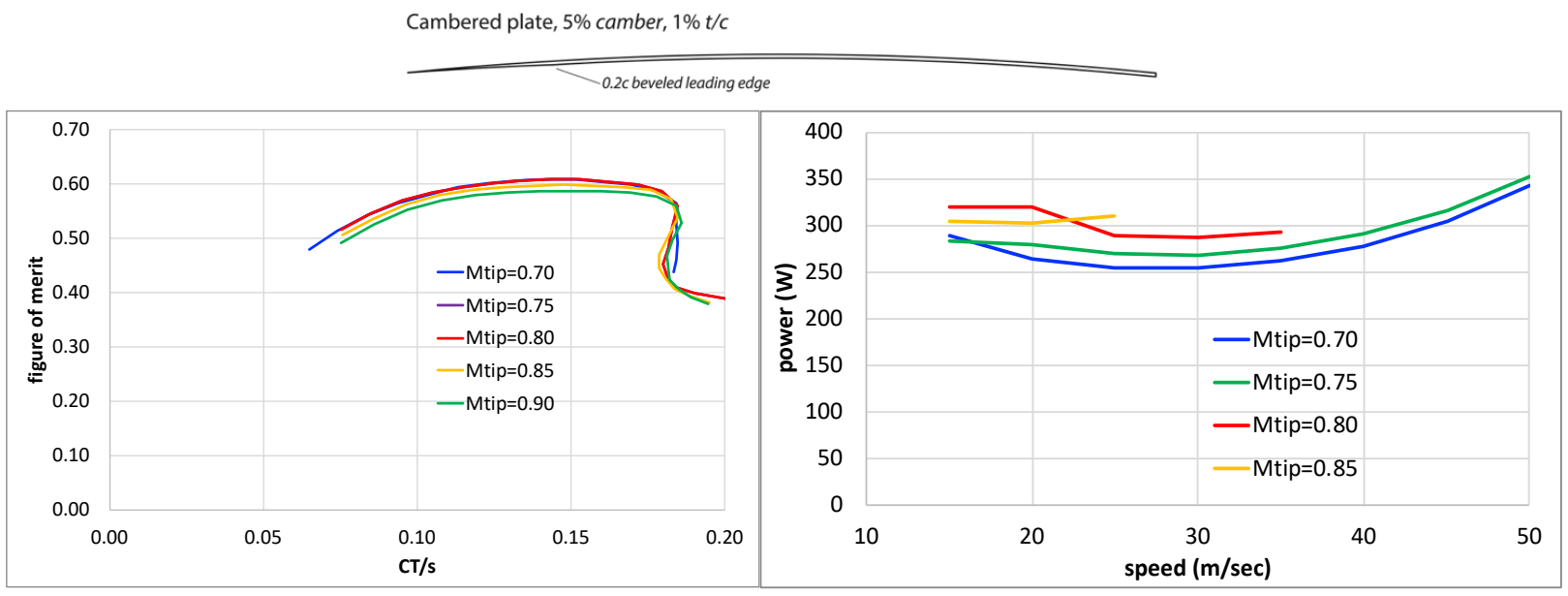

Figure 33. Hover and cruise performance of single hexacopter rotor, with circular arc outboard airfoils.
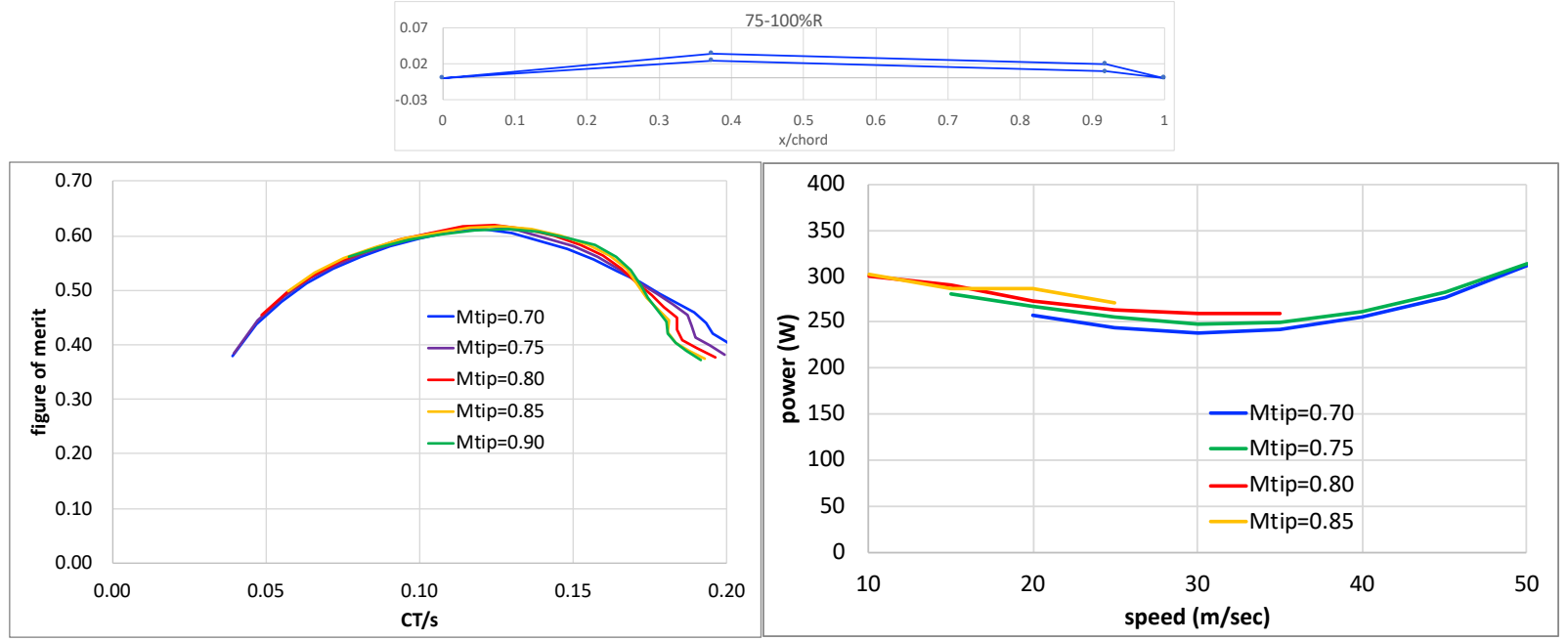

Figure 34. Hover and cruise performance of single hexacopter rotor, with optimized outboard airfoils. 


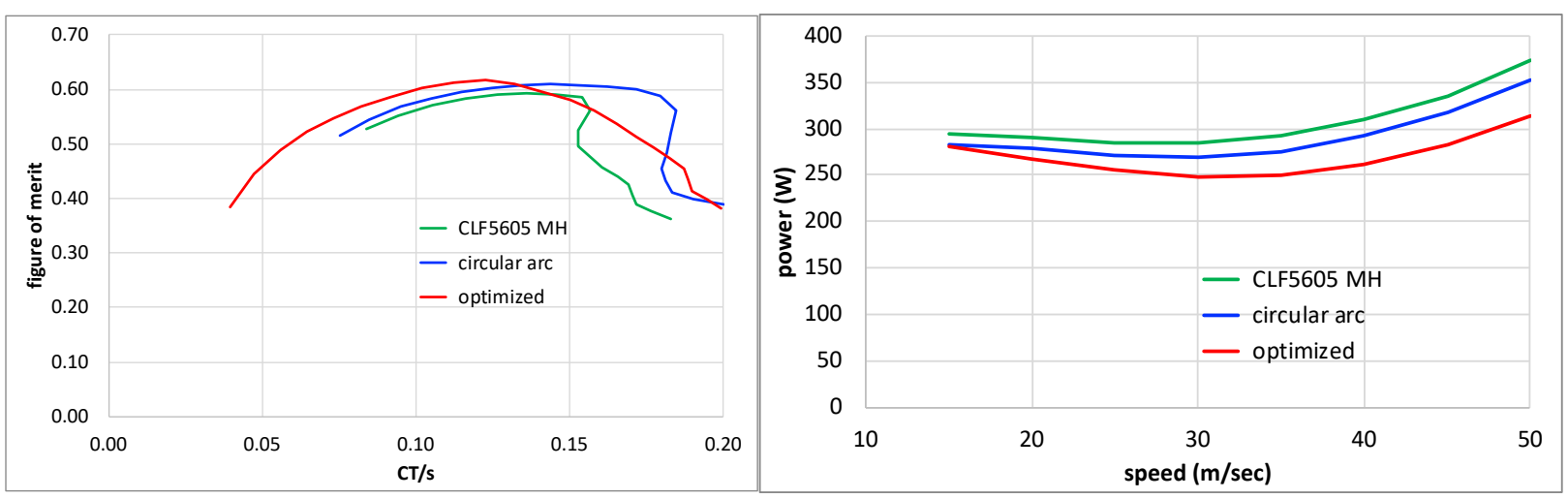

Figure 35. Hover and cruise performance of single hexacopter rotor for $\mathrm{M}_{\text {tip }}=0.75$, comparing CLF5605, circular arc, and double-edged plate outboard airfoils.

\section{Rotor Blade and Hub Structural Analysis}

The structure of the optimized blade was constructed using the CAD system CATIA analyzed using the three-dimensional finite element analysis code X3D from University of Maryland (Ref. 23). X3D can calculate the stress and strain of the rotating structure under loading, and it can obtain the natural frequencies of vibration. The objective of the analysis was to define the internal blade structure, identify the root thickness required to meet the structural requirements, and to provide updates to the blade and hub weight estimates.

The aerodynamic loads on the blade are small because of the low atmospheric density on Mars, resulting in less stiffness needed to meet stability and loads requirements, compared to rotor designs for operation on Earth. As a consequence, there are also more opportunities for innovative structural design to minimize weight.

The structural analysis was conducted for designs reflecting the tip speed and blade loading increases enabled by the advanced airfoils: $\mathrm{R}=0.64$, solidity $=0.142, \mathrm{M}_{\text {tip }}=0.8$ for the hexacopter; and $\mathrm{R}=1.25$, solidity $=0.122, \mathrm{M}_{\text {tip }}=0.8$ for the coaxial helicopter. The blades had the double-edged plate airfoil outboard, the diamond airfoils inboard, and the optimum twist and taper (Figure 17). Figure 36 shows a typical blade structure and root. Inside the outer skin there is a spar and inside the spar is a foam core. The root insert attaches to the thrust bearing. The materials used were MTM45-1 M46J 12K Uni 0 deg tape for the spar; carbon fiber 60 gsm HR40 spread tow Bi-D \pm 45 deg weave cloth with knocked down E for the skin; Rohacell 31F foam; and 7075 aluminum for the root insert. Figure 37 shows the blade designs

Figure 38 shows the modal frequencies calculated for several cases. The lowest blade frequency is for the flap mode. The dashed lines are constant per-rev values. Figure 39 illustrates the stress analysis results for the blade under centrifugal force loading.

Recall that in the absence of an investigation the control requirements and design for the MSH mission, the bandwidth criterion was based on the Mars Helicopter: $275 \mathrm{rad} / \mathrm{sec}$. The regressive flap mode frequency must be greater than $275 \mathrm{rad} / \mathrm{sec}$ for the coaxial helicopter with cyclic control. For design rotor speed of $1425 \mathrm{rpm}$, the coaxial blade would need a flap frequency of $2.8 / \mathrm{rev}$. The coning mode frequency must be greater than $275 \mathrm{rad} / \mathrm{sec}$ for the hexacopter with thrust control (collective pitch or rpm). For design rotor speed of $2782 \mathrm{rpm}$, the hexacopter blade would need a flap frequency greater than $1 / \mathrm{rev}$. The preliminary structural analysis (described above) was conducted for a flap frequency requirement of $1.5 / \mathrm{rev}$.

The following cases were analyzed:

a) The hexacopter blade, designed for the flap frequency $=1.5 / \mathrm{rev}$ at normal rotor speed $2782 \mathrm{rpm}$. The blade thickness was increased to $25 \%$ at the root $(9 \% \mathrm{R})$, and to $14 \%$ at $25 \% \mathrm{R}$ to achieve this frequency. 
The resulting blade weight was 78.1 g (skin 22.6, spar 45.2, foam 2.1, and root insert $8.2 \mathrm{~g}$ ) and the hub weight was $36 \mathrm{~g}$ (torque tube, thrust bearing, roller bearings, and screw). The skin had 7 layers of cloth at the root and 12 layers of cloth outboard of 50\%R (after the foam and spar end). The spar had 4 layers of Uni at the root and a ply drop-off of 1 layer throughout the spar ending with the spar at 50\%R. Figure $37 \mathrm{a}$ shows the blade design and Figure 38a shows the modal frequencies. The flap frequency is $1.512 / \mathrm{rev}$ at the design rotation speed $2782 \mathrm{rpm}$. The flap frequency is achieved by making the inboard part of the blade stiff, so there is an effective flap hinge at about $48.75 \%$ R. Figure 39 illustrates the stress analysis results, for the blade under centrifugal force loading.

b) The hexacopter blade designed for target blade weight of $52.5 \mathrm{~g}$. The resulting blade flap frequency was $1.2 / \mathrm{rev}$. The blade thickness was maintained at $8 \%$ at the root $(9 \% \mathrm{R})$ and at $25 \% \mathrm{R}$. The resulting blade weight was $50.4 \mathrm{~g}$ (skin 22.22, spar 22.5, foam 0.76, and root insert $4.93 \mathrm{~g}$ ). The skin had 7 layers of cloth at the root with a 1 ply drop-off up until $50 \%$ span. Outboard of $50 \% \mathrm{R}$ the skin had 12 layers of cloth. The spar had 4 layers of Uni at the root and a ply drop-off of 2 layers throughout the spar ending with the spar at $45 \%$ R. Figure $37 \mathrm{~b}$ shows the blade design and Figure $38 \mathrm{~b}$ shows the modal frequencies. The reduced weight is achieved by making the inboard part of the blade thinner, as a result bending starts immediately from $9 \%$ R.

c) The coaxial helicopter blade, with the same inboard airfoil thickness ratios as for (a). The resulting flap frequency was 1.446/rev at $1425 \mathrm{rpm}$, and the blade weight was $341.4 \mathrm{~g}$ (skin 87.4, spar 187.7, foam 16.5, and root insert $49.8 \mathrm{~g}$ ). The skin had 7 layers of cloth at the root and 12 layers of skin outboard of $50 \% \mathrm{R}$. The spar had 4 layers of Uni at the root and a ply drop-off of 1 layer throughout the spar ending with the spar at $50 \%$ R. Figure $38 \mathrm{c}$ shows the modal frequencies. The effective flap hinge is at about $48.75 \% \mathrm{R}$ (same as (a)) but the larger size produces a softer blade.

d) The coaxial helicopter blade, with the same inboard airfoil thickness ratios as for (b). The resulting flap frequency was $1.16 / \mathrm{rev}$ at $1425 \mathrm{rpm}$, and the blade weight was $237.5 \mathrm{~g}$ (skin 93.3, spar 104.2, foam 5.8, and root insert $34.2 \mathrm{~g}$ ). The skin had 7 layers of cloth at the root with a 1 ply drop-off up until $50 \% \mathrm{R}$. Outboard of 50\%R the skin had 17 layers of cloth. The spar had 4 layers of Uni at the root and a ply dropoff of 2 layers throughout the spar ending with the spar at $45 \%$ R. Figure $38 \mathrm{~d}$ shows the modal frequencies.

The hexacopter blade can be designed to meet the bandwidth criterion for flight dynamics and control within the allocated blade weight. The calculated hub weight is also less than the allocation in the conceptual design. The coaxial helicopter configuration would be feasible if sufficient mechanical or structural damping could be introduced for the flap motion, and the blade weight could be determined by strength requirements instead of flap frequency placement. Preliminary stress analysis indicates that the high stresses occur in the transition region of the structure (as expected), but the stresses are still well under material limits.

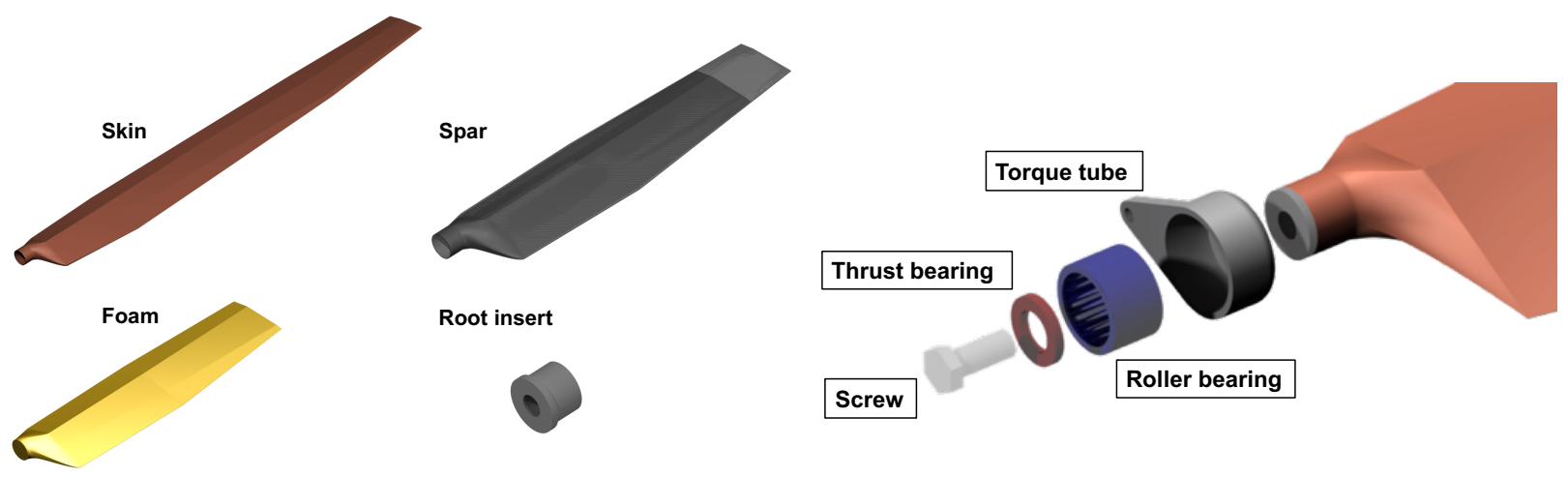

Figure 36. Hexacopter blade internal structure and root. 


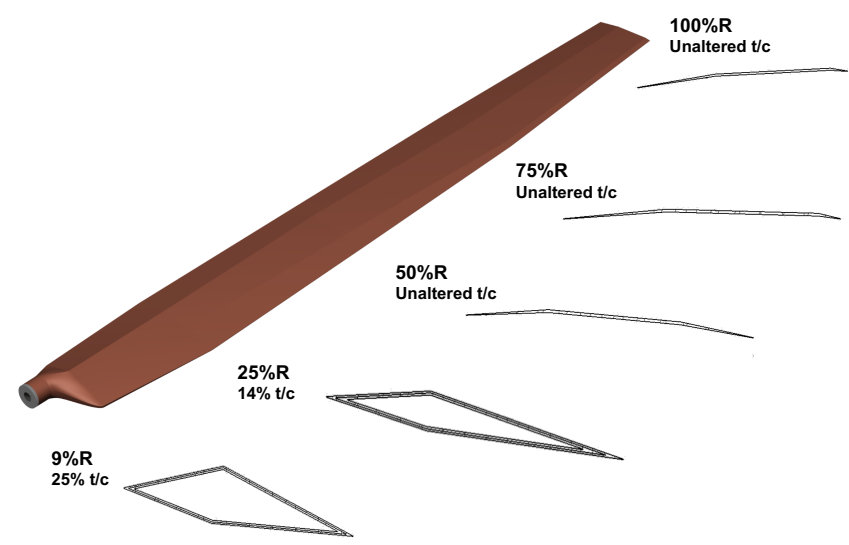

(a) Target flap frequency $1.5 / \mathrm{rev}$.

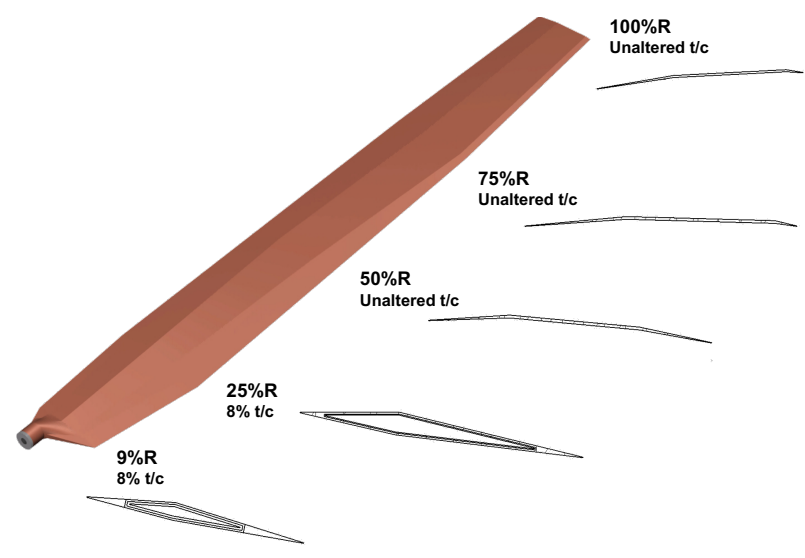

(b) Target blade weight $52.5 \mathrm{~g}$.

Figure 37. Hexacopter blade designs.
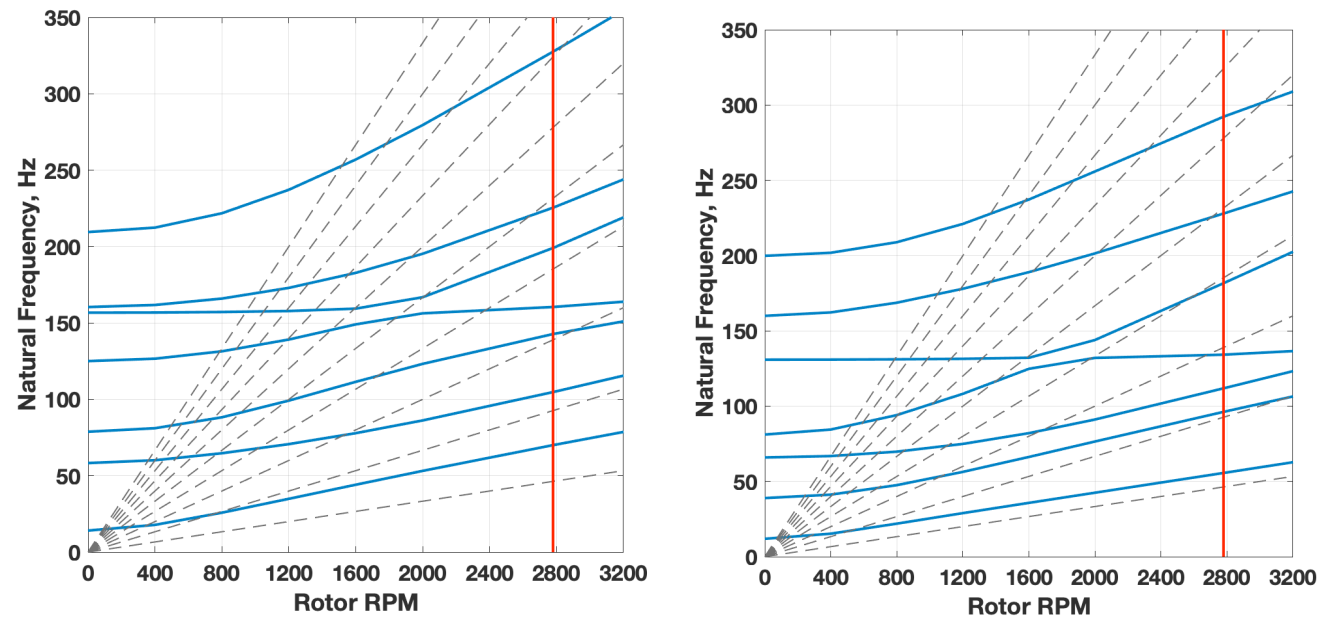

(a) Hexacopter, target flap frequency 1.5/rev.

(b) Hexacopter, target blade weight $52.5 \mathrm{~g}$.
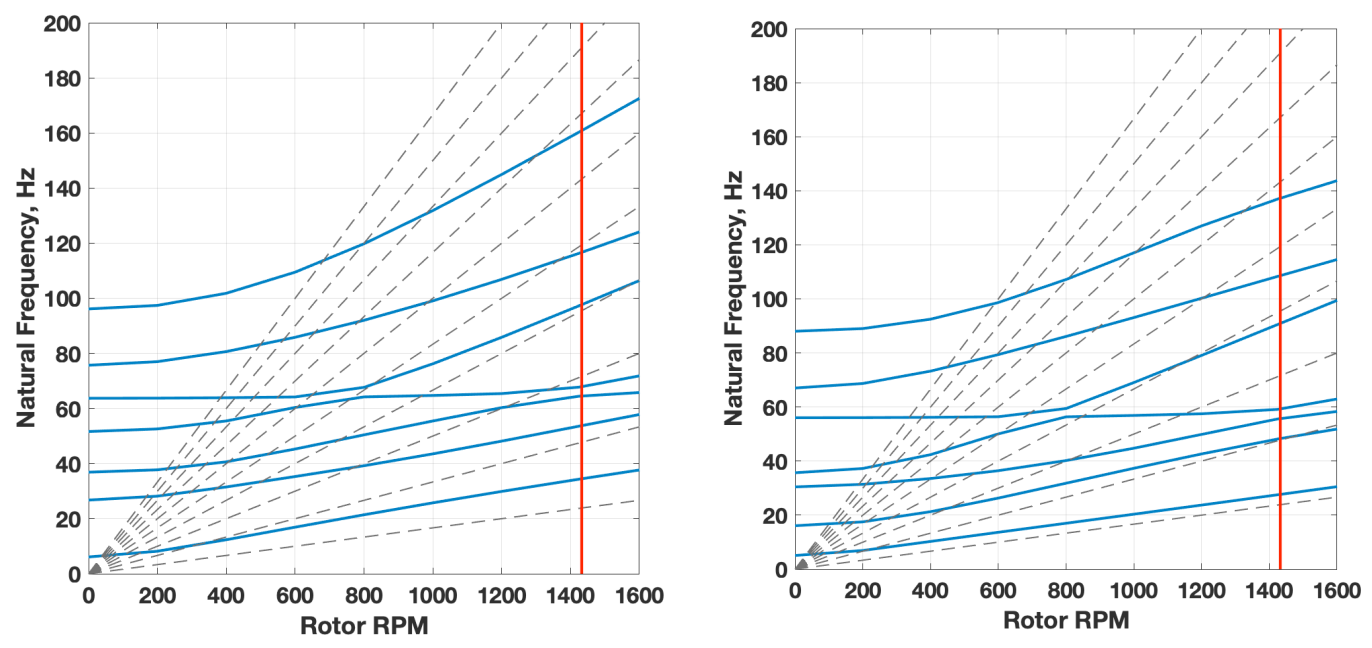

(d) Coaxial, same thickness ratio as (a).

(d) Coaxial, same thickness ratio as (b).

Figure 37. Calculated blade frequencies. 


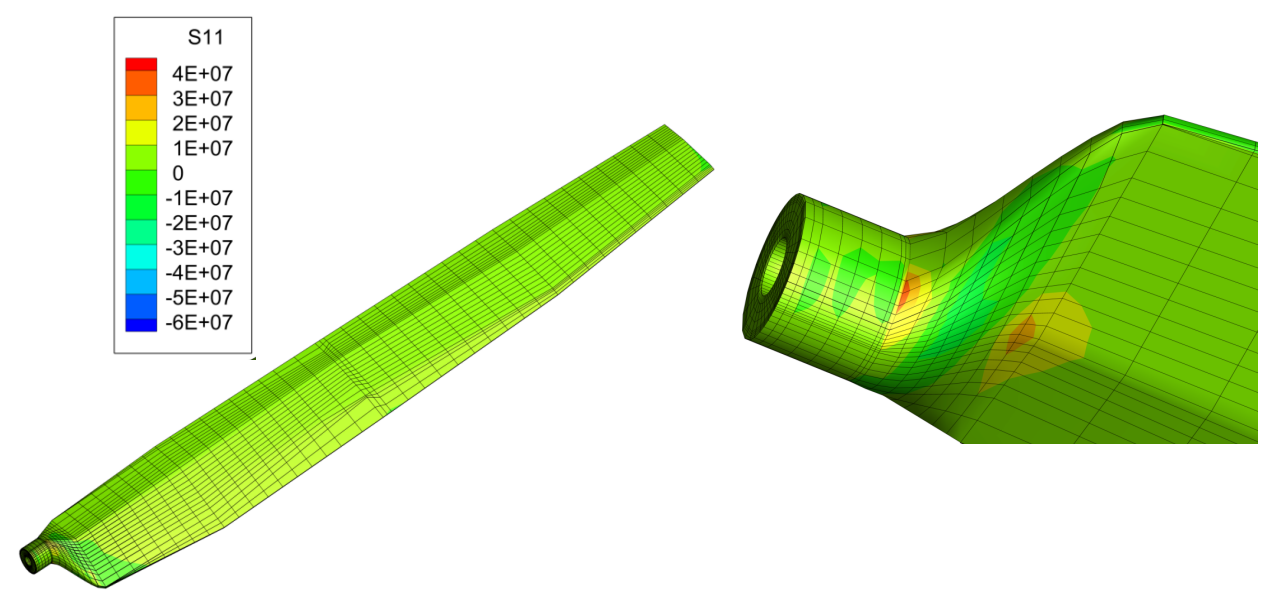

Figure 38. Hexacopter blade and root stress under centrifugal force loading.

\section{Updated Mars Science Helicopter Designs}

The Mars Science Helicopter designs were updated using the information from the rotor aerodynamic optimization. CAMRAD II was used to calculate the rotor performance in hover and forward flight, using the airfoil characteristics (tables of lift, drag, and moment coefficients) for the updated blade design (Figure 31). The CAMRAD II calculations were used to calibrate the NDARC rotor performance model. The initial NDARC rotor model was based on calculations using the circular arc airfoil characteristics. With the updated rotor performance model, the designs had lower power required in both hover and forward flight.

The initial MSH aircraft designs used a design blade loading of $C_{T} / \sigma=0.11$, which was $10 \%$ higher than the design loading of the Mars Helicopter, based on the performance improvements observed with the circular arc airfoil. Recall that the control authority requirement is $40 \%$ from design blade loading to stall. The calculated hover thrust capability with the double-edged plate airfoils (Figure 35) implied that the design blade loading could be increased significantly more. Until experimental verification is obtained for this behavior of the rotor approaching stall, a conservative increase was used: $C_{T} / \sigma=0.115$.

The calculated performance of the rotor showed that the power required increased as tip speed was increased (although not very much with the optimized airfoils), but there was no sign of a limit associated with drag divergence. This behavior is expected for these very thin airfoils, so it is reasonable to take advantage of the good behavior at high Mach number, by increasing flight speed or tip speed. A limit was imposed on advancing tip Mach number: $\mathrm{M}_{\mathrm{at}}<0.95$.

Table 8 summarizes the updated Mars Science Helicopter designs. The parameters of the initial designs were presented in Table 5. The blue numbers are the key design changes: blade loading $C_{T} / \sigma$, and either cruise speed or tip speed. Increasing the flight speed from $30 \mathrm{~m} / \mathrm{sec}$ (minimum power speed) to $50 \mathrm{~m} / \mathrm{sec}$ (nearly best range speed) reduced the energy required to fly the $1 \mathrm{~km}$ range, which resulted in modest reductions of aircraft weight, power, and energy. Increasing the design tip speed had more effect on the designs, since it reduced the blade area and weight. By increasing the tip Mach number from $\mathrm{M}_{\text {tip }}=0.7$ to 0.8 (advancing tip Mach number from $\mathrm{M}_{\mathrm{at}}=0.83$ to 0.93), the range and hover time were doubled for the same gross weight (red numbers). The increased mission effort required a larger battery, but the installed power was actually reduced for the hexacopter (green numbers).

These design results illustrate the relative impact of aerodynamic and structural improvements on the helicopter design. The direct effect of the aerodynamic performance improvements (lower power required and higher cruise speed) was a $2 \%$ reduction in gross weight and $10 \%$ reduction in power (for the 
hexacopter) with the same mission range and hover time. By using the aerodynamic performance improvement to increase the design tip speed, the required rotor blade area was reduced by about $25 \%$. The resulting reduction in aircraft structural weight permitted a 50\% increase in battery weight, giving twice the range and hover time compared to the original mission, for the same gross weight.

Table 8. Updated Mars Science Helicopter designs.

\begin{tabular}{|c|c|c|c|c|c|c|c|}
\hline & & \multicolumn{3}{|c|}{ " coaxial helicopter } & \multicolumn{3}{|c|}{ hexacopter } \\
\hline & & initial & $\begin{array}{c}\text { updated } \\
\text { cruise } \\
\text { speed }\end{array}$ & $\begin{array}{c}\text { updated } \\
\text { tip speed } \\
\mathrm{V}_{\text {tip }}\end{array}$ & initial & $\begin{array}{c}\text { updated } \\
\text { cruise } \\
\text { speed }\end{array}$ & $\begin{array}{c}\text { updated } \\
\text { tip speed } \\
V_{\text {tip }}\end{array}$ \\
\hline design $C_{T} / \sigma$ & & 0.11 & 0.115 & 0.115 & 0.11 & 0.115 & 0.115 \\
\hline $\operatorname{design} \mathrm{M}_{\text {tip }}$ & & 0.7 & 0.7 & 0.8 & 0.7 & 0.7 & 0.8 \\
\hline cruise speed & $\mathrm{m} / \mathrm{sec}$ & 30 & 50 & 30 & 30 & 50 & 30 \\
\hline advancing tip $\mathrm{M}_{\mathrm{at}}$ & & 0.83 & 0.87 & 0.93 & 0.83 & 0.87 & 0.93 \\
\hline payload & $\mathrm{kg}$ & 2.02 & 2.02 & 2.02 & 2.02 & 2.02 & 2.02 \\
\hline range & $\mathrm{km}$ & 1 & 1 & 2 & 1 & 1 & 2 \\
\hline hover time & $\min$ & 2.5 & 2.5 & 4.5 & 2.5 & 2.5 & 4.5 \\
\hline rotor radius & $\mathrm{m}$ & 1.25 & 1.25 & 1.25 & 0.64 & 0.64 & 0.64 \\
\hline gross weight & $\mathrm{kg}$ & 18.03 & 17.57 & 19.31 & 17.66 & 17.33 & 17.69 \\
\hline number rotors & & 2 & 2 & 2 & 6 & 6 & 6 \\
\hline number blades & & 4 & 4 & 4 & 4 & 4 & 4 \\
\hline disk area & $\mathrm{m}^{2}$ & 4.91 & 4.91 & 4.91 & 7.72 & 7.72 & 7.72 \\
\hline disk loading & $\mathrm{kg} / \mathrm{m}^{2}$ & 3.67 & 3.58 & 3.94 & 2.29 & 2.24 & 2.29 \\
\hline solidity & & 0.310 & 0.290 & 0.244 & 0.193 & 0.181 & 0.142 \\
\hline tip speed & $\mathrm{m} / \mathrm{sec}$ & 163.2 & 163.2 & 186.5 & 163.2 & 163.2 & 186.5 \\
\hline rotor speed & $\mathrm{rpm}$ & 1247 & 1247 & 1425 & 2435 & 2435 & 2782 \\
\hline total power & $\mathrm{kW}$ & 3.17 & 3.13 & 3.58 & 3.31 & 3.02 & 2.80 \\
\hline solar cell & $\mathrm{m}^{2}$ & 0.62 & 0.62 & 0.62 & 0.62 & 0.62 & 0.62 \\
\hline battery & $\mathrm{Ah}$ & 128 & 122 & 225 & 113 & 104 & 172 \\
\hline rotor group & $\mathrm{kg}$ & 2.72 & 2.58 & 2.41 & 3.32 & 3.34 & 3.00 \\
\hline controls & $\mathrm{kg}$ & 1.47 & 1.37 & 1.16 & 1.44 & 1.36 & 1.06 \\
\hline motor weight & $\mathrm{kg}$ & 1.49 & 1.33 & 1.35 & 0.74 & 0.69 & 0.64 \\
\hline battery weight & $\mathrm{kg}$ & 1.73 & 1.65 & 3.03 & 1.52 & 1.41 & 2.31 \\
\hline
\end{tabular}




\section{Designs for Representative Mars Sites}

JPL identified three Mars landing sites that are representative of missions suitable for a science helicopter, and of interest to scientific community. These are examples, not site recommendations, considered here to examine the sensitivity of the helicopter to design operating conditions. The atmospheric conditions depend on the location on Mars (latitude, longitude, elevation), and on the time of day and time of year. The aircraft size depends on the design blade loading $C_{T} / \sigma$ and tip Mach number $\mathrm{M}_{\text {tip. }}$ As the design atmospheric density decreases, the required rotor blade area and rotor power increase, which increases the aircraft total weight, further increasing the blade area and power. As the temperature decreases, the speed of sound decreases, which reduces the rotor tip speed, requiring more blade area.

For the Mars Science Helicopter design mission, the operation site chosen was the Jezero Crater in the spring, for which the typical atmospheric conditions are a density of $0.015 \mathrm{~kg} / \mathrm{m}^{3}$ and temperature of -50 deg C. For reference, Figure 40 shows the design conditions for the Mars Helicopter, with Jezero the final choice for landing.

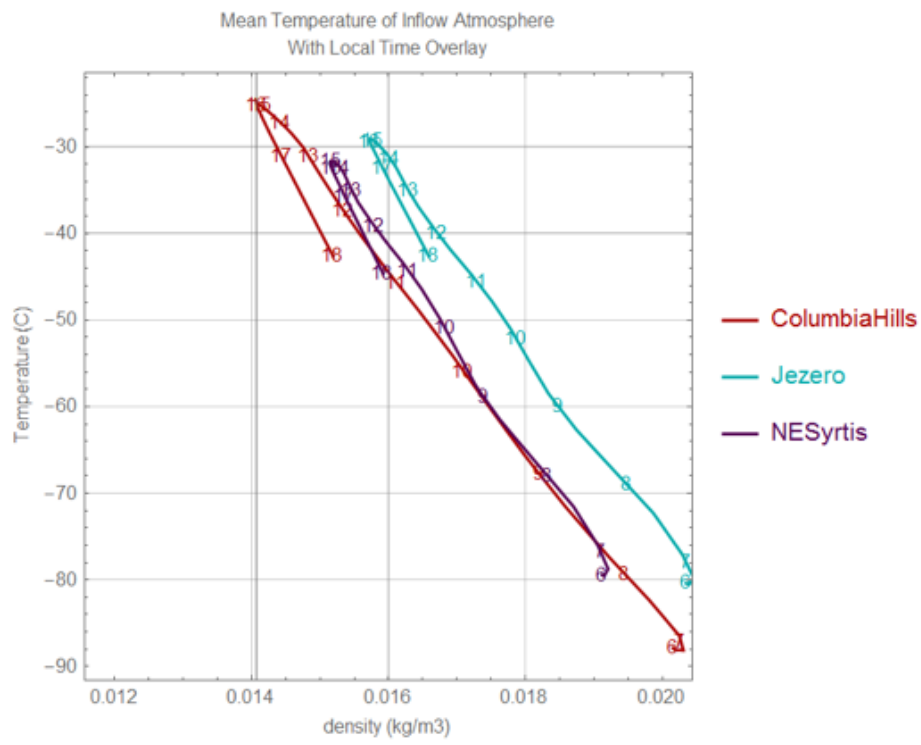

Figure 40. Design atmospheric conditions for the Mars Helicopter.

The three representative Mars sites were the Milankovic Crater, Becquerel Crater, and Palikir Crater. The science missions and required payloads were:

a) Milankovic Crater: Massive ice deposits are exposed in pole-facing scarps. The science objectives were investigating the ice and recent/modern climate. The payload weight was 1200-2100 g.

b) Becquerel Crater: Rhythmic layered sediment mound in south floor of crater. The science objectives were investigating ancient climate, detailed 3D geologic mapping, possible lake sediments, cyclic sedimentation, and habitability. The payload weight was $1890-2700 \mathrm{~g}$.

c) Palikir Crater: Recurring Slope Lineae (RSL) on the crater interior rim. The science objectives were access and monitoring activity of RSLs over multiple seasons. The payload weight was $1200-2100 \mathrm{~g}$.

Figures 41-43 show for these three sites the annual variation of density and temperature, for three times during the day. Figure 44 shows the corresponding wind speed and solar flux. 

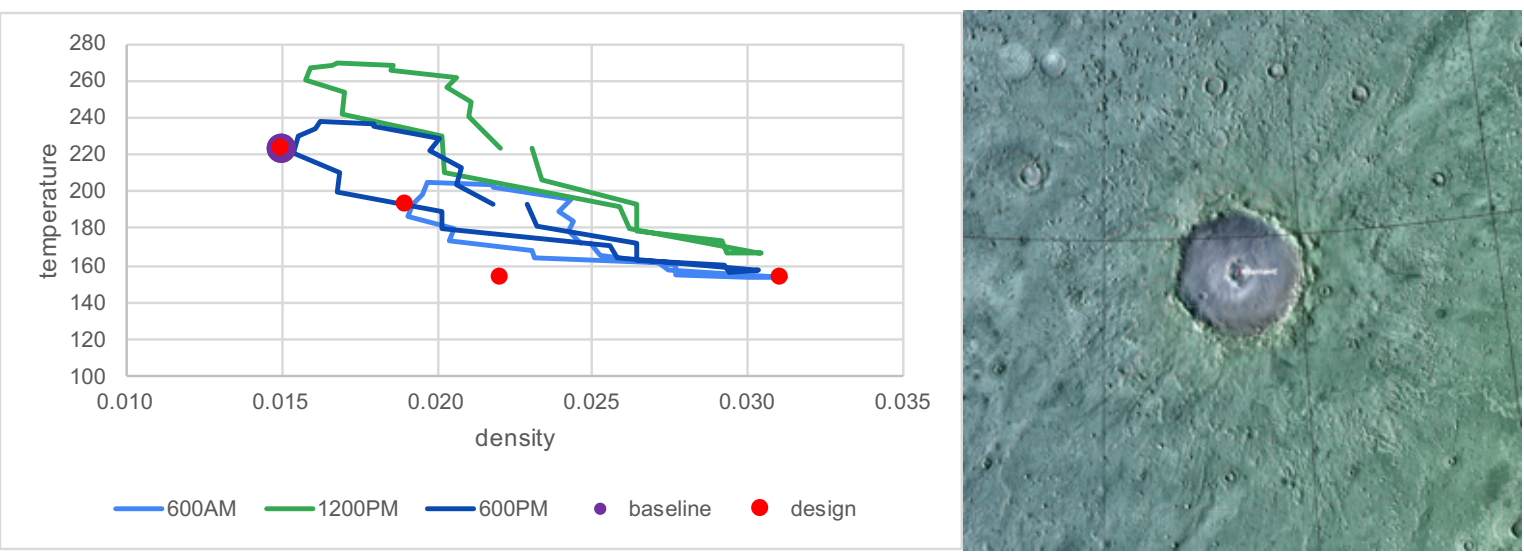

Figure 41. Annual and diurnal variation of density $\left(\mathrm{kg} / \mathrm{m}^{3}\right)$ and temperature (deg $\left.\mathrm{K}\right)$ at the Milankovic Crater.
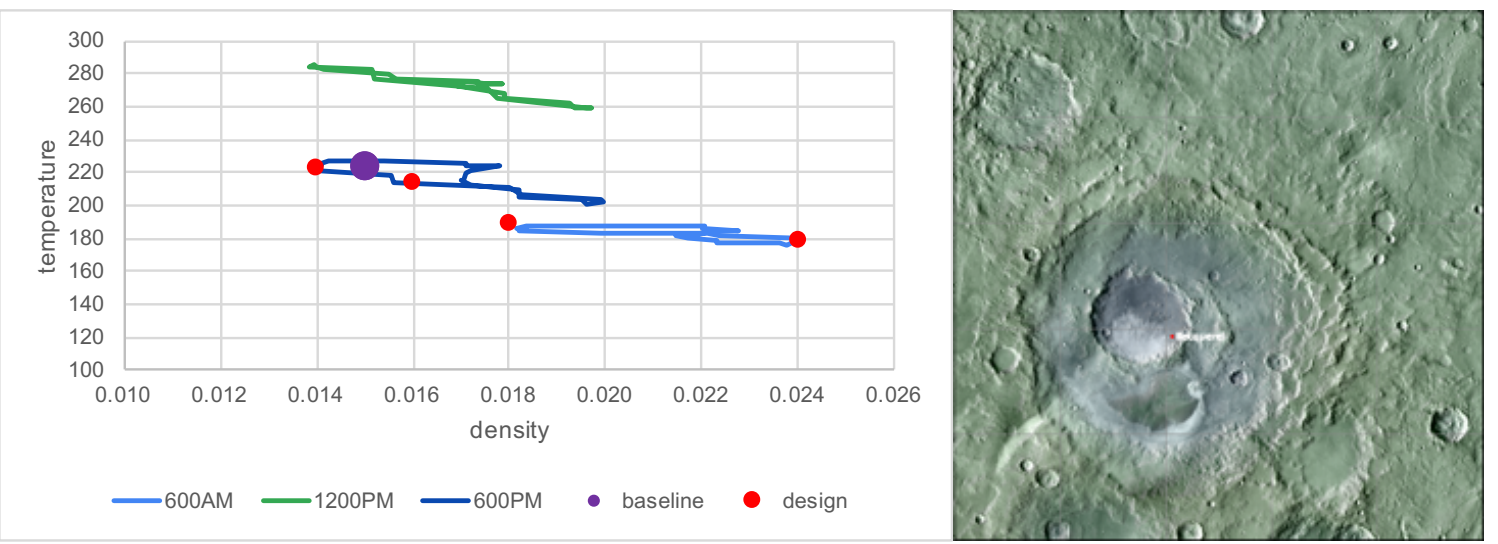

Figure 42. Annual and diurnal variation of density $\left(\mathrm{kg} / \mathrm{m}^{3}\right)$ and temperature $(\mathrm{deg} \mathrm{K})$ at the Becquerel Crater.

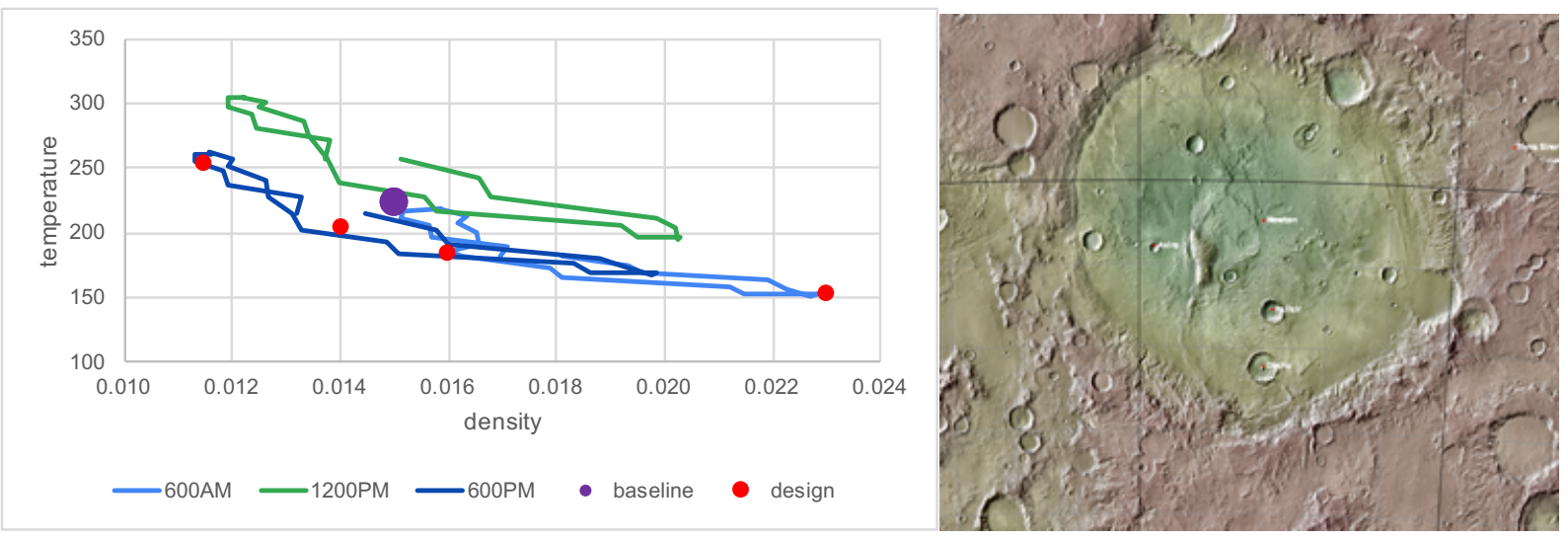

Figure 43. Annual and diurnal variation of density $\left(\mathrm{kg} / \mathrm{m}^{3}\right)$ and temperature $(\mathrm{deg} \mathrm{K})$ at the Palikir Crater. 

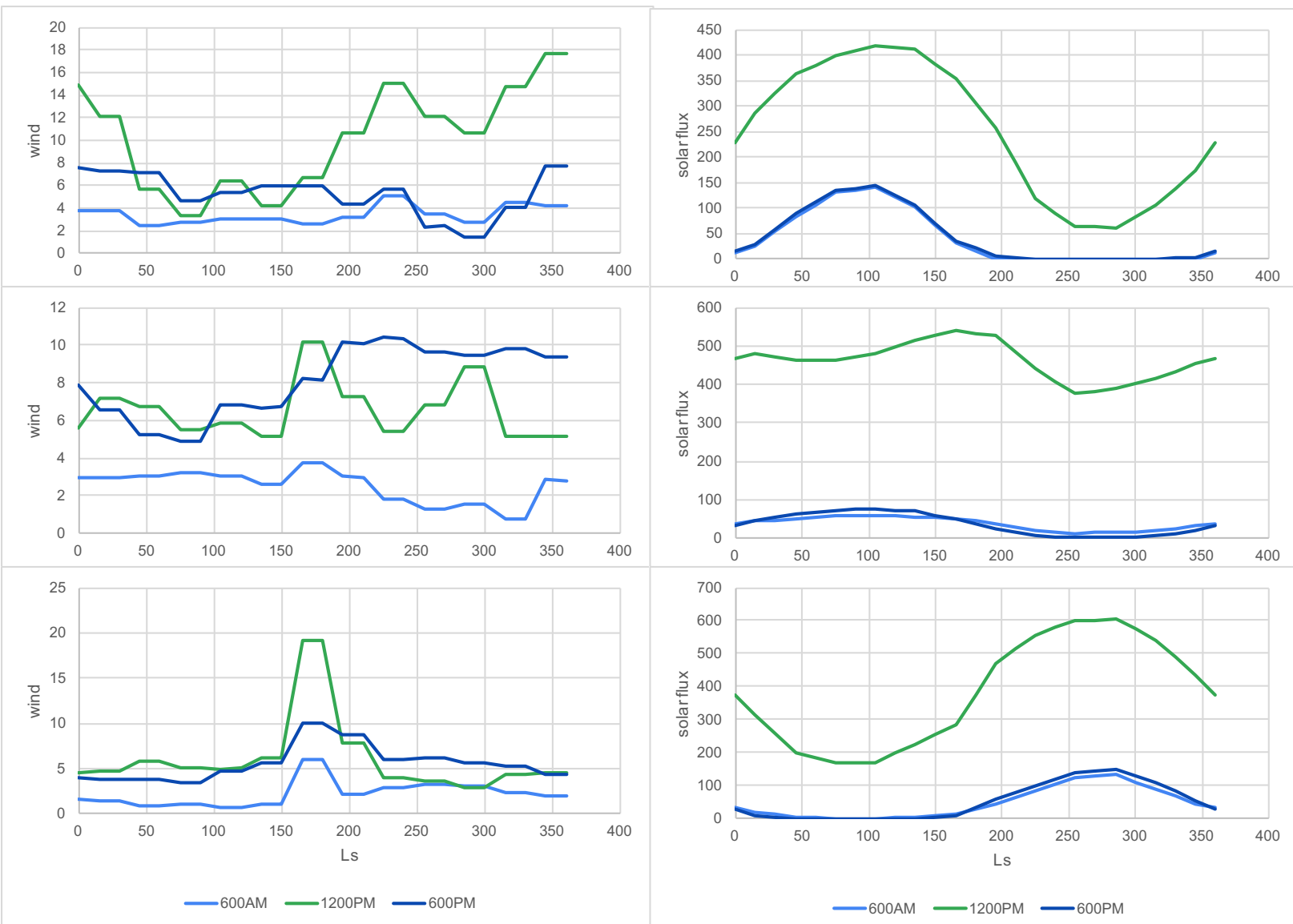

Figure 44. Wind speed $(\mathrm{m} / \mathrm{sec})$ and solar flux $\left(\mathrm{W} / \mathrm{m}^{2}\right)$ annual and diurnal variation at Milankovic Crater (top), Becquerel Crater (center), and Palikir Crater (bottom).

Helicopters were designed for operations at these three representative sites. The configuration was the hexacopter, with the rotor radius fixed at $0.64 \mathrm{~m}$; the baseline design is described in Table 8 . The range and hover time were the same as for the baseline mission, with the payload required for the science objectives at each site. The weight and performance depend primarily on atmospheric density and payload. Since each site had a range of conditions over the year and during the day, several design conditions were used in NDARC. These conditions were chosen to capture the minimum densities and minimum temperatures, indicated by the red dots on Figures 41-43. For comparison, the purple dots show the baseline design conditions $\left(0.015 \mathrm{~kg} / \mathrm{m}^{3}\right.$ and $\left.-50 \mathrm{deg} \mathrm{C}\right)$. Cold temperature (lower speed of sound, so lower tip speed) usually occurs with higher density, which is good for helicopter performance. Generally, the minimum density condition determined the aircraft size.

Table 9 summarizes the hexacopter designs, compared to the baseline aircraft (the updated tip speed case in Table 8). The Milankovic aircraft was about the same size as the baseline. The Becquerel was larger, because the payload was larger. The Palikir aircraft was larger because the density was lower. The baseline aircraft could operate at Milankovic crater, although the helicopter would likely not fly in the high wind at 1200PM (Figure 44). At Becquerel crater, the density was almost as much as for the baseline, but the mission required a significantly larger payload. At Palikir crater, the density is so low that the baseline aircraft could only fly in the morning, and no helicopter would fly in the middle of the year because of the high winds (Figure 44). 
These results demonstrate the overall robustness of the Mars Science Helicopter concept. A more extensive design effort would include assessing thermal inertia, slopes, hazards to landing, and other aspects of the sites. In addition, more work is needed on sizing the solar cell, based on the variation of the solar flux and the science mission operational scenarios.

Table 9. Hexacopters for representative Mars sites.

\begin{tabular}{|c|c|c|c|c|c|}
\hline & & baseline & Milankovic & Becquerel & Palikir \\
\hline density & & 0.015 & 0.015 & 0.014 & $0.0115 \& 0.014$ \\
\hline temperature & & -50 & -50 & -50 & $-20 \&-70$ \\
\hline $\operatorname{design} C_{T} / \sigma$ & & 0.115 & 0.115 & 0.115 & 0.115 \\
\hline $\operatorname{design} \mathrm{M}_{\text {tip }}$ & & 0.8 & 0.8 & 0.8 & 0.8 \\
\hline cruise speed & $\mathrm{m} / \mathrm{sec}$ & 30 & 30 & 30 & 30 \\
\hline advancing tip $\mathrm{M}_{\mathrm{at}}$ & & 0.93 & 0.93 & 0.93 & 0.93 \\
\hline payload & $\mathrm{kg}$ & 2.02 & 2.1 & 2.7 & 2.1 \\
\hline range & $\mathrm{km}$ & 2 & 2 & 2 & 2 \\
\hline hover time & $\min$ & 4.5 & 4.5 & 4.5 & 4.5 \\
\hline rotor radius & $\mathrm{m}$ & 0.64 & 0.64 & 0.64 & 0.64 \\
\hline gross weight & $\mathrm{kg}$ & 17.69 & 17.12 & 20.73 & 21.03 \\
\hline number rotors & & 6 & 6 & 6 & 6 \\
\hline number blades & & 4 & 4 & 4 & 4 \\
\hline disk area & $\mathrm{m}^{2}$ & 7.72 & 7.72 & 7.72 & 7.72 \\
\hline disk loading & $\mathrm{kg} / \mathrm{m}^{2}$ & 2.29 & 2.22 & 2.69 & 2.72 \\
\hline solidity & & 0.142 & 0.144 & 0.178 & 0.198 \\
\hline tip speed & $\mathrm{m} / \mathrm{sec}$ & 186.5 & 186.5 & 186.5 & 177.9 \\
\hline rotor speed & $\mathrm{rpm}$ & 2782 & 2782 & 2782 & 2655 \\
\hline total power & $\mathrm{kW}$ & 2.80 & 2.85 & 3.59 & 3.80 \\
\hline solar cell & $\mathrm{m}^{2}$ & 0.62 & 0.62 & 0.62 & 0.62 \\
\hline battery & $\mathrm{Ah}$ & 172 & 175 & 215 & 236 \\
\hline rotor group & $\mathrm{kg}$ & 3.00 & 3.03 & 3.45 & 3.67 \\
\hline controls & $\mathrm{kg}$ & 1.06 & 1.07 & 1.33 & 1.48 \\
\hline motor weight & $\mathrm{kg}$ & 0.64 & 0.65 & 0.79 & 0.83 \\
\hline battery weight & $\mathrm{kg}$ & 2.31 & 2.35 & 2.89 & 3.18 \\
\hline
\end{tabular}

\section{Limits of Design Assumptions}

Among the first decisions for a future Mars Science Helicopter program will be choice of aeroshell and lander, which fixes the aircraft size, particularly the rotor radius and disk area. Sufficient confidence in the design assumptions to make that choice will be needed, anticipating growth of weight and power and requirements (payload) that are encountered in all aircraft development programs. The project manager and designer must recognize when a helicopter designed for constrained size is near limits of technical feasibility. Such limits are indicated by accelerating growth of aircraft size as a function of mission 
parameters or design uncertainty. Key aircraft attributes reflecting such divergence of the design solution are motor power, battery capacity, gross weight, and rotor solidity. Confidence is needed in where the limits are, so the aircraft will not be designed too close to the limit of feasibility.

Helicopters were designed to explore the limits of the assumptions, in terms of capability and uncertainty. The aircraft considered is the hexacopter with fixed rotor radius of $0.64 \mathrm{~m}$. The characteristics of the baseline design (Table 8) are:

Mission: payload $2.02 \mathrm{~kg}$, range $2 \mathrm{~km}$, hover time 4 min.

Size: gross weight $17.7 \mathrm{~kg}$, power $2.8 \mathrm{~kW}$, energy $1.8 \mathrm{MJ}$, rotor solidity 0.142 .

Figure 45 shows the influence of the MSH mission requirement on the hexacopter size, relative $2.02 \mathrm{~kg}$ payload, $1 \mathrm{~km}$ range, and 2 min hover time. The attributes shown are gross weight, power, battery capacity, and rotor solidity. Large solidity implies large disk loading, hence high hover power and low-aspect ratio (inefficient) blades; a solidity value of 0.25 would be considered large for a helicopter rotor. Aircraft size was roughly linear with payload, up to about $11 \mathrm{~kg}$ for a solidity of 0.30 . The growth factor was $\mathrm{d}$ (gross weight $) / \mathrm{d}$ (payload $)=2.5$, which is a typical value for a well-designed helicopter. With increasing range or hover time, divergence of the design solution was observed at large values. With the $2.02 \mathrm{~kg}$ payload, a $20 \mathrm{~kg}$ aircraft can fly either $10 \mathrm{~km}$ with 2 min hover time, or $1 \mathrm{~km}$ with 6 min hover time, with a margin from the design divergence to allow for uncertainty in the models.
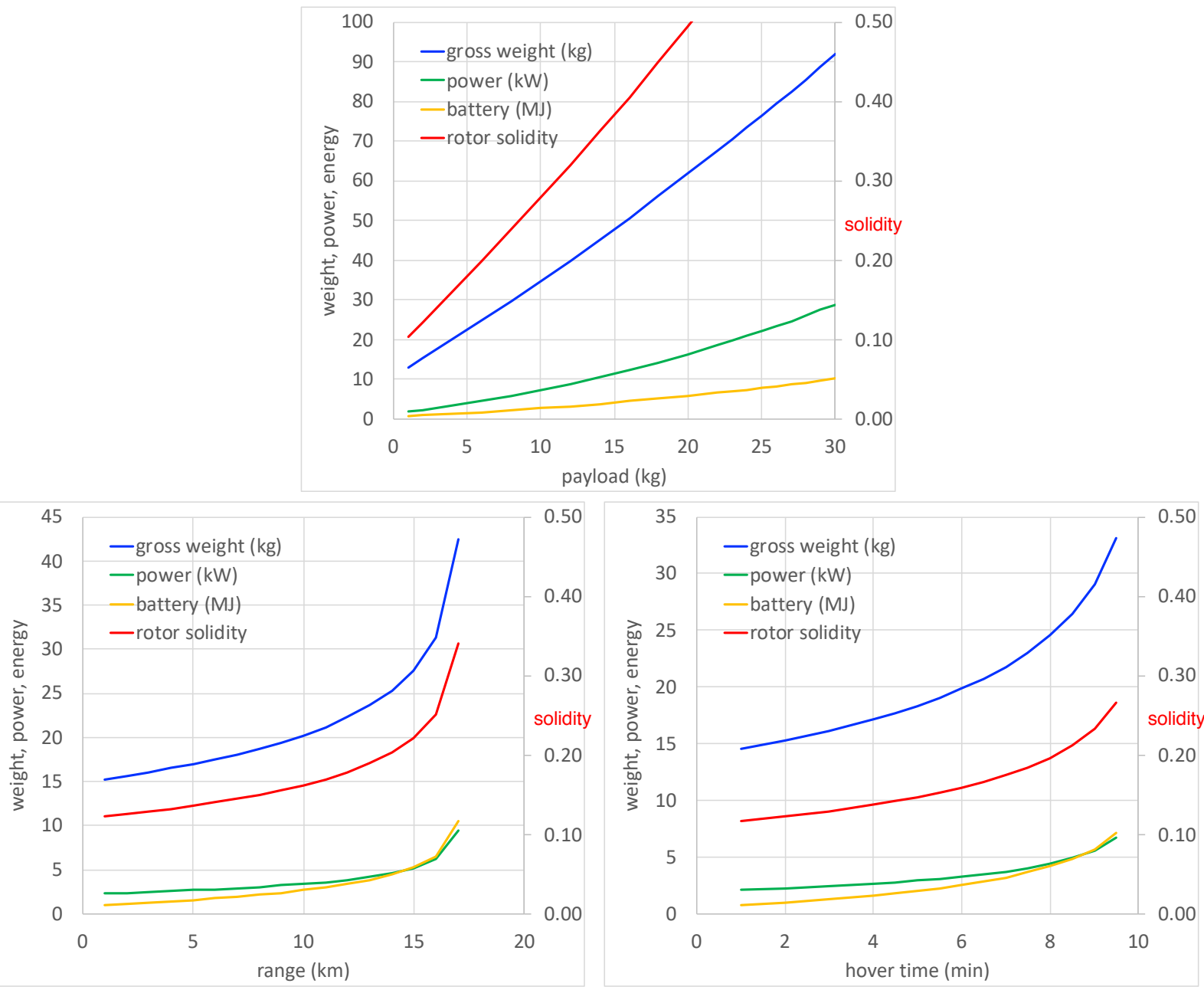

Figure 45. Influence of mission requirement on hexacopter size. 
Figure 46 shows the influence of weight estimation uncertainty on the hexacopter size for a fixed mission of $2.02 \mathrm{~kg}$ payload, $2 \mathrm{~km}$ range, and 4 min hover time. With the rotor radius fixed, empty weight growth must eventually mean that there is no feasible design. The baseline contingency weight was $20 \%$ of weight empty. The designs did not close above a contingency factor of about $35 \%$. Factors were introduced to increase the fuselage, motor, and control system weight (which all scale with aircraft size); a factor value of 1.0 was the baseline weight estimate. The design was still feasible if the fuselage or control system weight was three times the baseline estimate. The aircraft size was less sensitive to uncertainty in motor weight, because the motors were a relatively small fraction of the weight empty.
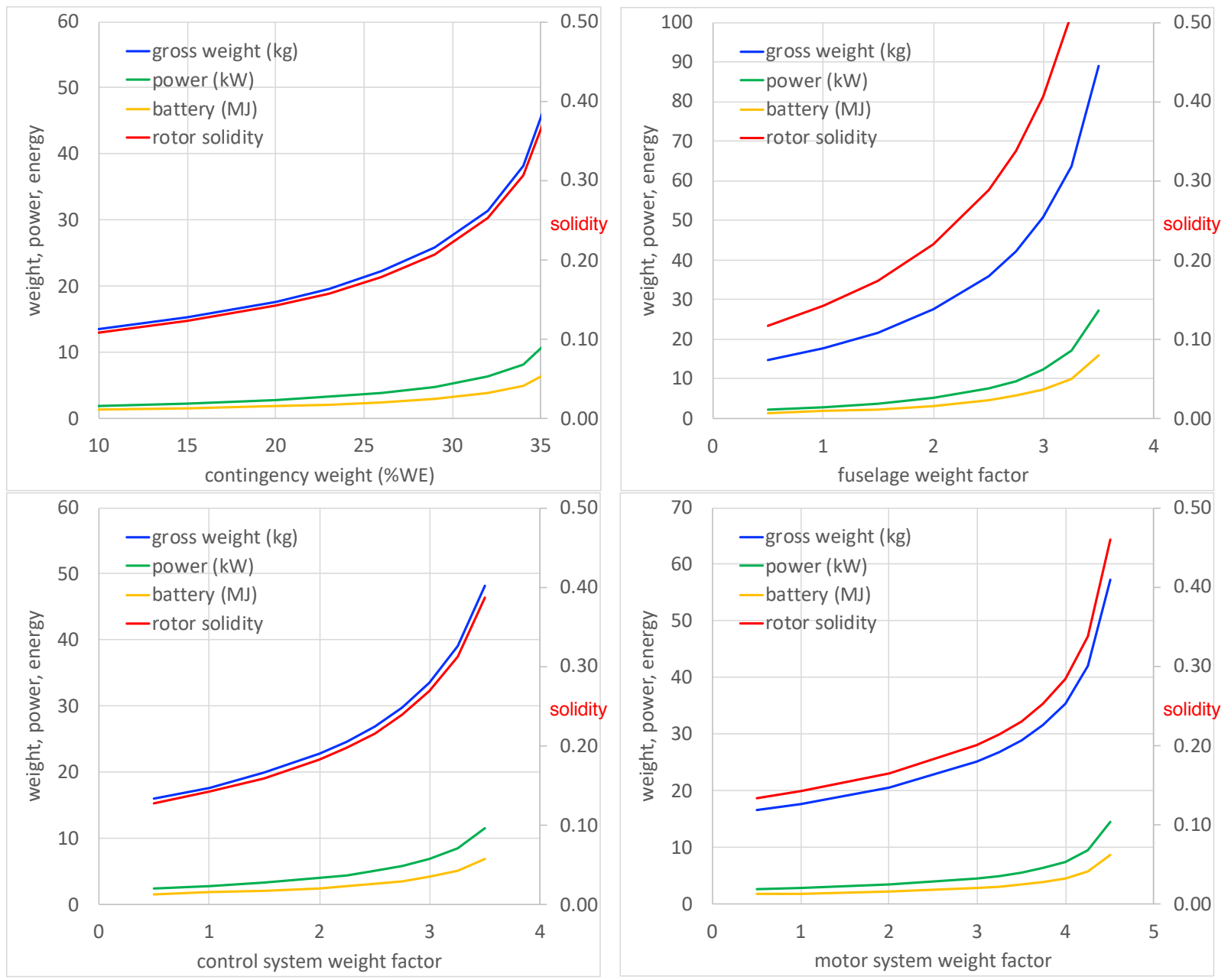

Figure 46. Influence of weight uncertainty on hexacopter size.

The conclusion from these design excursions is that a more capable Mars Science Helicopter can be designed, even with more conservatism in the weight estimation. A hexacopter with a gross weight of about $30 \mathrm{~kg}$ and rotor solidity of 0.25 would have significantly more payload, range, and hover time capability than the baseline MSH mission. Using a larger aeroshell and lander, hence larger rotors, would permit even more capability.

There are additional aspects of the design that need exploration in order to confirm this calculated capability. The solar cells must be sized based on the mission operational scenarios, taking into account the solar flux magnitude and variation (annual and diurnal) at the site. The impact of frost or ice must be considered, especially on the rotors. For the hexacopter configuration, the impact of one-rotor-inoperative (either motor or rotor failure) on aircraft size and control must be examined. 


\section{Potential Capability of a Mars Science Helicopter}

The potential capabilities of the Mars Science Helicopter were explored by designing for maximum capability at a fixed size. The hexacopter with $0.64 \mathrm{~m}$ rotor radius was considered, at the Jezero Crater in the spring $\left(0.015 \mathrm{~kg} / \mathrm{m}^{3},-50 \mathrm{deg} \mathrm{C}\right)$. The designs were somewhat more conservative than the baseline: the contingency weight was increased to $25 \%$, and the rotor solidity was limited to 0.25 . The resulting aircraft had a gross weight of $31.2 \mathrm{~kg}$ and power of $6.2 \mathrm{~kW}$. At this size, the design can trade payload for battery weight (total energy), and trade range for hover time in the mission. Note that all the designs carried the equipment and avionics weight of $1.2 \mathrm{~kg}$, had $20 \%$ energy reserve for the design mission, and the mission started with $0.5 \mathrm{~min}$ for takeoff.

Figure 47 shows the range and hover time capability of hexacopters designed for payloads of $0,2,5$, and $8 \mathrm{~kg}$. The corresponding battery capacity decreased as payload increased, for the same aircraft gross weight. With the baseline payload of $2 \mathrm{~kg}$, significant range $(8 \mathrm{~km})$ or hover time $(15 \mathrm{~min})$ was available for conducting the science missions. Figure 48 shows the range and hover time when each aircraft was operated at reduced payload. The reduced rotor power required allowed greater range or time. Figure 49 shows the capability of the aircraft designed for $8 \mathrm{~kg}$ payload, operated either with reduced payload, or swapping payload for batteries. Table 10 summarizes the range and hover time capabilities.

Table 10. Mars Science Helicopter capability; gross weight $31.2 \mathrm{~kg}$, power $6.2 \mathrm{~kW}$.

\begin{tabular}{ccc}
\hline \hline \multicolumn{3}{c}{ Design for Payload = $\mathrm{xg}$} \\
\hline Design Payload (kg) & Range $(\mathrm{km})$ & Hover Time (min) \\
\hline \hline 8 & 3.2 & OR \\
5 & 9.6 & 4.5 \\
2 & 16 & 7.8 \\
0 & 20.4 & 9.9 \\
\multicolumn{5}{c}{} \\
\hline \hline Design for Payload = 8 kg, Swap Payload and Batteries \\
\hline \hline Operating Payload (kg) & Range (km) & Hover Time (min) \\
\hline 8 & 3.2 & 1.5 \\
5 & 11.7 & 5.7 \\
0 & 20.3 & 9.9 \\
\hline \hline
\end{tabular}




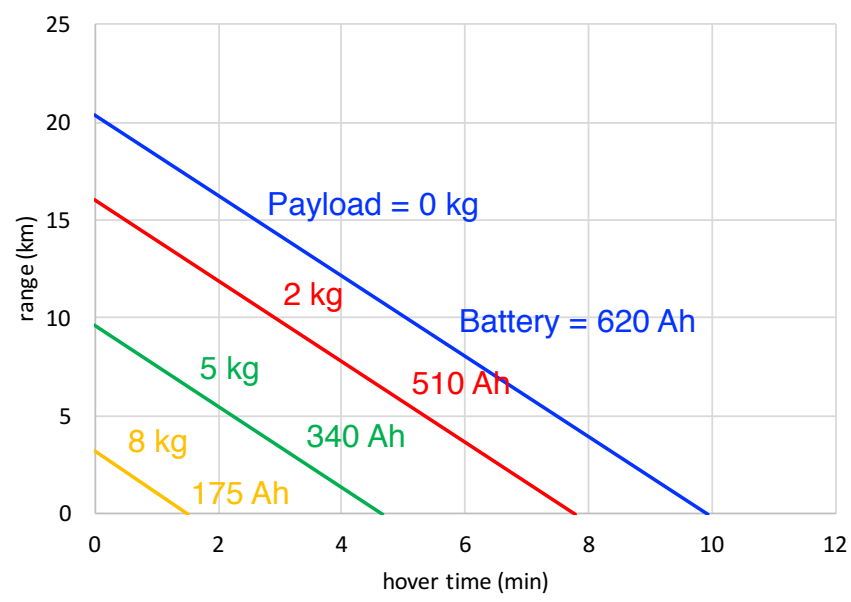

Figure 47. Range and hover time capability of hexacopter designed for various payloads; gross weight $31.2 \mathrm{~kg}$, power $6.2 \mathrm{~kW}$.

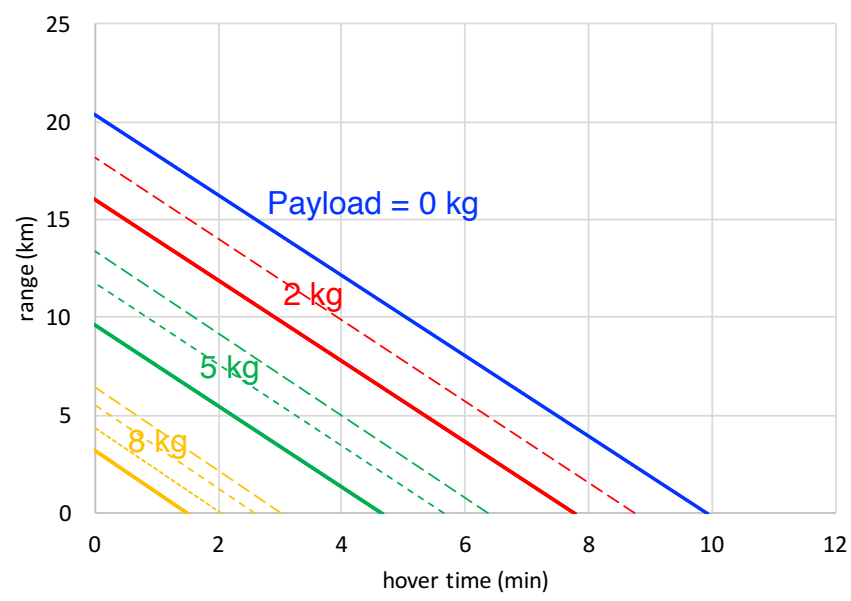

Figure 48. Range and hover time capability of hexacopter designed for various payloads, operated at reduced payload

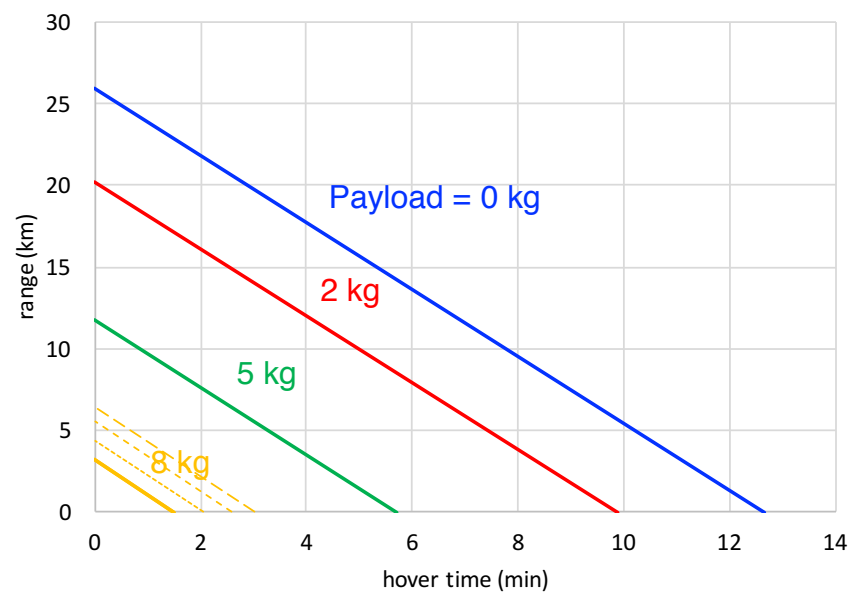

Figure 49. Range and hover time capability of hexacopter designed for $8 \mathrm{~kg}$ payload, operated either at reduced payload (yellow) or swapping payload for batteries. 
As another example of potential capability of the MSH concept, hexacopters were designed for cave exploration. The caves of interest are at higher elevations, so the atmosphere is much less dense: 0.0106 $\mathrm{kg} / \mathrm{m}^{3}$ and $-64.35 \mathrm{deg}$ C. Figure 50 shows the range and hover time capability, which was significantly less than what was possible at lower elevations (Figure 47) since the rotor size was still $0.64 \mathrm{~m}$ radius. For a payload of $2.0 \mathrm{~kg}$, this aircraft had $23.5 \mathrm{~kg}$ gross weight, $4.9 \mathrm{~kW}$ power, and $175 \mathrm{Ah}$ total energy. Increasing the payload to $4.0 \mathrm{~kg}$ required a larger solidity of 0.35 .

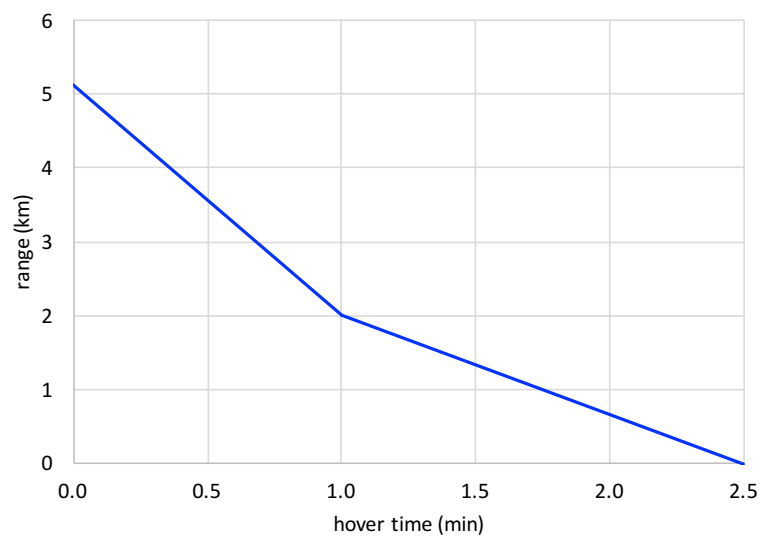

payload $=2.0 \mathrm{~kg}$, solidity $=0.25$

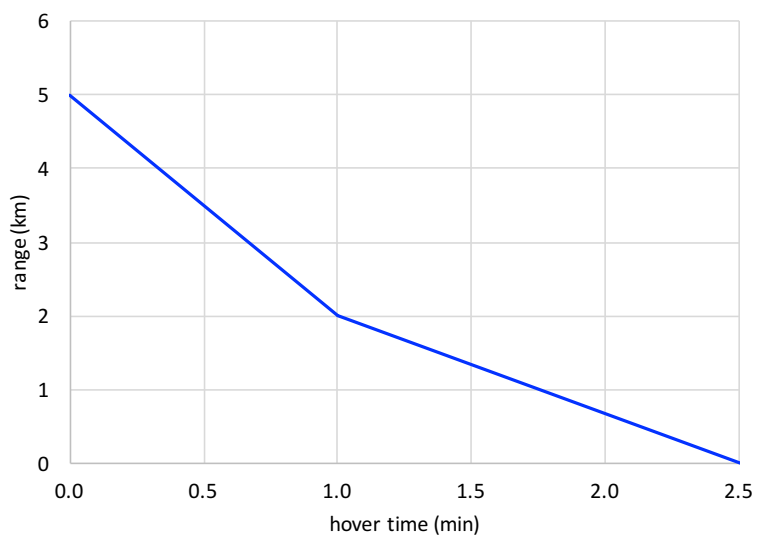

payload $=4.0 \mathrm{~kg}$, solidity $=0.35$

Figure 50. Range and hover time capability of hexacopter design for cave exploration.

\section{Advanced Mars Helicopter}

The design features that enable the performance and mission capability of the Mars Science Helicopter could also be applied to an aircraft the same size as the Mars Helicopter: advanced airfoils, higher tip speed, more blade area, higher flight speed, larger motor, larger battery - all enabling a useful science payload. The MH is a coaxial helicopter with blade radius of $0.605 \mathrm{~m}$. Table 11 compares the $\mathrm{MH}$ with the Advanced Mars Helicopter. The blue numbers are the key design parameters, and the red numbers highlight the mission capability. Figure 51 shows the range and hover time possible with a payload of $1.3 \mathrm{~kg}$.
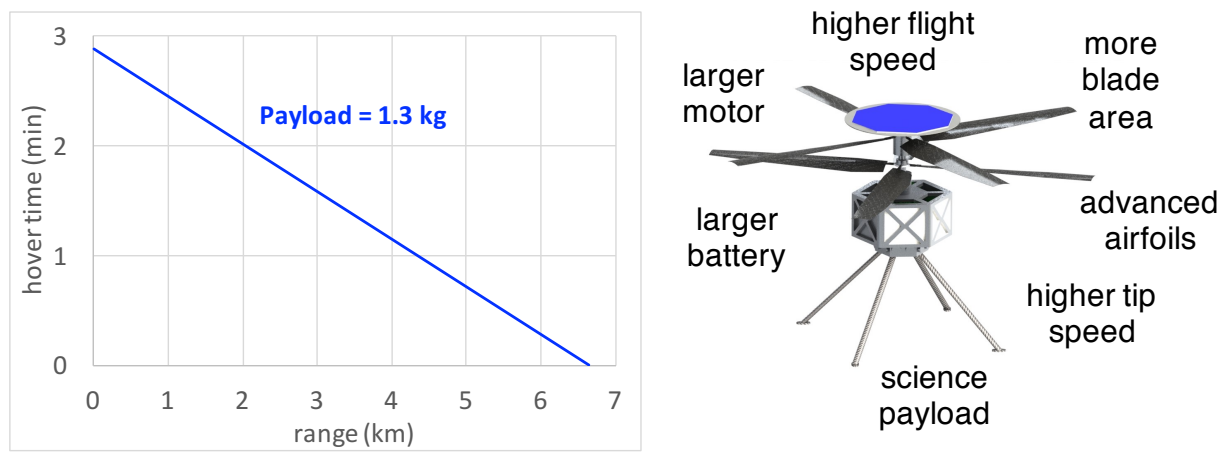

Figure 51. Range and hover time of Advanced Mars Helicopter. 
Table 11. Advanced Mars Helicopter design summary.

\begin{tabular}{llcc}
\hline & & MH & Advanced Design \\
\hline \hline design $C_{T} / \sigma$ & & $\mathbf{0 . 1 0}$ & $\mathbf{0 . 1 1 5}$ \\
design $\mathrm{M}_{\text {tip }}$ & & $\mathbf{0 . 7}$ & $\mathbf{0 . 8}$ \\
cruise speed & $\mathrm{m} / \mathrm{sec}$ & $\mathbf{2}$ & $\mathbf{3 0}$ \\
advancing tip $\mathrm{M}_{\mathrm{at}}$ & & 0.71 & 0.93 \\
payload & $\mathrm{kg}$ & $\mathbf{0}$ & $\mathbf{1 . 3}$ \\
range & $\mathrm{km}$ & $\mathbf{0 . 1 8} \mathbf{O R}$ & $\mathbf{2}$ AND \\
hover time & $\mathrm{min}$ & $\mathbf{1 . 5}$ & $\mathbf{2}$ \\
rotor radius & $\mathrm{m}$ & $\mathbf{0 . 6 0 5}$ & $\mathbf{0 . 6 0 5}$ \\
gross weight & $\mathrm{kg}$ & 1.8 & 4.6 \\
number rotors & & 2 & 2 \\
disk loading & $\mathrm{kg} / \mathrm{m}^{2}$ & 0.8 & 2 \\
solidity & & $\mathbf{0 . 1 4 8}$ & $\mathbf{0 . 2 4 8}$ \\
tip speed & $\mathrm{m} / \mathrm{sec}$ & 163 & 186 \\
rotor speed & $\mathrm{rpm}$ & 2575 & 2943 \\
total power & $\mathrm{kW}$ & 0.36 & 0.88 \\
solar cell & $\mathrm{m} 2$ & 0.04 & 0.06 \\
battery & $\mathrm{Ah}$ & 12 & 46 \\
\hline \hline
\end{tabular}

\section{Conclusions and Recommendations}

The design and performance of a Mars Science Helicopter have been explored. The MSH is secondgeneration Mars rotorcraft capable of conducting science investigations independently of a lander or rover. Coaxial helicopter and hexacopter configurations were considered, initially with a payload of $2 \mathrm{~kg}$ and aircraft mass around $20 \mathrm{~kg}$. Initial estimates of weight and performance were based on the capabilities of the Mars Helicopter. Rotorcraft designs for Mars are constrained by the dimensions of the aeroshell for the trip to the planet, so packaging options were explored. Aerodynamic performance optimization was conducted, particularly through airfoils designed specifically for the low Reynolds number and high Mach number inherent in operation on Mars. Rotor structural designs were developed that met blade frequency and weight targets, subject to material stress limits. The examination of the potential of the helicopter (Table 10) produced designs that show a substantial capability for science operations on Mars: a $31 \mathrm{~kg}$ hexacopter that fits within a $2.5 \mathrm{~m}$ diameter aeroshell could carry a $5 \mathrm{~kg}$ payload for $10 \mathrm{~min}$ of hover time or over a range of $5 \mathrm{~km}$.

\section{Continuing Conceptual Design}

Additional work is needed on conceptual design of the MSH.

Structural analysis and design of the airframe is needed to minimize the weight given the criteria for deflection and strain, and the constraints on coupling of the airframe dynamics with rotor control. The airframe design includes the landing gear, and the folding hinges and mechanisms. 
The rotor structural analysis should be extended to a complete model of the blade root, pitch bearing, hub, and control system. Critical load conditions must be established, resulting in weight estimates for the rotor system.

Three-dimensional computational fluid dynamics analysis of the rotor and the complete aircraft would provide refined estimates of the rotor performance and aircraft drag.

Analysis and assessment of flight dynamics and control is needed, for both the hexacopter and coaxial helicopter configurations. Important issues are defining the criteria for flapping frequency and airframerotor coupling, and assessing the capabilities of rpm control for the hexacopter rotors.

Detailed consideration of the helicopter energy management on Mars is required, including thermal control and heat rejection. The solar cells must be sized based on the mission operational scenarios, taking into account the solar flux magnitude and variation (annual and diurnal) at the site. The designs developed for this report included sufficient energy for survival, but the solar cell sizing did not include a requirement on duration of the recharging. A base station might be available to contribute to the energy management, but the aircraft would always need some solar cells so it could re-charge independently. Non-solar energy sources can also be assessed.

\section{Risk Reduction for Future Design}

Work is needed to reduce the risk of weight and performance estimation, as a foundation for confident aircraft design once the Mars Science Helicopter mission has been defined.

Experimental verification of the rotor aerodynamic performance is required. The predicted MSH capabilities depend on the low Reynolds number and high Mach number behavior, and the resulting rotor performance, stall and thrust limit, and drag divergence limit. If the performance predictions are confirmed, it might even be possible to increase the blade loading and tip speed of the designs.

Experimental verification of the rotor structural design concept is required. The rotor weight depends on designing the blades to meet the frequency and load requirements, subject to limits on material strain and stress.

A generic analysis and simulation capability for helicopters on Mars must be developed. The JPL HeliCat code (Ref. 12) is probably the best foundation for such a tool. Control systems must be designed as required for the mission operations, including accommodation of low-damped blade modes and airframerotor coupling. Guidance and navigation concepts that will permit the required flight speeds must be developed.

Concepts for mechanical or structural damping of the blade modes should be identified and developed. Such damping is required in order to consider larger coaxial rotor designs, and would be beneficial to all rotors for operation on Mars.

A Mars Helicopter Concept Vehicle (MHCV) and associated test articles must be designed, built, and tested. A second real aircraft design (the $\mathrm{MH}$ is the first) is needed to increase confidence in the performance and weight estimates for the next helicopter on Mars. Testing must be in the correct atmosphere, but initially could be just hover with a tether compensating for the weight in Earth's gravity. Results from testing this MHCV would substantiate and update the design assumptions, including component weight, power required, and flight dynamics and controllability. 


\section{References}

1) Balaram, J.; Daubar, I.J.; Bapst, J.; and Tzanetos, T. "Helicopters on Mars: Compelling Science of Extreme Terrains Enabled by an Aerial Platform." Ninth International Conference on Mars, Pasadena, CA, July 2019.

2) Balaram, J.B.; Canham, T.; Duncan, C.; Golombek, M.; Grip, H.F.; Johnson, W.; Maki, J.; Quon, A.; Stern, R.; and Zhu, D. "Mars Helicopter Technology Demonstrator." AIAA Paper No. 2018-0023, January 2018.

3) Young, L.A. "Vertical Lift — Not Just for Terrestrial Flight." American Helicopter Society International Powered Lift Conference, Crystal City, VA, October 2000.

4) Young, L.A., and Aiken, E.W. "Vertical Lift Planetary Aerial Vehicles: Three Planetary Bodies and Four Conceptual Design Cases." Twenty-Seventh European Rotorcraft Forum, Moscow, Russia, September 2001.

5) Young, L.A.; Aiken, E.W.; Derby, M.R.; Demblewski, R.; and Navarrete, J. "Experimental Investigation and Demonstration of Rotary-Wing Technologies for Flight in the Atmosphere of Mars." American Helicopter Society 58th Annual Forum, Montreal, Canada, June 2002.

6) Young, L.A.; Aiken, E.W.; Gulick, V.; Mancinelli, R.; and Briggs, G.A. "Rotorcraft as Mars Scouts." IEEE Aerospace Conference, Paper No. 10.1109, March 2002.

7) Datta, A.; Roget, B.; Griffiths, D.; Pugliese, G.; Sitaraman, J.; Bao, J.; Liu, L.; and Gamard, O. "Design of a Martian Autonomous Rotary-Wing Vehicle." Journal of Aircraft, Volume 40, Number 3 (May-June 2003).

8) O’Brien, P.C. "Using a Robotic Helicopter to Fuel Interest in and Augment the Human Exploration of the Planet Mars", AIAA Paper No. 2003-6275, September 2003.

9) Lacerda, M.; Park, D.; Patel, S.; and Schrage, D. "A Preliminary Systems Engineering Study on a Concept for Mars Exploration with an Unmanned Autonomous Vehicle and Ground Rover Configuration." American Helicopter Society 74th Annual Forum, Phoenix, AZ, May 2018.

10) Boelhouwer, R.N.J.; Bunschoten, E.C.; Debusscher, C.M.J.; Frijters, W.; van Goeverden, R.J.; Legrand, E.B.; Matton, J.; Paliusis, K.; and Verheyen, J.K.N. "Design Report, Martian Advanced Reconnaissance System.” Delft University of Technology, June 2018.

11) Fujita, K.; Karaca, H.; and Nagai, H. "Parametric Study of Mars Helicopter for Pit Crater Exploration." AIAA Paper No. 2020-1734, January 2020.

12) Grip, H.F.; Johnson, W.; Malpica, C.; Scharf, D.P.; Mandic, M.; Young, L.; Allan, B.; Mettler, B.; San Martin, M.; and Lam, J. "Modeling and Identification of Hover Flight Dynamics for NASA's Mars Helicopter." Journal of Guidance, Control, and Dynamics, Volume 43, Number 2 (February 2020).

13) Grip, H.F.; Scharf, D.P.; Malpica, C.; Johnson, W.; Singh, G.; and Young, L. "Guidance and Control for a Mars Helicopter.” AIAA Paper No. 2018-1849, January 2018.

14) Grip, H.F.; Lam, J.N.; Bayard, D.; Conway, D.T.; Singh, G.; Brockers, R.; Delaune, J.; Matthies, L.; Malpica, C.; Brown, T.; Jain, A.; San Martin, M.; and Merewether, G. "Flight Control System for NASA's Mars Helicopter.” AIAA Paper No. 2019-1289, January 2019.

15) Pipenberg, B.T.; Keennon, M.T.; Tyler, J.D.; Langberg, S.A.; Hibbs, B.; Balaram, J.B.; Grip, H.F.; and Pempejian, J. "Design and Fabrication of the Mars Helicopter Rotor, Airframe, and Landing Gear Systems." AIAA Paper No. 2019-0620, January 2019.

16) Pipenberg, B.T.; Keennon, M.T.; Langberg, S.A.; and Tyler, J.D. "Development of the Mars Helicopter Rotor System.” American Helicopter Society 75th Annual Forum, Philadelphia, PA, May 2019. 
17) Koning, W.J.F.; Johnson, W.; and Grip, H.F. "Improved Mars Helicopter Aerodynamic Rotor Model for Comprehensive Analyses.” AIAA Journal, Volume 57, Number 9 (September 2019).

18) Johnson, W. Rotorcraft Aeromechanics. New York: Cambridge University Press, 2013.

19) Johnson, W. "NDARC. NASA Design and Analysis of Rotorcraft.” NASA TP 2015-218751, April 2015.

20) Johnson, W., "Technology Drivers in the Development of CAMRAD II," American Helicopter Society Aeromechanics Specialist Meeting, San Francisco, California, January 1994.

21) Johnson, W. "Rotorcraft Aeromechanics Applications of a Comprehensive Analysis." HeliJapan 1998: AHS International Meeting on Rotorcraft Technology and Disaster Relief, Gifu, Japan, April 1998.

22) Johnson, W. "Rotorcraft Aerodynamic Models for a Comprehensive Analysis." American Helicopter Society 54th Annual Forum, Washington, D.C., May 1998.

23) Datta, A. "X3D - A 3D Solid Finite Element Multibody Dynamic Analysis for Rotorcraft." American Helicopter Society Specialists' Conference on Aeromechanics Design for Vertical Lift, San Francisco, CA, January 2016.

24) Pulliam, T., "High Order Accurate Finite-Difference Methods: As Seen in OVERFLOW." AIAA Paper Number 2011-3851, June 2011.

25) Lawrence, B.; Theodore, C.R.; Johnson, W.; and Berger, T. “A Handling Qualities Analysis Tool for Rotorcraft Conceptual Designs.” The Aeronautical Journal, Volume 122, Number 1252 (June 2018).

26) Koning, W.J.F. “Airfoil Selection for Mars Rotor Applications.” NASA CR 2019-220236, July 2019.

27) Koning, W.J.F.; Romander, E.A.; and Johnson, W. "Low Reynolds Number Airfoil Evaluation for the Mars Helicopter Rotor.” American Helicopter Society 74th Annual Forum, Phoenix, AZ, May 2018.

28) McMasters, J., and Henderson, M., "Low-Speed Single-Element Airfoil Synthesis," Technical Soaring, Volume 6, Number 2 (1980).

29) Hoerner, S. F., Fluid-Dynamic Drag. Midland Park, NJ: Hoerner Fluid Dynamics, 1965.

30) Koning, W.J.F.; Romander, E.A.; and Johnson, W. "Performance Optimization of Plate Airfoils for Martian Rotor Applications Using a Genetic Algorithm." Forty-Fifth European Rotorcraft Forum, Warsaw, Poland, September 2019.

31) Koning, W.J.F.; Romander, E.A.; and Johnson, W. "Optimization of Low Reynolds Number Airfoils for Martian Rotor Applications Using an Evolutionary Algorithm." AIAA Paper No. 2020-0084, January 2020.

32) Traub, L.W., and Coffman, C. "Efficient Low-Reynolds-Number Airfoils." Journal of Aircraft, Volume 56, Number 5, September-October 2019.

33) Munday, P.M.; Taira, K.; Suwa, T.; Numata, D.; and Asai, K. "Nonlinear Lift on a Triangular Airfoil in Low-Reynolds-Number Compressible Flow." Journal of Aircraft, Volume 52, Number 3, May-June 2015. 